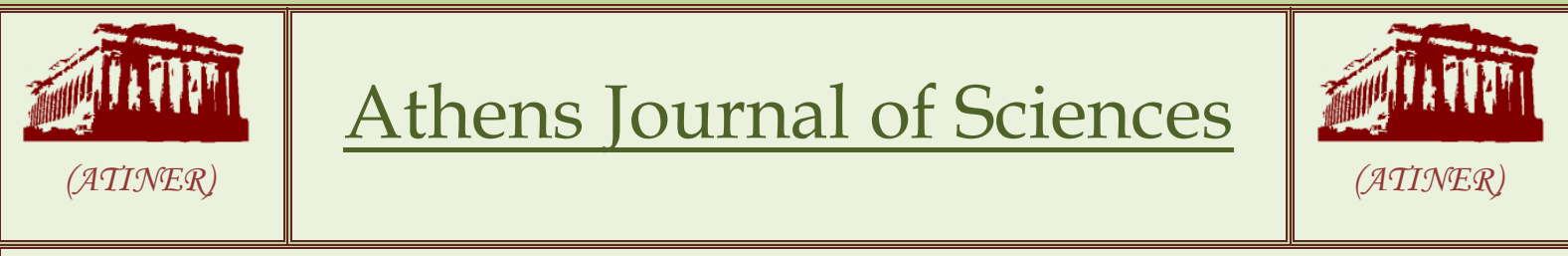 \\ Volume 8, Issue 1, March 2021 \\ Articles
}

Front Pages

TAREK M. EL-GEZIRY, IBRAHIM A. MAIYZA \&

MOHAMED S. KAMEL

Behaviour of Temperature Variations in Subsurface Layers in the South-Eastern Mediterranean Sea

ADEL RAZEK

Pragmatic Association of the Two Evaluation Concepts of Operational Observation and Mathematical Modeling

OLUTUNDE SAMUEL ODETUNDE, RASAKI KOLA ODUNAIKE E ADETORO TEMITOPE TALABI

A Modified System of Nonlinear Fractional-Order Differential Equations in the Study of the Dynamics of Marital Relationships and their Behavioural Features

ARMEN B AVAGYAN

Theory of Bioenergy Accumulation and Transformation: Application to Evolution, Energy, Sustainable Development, Climate Change, Manufacturing, Agriculture, Military Activity and Pandemic Challenges 


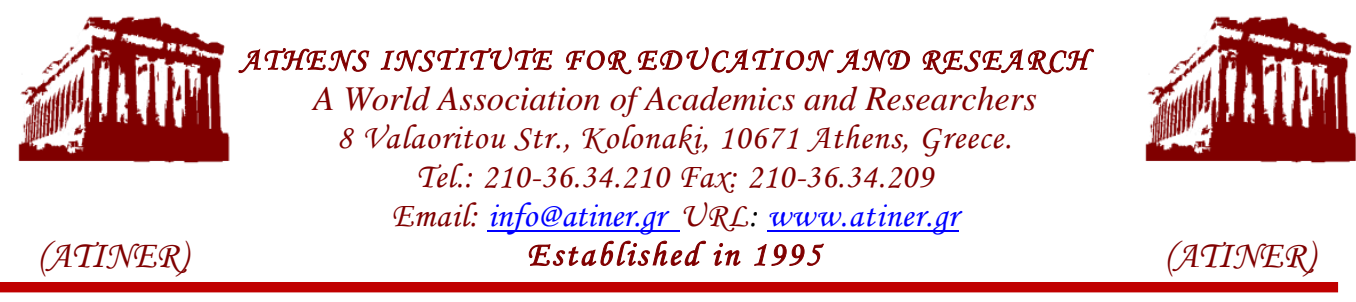

\section{Mission}

ATINER is an Athens-based World Association of Academics and Researchers based in Athens. ATINER is an independent and non-profit Association with a Mission to become a forum where Academics and Researchers from all over the world can meet in Athens, exchange ideas on their research and discuss future developments in their disciplines, as well as engage with professionals from other fields. Athens was chosen because of its long history of academic gatherings, which go back thousands of years to Plato's Academy and Aristotle's Lyceum. Both these historic places are within walking distance from ATINER's downtown offices. Since antiquity, Athens was an open city. In the words of Pericles, Athens"... is open to the world, we never expel a foreigner from learning or seeing". ("Pericles' Funeral Oration", in Thucydides, The History of the Peloponnesian War). It is ATINER's mission to revive the glory of Ancient Athens by inviting the World Academic Community to the city, to learn from each other in an environment of freedom and respect for other people's opinions and beliefs. After all, the free expression of one's opinion formed the basis for the development of democracy, and Athens was its cradle. As it turned out, the Golden Age of Athens was in fact, the Golden Age of the Western Civilization. Education and (Re)searching for the 'truth' are the pillars of any free (democratic) society. This is the reason why Education and Research are the two core words in ATINER's name. 
The Athens Journal of Sciences

ISSN NUMBER: 2241-8466- DOI: 10.30958/ajs

Volume 8, Issue 1, March 2021

Download the entire issue ( $\underline{\mathrm{PDF}})$

Front Pages

i-viii

Behaviour of Temperature Variations in Subsurface

9

Layers in the South-Eastern Mediterranean Sea

Tarek M. El-Geziry, Ibrahim A. Maiyza \&

Mohamed S. Kamel

Pragmatic Association of the Two Evaluation Concepts of Operational Observation and Mathematical Modeling Adel Razek

A Modified System of Nonlinear Fractional-Order Differential Equations in the Study of the Dynamics of Marital Relationships and their Behavioural Features

Olutunde Samuel Odetunde, Rasaki Kola Odunaike E Adetoro Temitope Talabi

Theory of Bioenergy Accumulation and Transformation:

Application to Evolution, Energy, Sustainable Development, Climate Change, Manufacturing, Agriculture, Military Activity and Pandemic Challenges

Armen B Avagyan 


\section{Athens Journal of Sciences Editorial and Reviewers' Board}

\section{Editors}

- Dr. Nicolas Abatzoglou, Head, Environment Unit, ATINER; Professor, Department of Chemical \& Biotechnological Engineering, Université de Sherbrooke, Canada; Chair Pfizer, Processes and Analytical Technologies in Pharmaceutical Engineering; Director of GRTP-C \& P (Groupe de recherches sur les technologies et procédés de conversion et pharmaceutiques); Fellow of Canadian Academy of Engineering.

- Dr. Christopher Janetopoulos, Head, Biology Unit, ATINER \& Associate Professor, University of the Sciences, USA.(Biology)

- Dr. Ethel Petrou, Academic Member, ATINER \& Professor and Chair, Department of Physics, Erie Community College-South, State University of New York, USA.

- Dr. Ellene Tratras Contis, Head, Chemistry Unit, ATINER \& Professor of Chemistry, Eastern Michigan University, USA.(Chemistry)

\section{Editorial Board}

- Dr. Colin Scanes, Academic Member, ATINER \& Emeritus Professor, University of Wisconsin Milwaukee, USA.

- Dr. Dimitris Argyropoulos, Professor, North Carolina State University, USA.

- Dr. Cecil Stushnoff, Emeritus Professor, Colorado State University, USA.

- Dr. Hikmat Said Hasan Hilal, Academic Member, ATINER \& Professor, Department of Chemistry, An-Najah N. University, Palestine.

- Dr. Jean Paris, Professor, Polytechnique Montreal, Canada.

- Dr. Shiro Kobayashi, Academic Member, ATINER \& Distinguished Professor, Kyoto Institute of Technology, Kyoto University, Japan.

- Dr. Jose R. Peralta-Videa, Academic Member, ATINER \& Research Specialist and Adjunct Professor, Department of Chemistry, The University of Texas at El Paso, USA.

- Dr. Jean-Pierre Bazureau, Academic Member, ATINER \& Professor, Institute of Chemical Sciences of Rennes ICSR, University of Rennes 1, France.

- Dr. Mohammed Salah Aida, Professor, Taibah University, Saudi Arabia.

- Dr. Zagabathuni Venkata Panchakshari Murthy, Academic Member, ATINER \& Professor/Head, Department of Chemical Engineering, Sardar Vallabhbhai National Institute of Technology, India.

- Dr. Alexander A. Kamnev, Professor, Institute of Biochemistry and Physiology of Plants and Microorganisms, Russian Academy of Sciences, Russia.

- Dr. Carlos Nunez, Professor, Physics Department, University of Wales Swansea, UK.

- Dr. Anastasios Koulaouzidis, Academic Member, ATINER \& Associate Specialist and Honorary Clinical Fellow of the UoE, The Royal Infirmary of Edinburgh, The University of Edinburgh, UK.

- Dr. Francisco Lopez-Munoz, Professor, Camilo Jose Cela University, Spain.

- Dr. Panagiotis Petratos, Professor, California State University-Stanislaus, USA.

- Dr. Yiannis Papadopoulos, Professor of Computer Science, Leader of Dependable Systems Research Group, University of Hull, UK.

- Dr. Joseph M. Shostell, Professor and Department Head, Math, Sciences \& Technology Department, University of Minnesota Crookston, USA.

- Dr. Ibrahim A. Hassan, Professor of Environmental Biology, Faculty of Science, Alexandria University, Egypt \& Centre of Excellence in Environmental Studies, King Abdulaziz University, Saudi Arabia.

- Dr. Laurence G. Rahme, Associate Professor, Department of Surgery, Microbiology and Immunobiology, Harvard Medical School, Boston, Massachusetts \& Director of Molecular Surgical Laboratory, Burns Unit, Department of Surgery, Massachusetts General Hospital, USA.

- Dr. Stefano Falcinelli, Academic Member, ATINER \& Associate Professor, Department of Civil and Environmental Engineering University of Perugia, Italy.

- Dr. Mitra Esfandiarei, Academic Member, ATINER \& Assistant Professor, Midwestern University, USA.

- Dr. Athina Meli, Academic Member, Academic Member, ATINER, Visiting Scientist and Research Scholar, University of Gent \& University of Liege, Belgium and Ronin Institute Montclair, USA.

- Vice President of Publications: Dr Zoe Boutsioli

- General Managing Editor of all ATINER's Publications: Ms. Afrodete Papanikou

- ICT Managing Editor of all ATINER's Publications: Mr. Kostas Spyropoulos

- Managing Editor of this Journal: Ms. Olga Gkounta ( $\underline{\text { bio }})$

\section{Reviewers' Board}

Click Here 


\section{President's Message}

All ATINER's publications including its e-journals are open access without any costs (submission, processing, publishing, open access paid by authors, open access paid by readers etc.) and is independent of presentations at any of the many small events (conferences, symposiums, forums, colloquiums, courses, roundtable discussions) organized by ATINER throughout the year and entail significant costs of participating. The intellectual property rights of the submitting papers remain with the author. Before you submit, please make sure your paper meets the basic academic standards, which includes proper English. Some articles will be selected from the numerous papers that have been presented at the various annual international academic conferences organized by the different divisions and units of the Athens Institute for Education and Research. The plethora of papers presented every year will enable the editorial board of each journal to select the best, and in so doing produce a top-quality academic journal. In addition to papers presented, ATINER will encourage the independent submission of papers to be evaluated for publication.

The current issue is the first of the eighth volume of the Athens Journal of Sciences (AJS), published by Natural \& Formal Sciences Division of ATINER.

Gregory T. Papanikos, President, ATINER. 


\section{Athens Institute for Education and Research}

A World Association of Academics and Researchers

\section{$9^{\text {th }}$ Annual International Conference on Chemistry 19-22 July 2021, Athens, Greece}

The Chemistry Unit of ATINER, will hold its $9^{\text {th }}$ Annual International Conference on Chemistry, 19-22 July 2021, Athens, Greece sponsored by the Athens Journal of Sciences. The aim of the conference is to bring together academics and researchers of all areas of chemistry and other related disciplines. You may participate as stream organizer, presenter of one paper, chair a session or observer. Please submit a proposal using the form available (https://www.atiner.gr/2021/FORMCHE.doc).

Academic Members Responsible for the Conference

- Dr. Ellene Tratras Contis, Head, Chemistry Unit, ATINER \& Professor of Chemistry, Eastern Michigan University, USA.

- Dr. Nicolas Abatzoglou, Head, Environment Unit, ATINER \& Professor, Department of Chemical \& Biotechnological Engineering, University of Sherbrook, Canada, Chair Pfizer, PAT in Pharmaceutical Engineering, Director GREEN-TPV and GRTP-C \& Pwelcomes.

\section{Important Dates}

- Abstract Submission: 22 March 2021

- Acceptance of Abstract: 4 Weeks after Submission

- Submission of Paper: 21 June 2021

\section{Social and Educational Program}

The Social Program Emphasizes the Educational Aspect of the Academic Meetings of Atiner.

- Greek Night Entertainment (This is the official dinner of the conference)

- Athens Sightseeing: Old and New-An Educational Urban Walk

- Social Dinner

- Mycenae Visit

- Exploration of the Aegean Islands

- Delphi Visit

- Ancient Corinth and Cape Sounion

\section{Conference Fees}

Conference fees vary from $400 €$ to $2000 €$ Details can be found at: https://www.atiner.gr/2021fees 


\section{Athens Institute for Education and Research}

A World Association of Academics and Researchers

\section{9th Annual International Conference on Physics \\ 19-22 July 2021, Athens, Greece}

The Physics Unit of ATINER, will hold its $9^{\text {th }}$ Annual International Conference on Physics, 19-22 July 2021, Athens, Greece sponsored by the Athens Journal of Sciences. The aim of the conference is to bring together academics and researchers of all areas of physics and other related disciplines. Please submit a proposal using the form available (https://www.atiner.gr/2021/FORMPHY.doc).

\section{Important Dates}

- Abstract Submission: 22 March 2021

- Acceptance of Abstract: 4 Weeks after Submission

- Submission of Paper: 21 June 2021

\section{Academic Member Responsible for the Conference}

- Dr. Ethel Petrou, Academic Member, ATINER \& Professor and Chair, Department of Physics, Erie Community College-South, State University of New York, USA.

- Dr. Bala Maheswaran, Head, Electrical Engineering Unit, ATINER \& Professor, Northeastern University, USA.

\section{Social and Educational Program}

The Social Program Emphasizes the Educational Aspect of the Academic Meetings of Atiner.

- Greek Night Entertainment (This is the official dinner of the conference)

- Athens Sightseeing: Old and New-An Educational Urban Walk

- Social Dinner

- Mycenae Visit

- Exploration of the Aegean Islands

- Delphi Visit

- Ancient Corinth and Cape Sounion

More information can be found here: https://www.atiner.gr/social-program

\section{Conference Fees}

Conference fees vary from $400 €$ to $2000 €$

Details can be found at: https://www.atiner.gr /2021fees 





\title{
Behaviour of Temperature Variations in Subsurface Layers in the South-Eastern Mediterranean Sea
}

\author{
By Tarek M. El-Geziry ${ }^{*}$ Ibrahim A. Maiyza ${ }^{ \pm} \&$ Mohamed S. Kamel ${ }^{*}$
}

The present work is a qualitative research, which aims at drawing the general behaviour of variations in the subsurface seawater temperatures within three distinctive subsurface layers in the south-eastern Mediterranean region. The work is based on hydrographic data collected over 65 years (1948-2012). The investigated layers are the subsurface, the intermediate and the deep water layers. The general trend of the mean annual temperature anomaly (MATA) was examined using the linear and quadratic regressions. Results revealed that the MATA over the water column in the south-eastern Mediterranean has the same trend, regardless of the place (layer) of investigation. Linearly, all MATA have increasing trends with different rates, with the exception of the $75 \mathrm{~m}$ level, which has a decreasing trend following that previously concluded for the surface water in the region. Also, the quadratic approach reflects the same trend of MATA over the water column, with different years of minimum occurrence. These same trends from the surface to deep can be attributed to the vertical convection processes in this region, and to the expanded impact of solar radiation which may reach more than $30 \mathrm{~m}$ depth.

Keywords: South-eastern Mediterranean Sea, seawater temperature, linear regression, quadratic regression, cyclic trend

\section{Introduction}

The Mediterranean Sea is known to be one of the few basins in the world where physical and dynamical processes interact; due to the deep convection processes and formation of intermediate and deep water masses (Wu and Haines 1996). The Mediterranean is known to play an indirect role in the water formation processes and thermohaline circulation in the North Atlantic with its very saline outflow to the Atlantic through the Strait of Gibraltar (Reid 1979, Lozier et al. 1995, Bethoux et al. 1998). In recent decades, the Mediterranean Sea has examined rapid change of increase in its temperature and salinity (Rohling and Bryden 1992, Schroeder et al. 2017, Iona et al. 2018), reflecting the global general warming trend (Levitus et al. 2012). During the period between late 1980s and mid-1990s, the circulation pattern the eastern Mediterranean basin practiced a remarkable change from the surface to the deep layers (Iona et al. 2018).

In the Eastern Mediterranean Basin, three water masses can be identified:

\footnotetext{
*Associate Research Professor, Laboratory of Physical Oceanography, Division of Marine Environment, National Institute of Oceanography and Fisheries (NIOF), Egypt.

${ }^{ \pm}$Emeritus Professor, Laboratory of Physical Oceanography, Division of Marine Environment, National Institute of Oceanography and Fisheries (NIOF), Egypt.

${ }^{\ddagger}$ Emeritus Professor, Laboratory of Physical Oceanography, Division of Marine Environment, National Institute of Oceanography and Fisheries (NIOF), Egypt.
} 
1. The surface water, of Atlantic origin, which invades the eastern Mediterranean basin through the Strait of Sicily and extends from the surface to a depth of more than $100 \mathrm{~m}$. During the cold period of the year, this surface water mass is a mixture of the surface old Mediterranean waters and the subsurface waters of Atlantic origin. In the warm period of the year, the former is overlying the later.

2. The Levantine Intermediate Water (LIW), which is formed by winter cooling and continuous evaporation processes in the region south-southeast of Rhodes. This layer extends from 150 to $600 \mathrm{~m}$ depth, and flows westward and out through the Strait of Gibraltar into the Atlantic Ocean (Maiyza 1984, Millot and Taupier-Letage 2005).

3. The Deep Eastern Mediterranean Water, which is partially formed by strong winter cooling, continuous evaporation and wind mixing processes, in the cold years, in the area between Rhodes and Crete islands (Maiyza 1984). According to Nielsen (1912), the Adriatic is also considered as a main source of this water mass.

All these water masses are strictly related in a form that any significant modification involving a single water mass may propagate its effects to the others. The observational evidence shows that significant surface anomalies in the Eastern Mediterranean may affect its deeper layers (Astraldi et al. 2002).

The Mediterranean Sea is characterized by seawater temperatures varying between $15.0^{\circ} \mathrm{C}$ and $17.0^{\circ} \mathrm{C}$ along its upper $400 \mathrm{~m}$ in winter, while in summer, due to the warming effect, the sea surface temperature $(30-50 \mathrm{~m})$ increases to $28.0^{\circ} \mathrm{C}$ and, consequently, a strong thermocline is developed (Millot and Taupier-Letage 2005). Between 50 and $100 \mathrm{~m}$ depth, the seawater temperature ranges between $17.0^{\circ} \mathrm{C}$ and $22.0^{\circ} \mathrm{C}$; identified as the Atlantic water mass (Sharaf El-Din and ElGindy 1987). Below this Atlantic layer, an intermediate water mass takes place with a temperature ranging between $15.0^{\circ} \mathrm{C}$ and $17.0^{\circ} \mathrm{C}$. Below the $1,000 \mathrm{~m}$ depth, the seawater temperature fluctuates between $13.3^{\circ} \mathrm{C}$ and $13.5^{\circ} \mathrm{C}$ (Said 1990). Using Extended Bathy-Thermograph (XBT) data, the temporal and spatial variabilities of seawater temperatures were found to be significantly different in the Western and Eastern Mediterranean Basins (Fusco et al. 2003). While, in the former the winter cooling results in a loss of thermal stratification, the latter examines permanent stratification varying with the seasons and strongly affected by the system of gyres.

The long-term trends of temperature in the Mediterranean Sea have been the subject of many researches since the 1990s. Table 1 in Vargas-Yanez et al. (2009) summarises the main findings of the previous work on the long-term trends of temperature in the Mediterranean basin over the period 1990-2006. The long term variations in the sea surface and air temperatures anomalies in the south-eastern Mediterranean region were previously investigated by Maiyza and Kamel (2009), Maiyza et al. (2010), Maiyza et al. (2011). Their results revealed a cyclic behaviour in the changes of these thermal anomalies over decades instead of the common idea of continuous increase. The linear trends of variations in the two parameters were also examined by many authors, of them: Nykjaer (2009), Samuel-Rhoads et 
al. (2013), Shaltout and Omstedt (2014), Adloff et al. (2015), Tonbol and El-Geziry (2015), Pastor et al. (2018), Tonbol et al. (2018).

The present work is a qualitative research aiming to draw the general behaviour of variations in the seawater temperature anomalies in the south-eastern Mediterranean region at three distinctive layers, namely: subsurface, intermediate and deep. The work is based on hydrographic data collected between 1948 and 2012. This can be considered as a continuation of the previous work, by the authors, on the variations of sea surface temperature; in order to build a robust conclusion on the behaviour of variation of seawater temperature in the southeastern Mediterranean region.

\section{Data and Methods of Analysis}

The present area of investigation occupies the region of the south-eastern Mediterranean Sea off the Egyptian Mediterranean coast, divided into 5 grids of $2^{\circ}$ x $3^{\circ}$ size each. This area extends latitudinally from the Egyptian Mediterranean coast to $33^{\circ} \mathrm{N}$ and longitudinally from $25^{\circ} \mathrm{E}$ to the Asian coast (Figure 1).

The available seawater temperature data covers 65 years (1948-2012). The data files arise from the World Data Centre (WDC) A (Washington) \& WDC B (Moscow), from the Russian cruises through the Physical Oceanography of Eastern Mediterranean (POEM) project and from the Egyptian National Oceanographic Data Centre (ENODC). However, the present work can be considered as a qualitative research; due to the well-known bad spatial and temporal data distributions.

Figure 1. The Five Grids of Interest, and Locations of Water Mass Formation in the Eastern Mediterranean (LIW: Levantine Intermediate Water, DEMW: Deep Eastern Mediterranean Water)

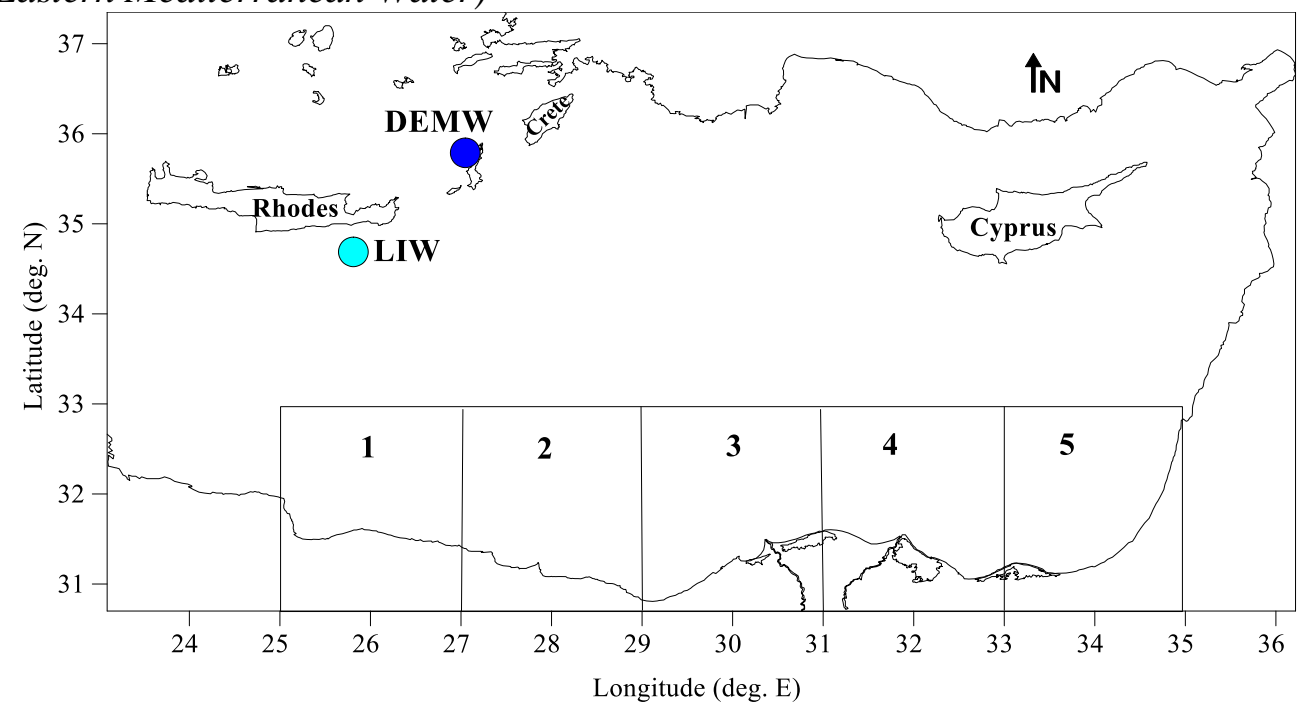

The whole data set is categorised in three main subsurface temperature groups: a subsurface layer (represented by 75 and $100 \mathrm{~m}$ levels), an intermediate 
layer (300 and $500 \mathrm{~m}$ levels) and a deep layer (1,000, 1,500 and 2,000 m levels). Variations in the seawater temperature anomalies in each layer are discussed.

The deviation from the monthly mean, obtained from the Climatological Atlas of the Mediterranean Sea (Maiyza et al. 1993), is computed on monthly basis to express the monthly temperature anomaly (MTA), using the following equation:

$$
\Delta T=T-T_{m}
$$

where,

$\Delta \mathrm{T}$ is the MTA,

$\mathrm{T}$ is the mean monthly temperature, mean for specific month every year and

$\mathrm{T}_{\mathrm{m}}$ is the monthly mean temperature, mean for specific month of all years

The mean monthly temperature anomaly (MMTA) of all occupied grids is considered as the MMTA of the area under study. Also, the mean annual temperature anomaly (MATA) of all occupied months is considered as the area MATA.

Standard deviation and variance were calculated for the entire population of raw data from which the means (monthly, annual, and anomalies) at each level were calculated; to show whether the derived annual values are reliable or not.

The general trends of the MATA variations are examined using both the linear and the quadratic regression approaches. The representative equations for each level in every specified layer are generated.

\section{Results}

\section{Statistical Summary of the Present Data Population}

Table 1 shows the minimum, maximum, arithmetic mean, standard deviation and variance of the calculated anomaly at each examined level. The year of occurrence is also mentioned. It can be shown that the maximum MATA is reached in the same year over the different levels of concern at every layer. This has one exception: the $2,000 \mathrm{~m}$, which differed that the two levels in the same deep layer: 1,000 and $1,500 \mathrm{~m}$. The low values of standard deviations and variances reflect a sort of homogeneity in the applied data.

Table 1. Statistical Analysis of MATA at Every Level

\begin{tabular}{|l|c|c|c|c|c|c|c|}
\hline & $75 \mathrm{~m}$ & $100 \mathrm{~m}$ & $300 \mathrm{~m}$ & $500 \mathrm{~m}$ & $1000 \mathrm{~m}$ & $1500 \mathrm{~m}$ & $2000 \mathrm{~m}$ \\
\hline \multirow{2}{*}{ Min. $\left({ }^{\circ} \mathrm{C}\right)$} & -1.75 & -2.47 & -0.99 & -0.19 & -0.03 & -0.11 & -0.12 \\
& $(1967)$ & $(1958)$ & $(1993)$ & $(1962)$ & $(1965)$ & $(1965)$ & $(1948)$ \\
\hline \multirow{2}{*}{ Max. $\left({ }^{\circ} \mathrm{C}\right)$} & +4.64 & +6.09 & +0.39 & +0.19 & +0.05 & +0.03 & +0.20 \\
& $(2007)$ & $(2007)$ & $(2012)$ & $(2012)$ & $(1990)$ & $(1990)$ & $(2012)$ \\
\hline Mean $\left({ }^{\circ} \mathrm{C}\right)$ & -0.04 & +0.15 & -0.06 & -0.02 & +0.005 & -0.07 & +0.02 \\
\hline St. Dev. & 1.20 & 1.30 & 0.29 & 0.10 & 0.03 & 0.04 & 0.08 \\
\hline Var. & 1.46 & 1.80 & 0.08 & 0.01 & 0.00 & 0.002 & 0.006 \\
\hline
\end{tabular}




\section{Subsurface Layer (75 and 100 m levels)}

Over the period of investigation (1948-2012), the linear trend of the MATA distribution at the $75 \mathrm{~m}$ level (Figure 2) has the same decreasing trend concluded by Maiyza and Kamel (2009) for the surface layer. The same slight decrease in the MATA trend is proven with a rate of $-0.003^{\circ} \mathrm{C} /$ year. On the other hand, at the 100 $\mathrm{m}$ level the liner trend (Figure 3 ) is reversed to be an increasing one with a rate of $+0.02^{\circ} \mathrm{C} /$ year. From a quadratic point of view, the trends of two anomalies tend to follow that of the surface temperature anomaly concluded by Maiyza and Kamel (2009). The obtained parabolic curves seem to be of cyclic behaviour. However, this cycle is more obvious for the $75 \mathrm{~m}$ level (Figure 2) than for the $100 \mathrm{~m}$ one (Figure 3). While for the $75 \mathrm{~m}$ level there is a general decrease from 1948 to 1985 followed by a general increase onwards, there is an all over decrease from 1948 to 1955 followed by an onward increase for the $100 \mathrm{~m}$ level.

At the $75 \mathrm{~m}$ level, the trend models of the MATA are respectively represented by the Equations:

$$
\begin{aligned}
& y=-0.0035 x-0.0942 ; r=0.08 \\
& y=0.0003 x^{2}-0.0223 x+0.1441 ; r=0.13
\end{aligned}
$$

At the $100 \mathrm{~m}$ level, the variations of the subsurface MATA are respectively given by:

$$
\begin{aligned}
& y=0.0234 x-0.6726 ; r=0.31 \\
& y=0.0004 x^{2}-0.0056 x-0.2748 ; r=0.32
\end{aligned}
$$

The predicted half cycle at the $75 \mathrm{~m}$ level, based on the roots pf the resultant quadratic equation (3) extended from 1954 to 2014, i.e., 60 years, while that at the $100 \mathrm{~m}$ level (Equation 5) extended from 1929 to 1981, i.e., 53 years.

Figure 2. General Regressions of Subsurface Temperature at the $75 \mathrm{~m}$ Level

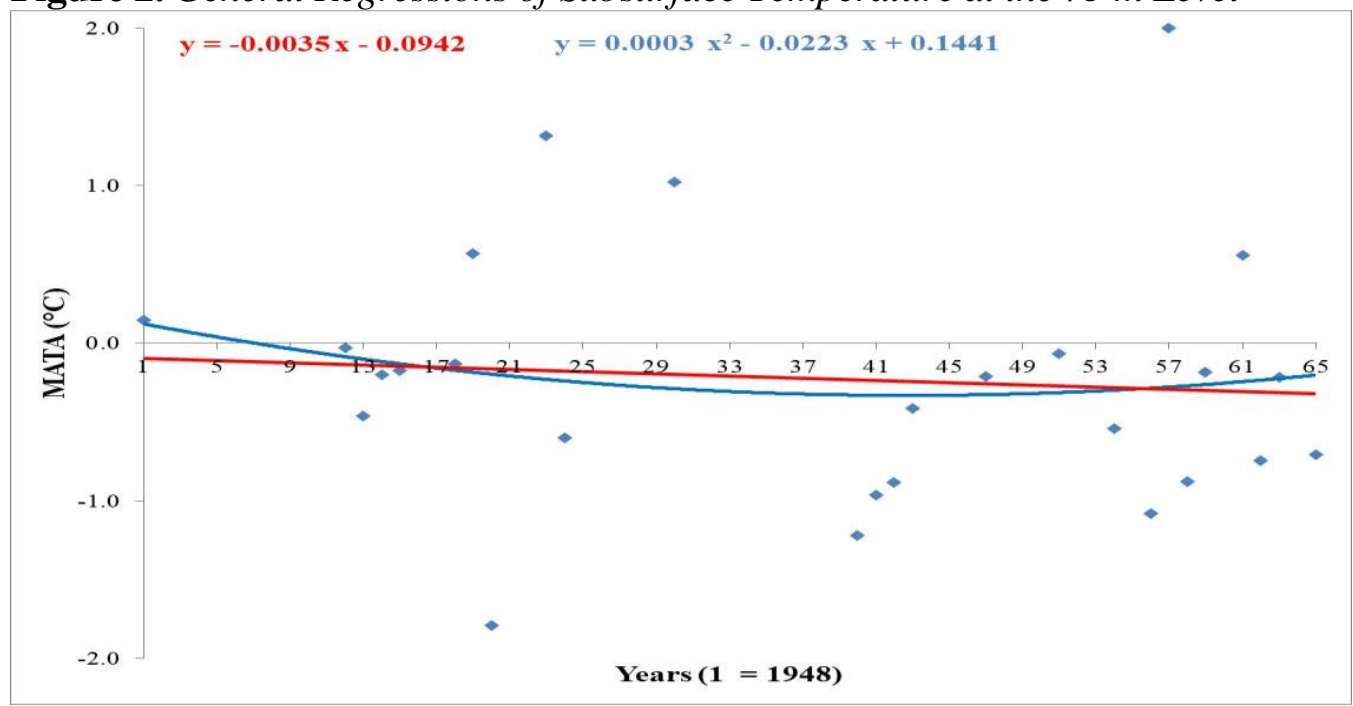


Figure 3. General Regressions of Subsurface Temperature at the $100 \mathrm{~m}$ Level

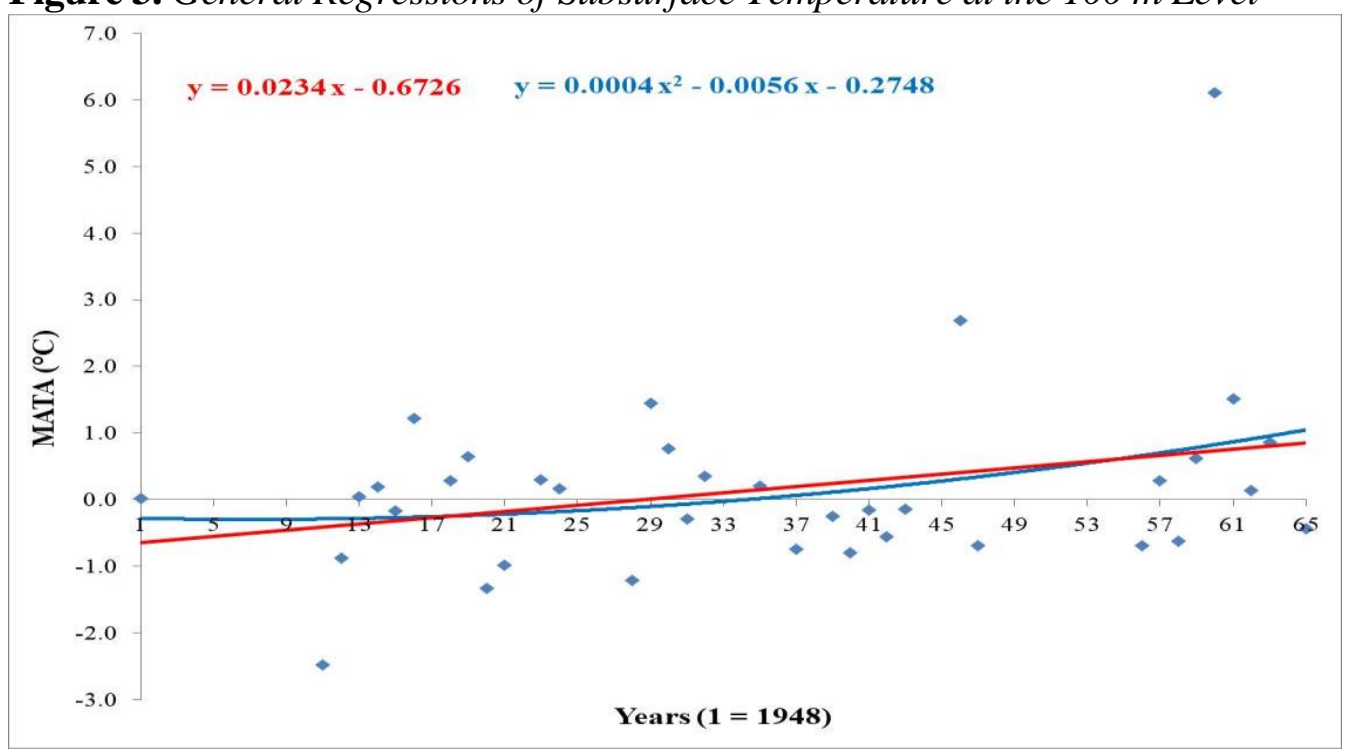

Intermediate Layer (300 and $500 \mathrm{~m}$ Levels)

The Eastern Levantine Intermediate Water (ELIW) mass is the warmest and saltiest mass created in the entire Mediterranean basin and can simply be followed up to Gibraltar just beneath the incoming surface Atlantic waters (El-Geziry 2010, El-Geziry and Bryden 2010). It is a fact that this LIW mass, during its spreading phase, reaches the basin's deep water formation areas and, being extremely saline (39 salinity), helps in the preconditioning of the water column (Drakopoulos and Lascaratos 1999).

The distributions and regressions of the MATA at the two levels presenting the LIW are shown in Figures 4 and 5. Linearly, the MATA at the two levels examines increasing trends with rates of $+0.002{ }^{\circ} \mathrm{C} / \mathrm{yr}$ and $+0.005{ }^{\circ} \mathrm{C} / \mathrm{yr}$ for the $300 \mathrm{~m}$ and $500 \mathrm{~m}$ levels, respectively. Quadratically, the two figures may reflect a general cyclic trend in the intermediate MATA, as in the subsurface layer. This is more obvious in the $300 \mathrm{~m}$ level with a general decrease from 1948 to 1974 , followed by an onward increase.

The MATA regression models at the $300 \mathrm{~m}$ level are respectively presented by the Equations:

$$
\begin{aligned}
& y=0.0016 x-0.0543 ; r=0.13 \\
& y=0.0003 x^{2}-0.0156 x+0.1541 ; r=0.42
\end{aligned}
$$

The MATA regression models at the $500 \mathrm{~m}$ level are given by:

$$
\begin{aligned}
& y=0.0054 x-0.1763 ; r=0.91 \\
& y=4 E-05 x^{2}+0.003 x-0.1504 ; r=0.91
\end{aligned}
$$


The roots of Equations (7) and (9) revealed half cycles of 28 years (19601987) and of 144 years (1839-1982) for the MATA at the $300 \mathrm{~m}$ and $500 \mathrm{~m}$ levels of intermediate layer, respectively.

Figure 4. General Regressions of Intermediate Temperature at the $300 \mathrm{~m}$ Level

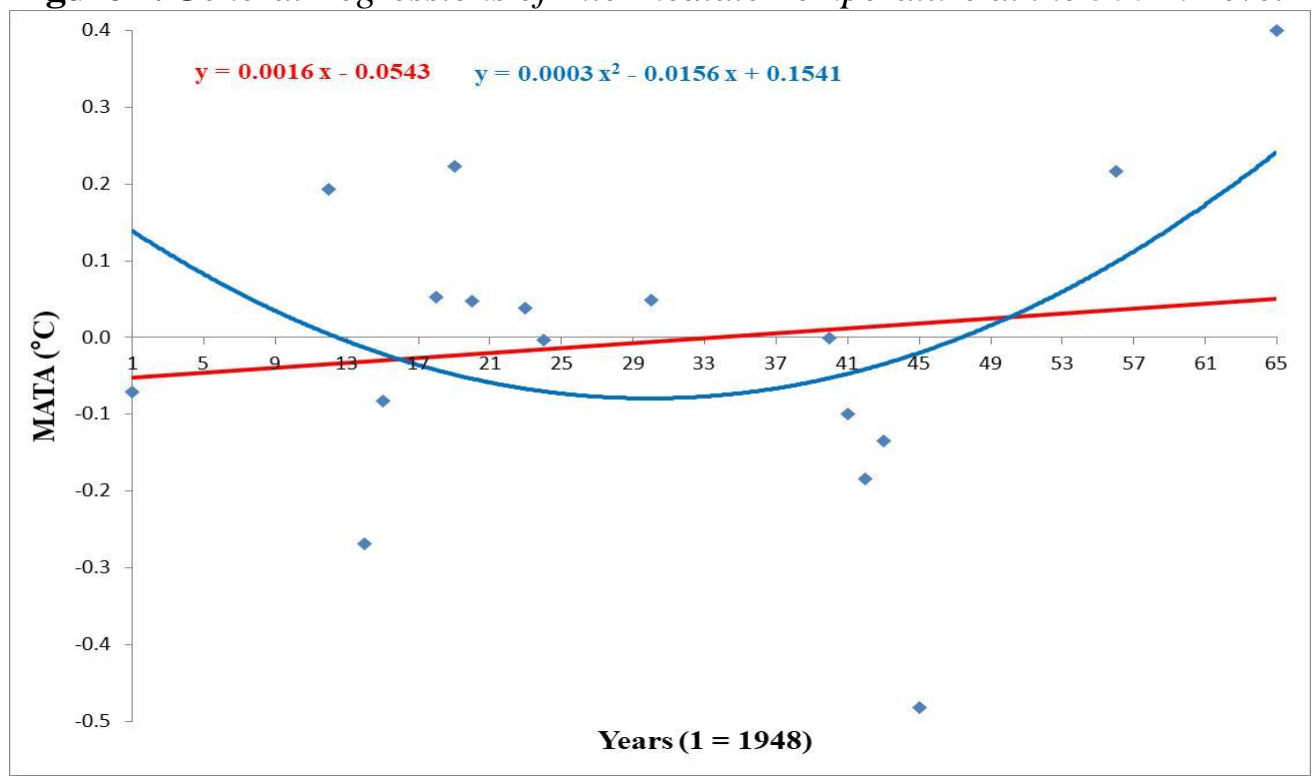

Figure 5. General Regressions of Intermediate Temperature at the $500 \mathrm{~m}$ Level

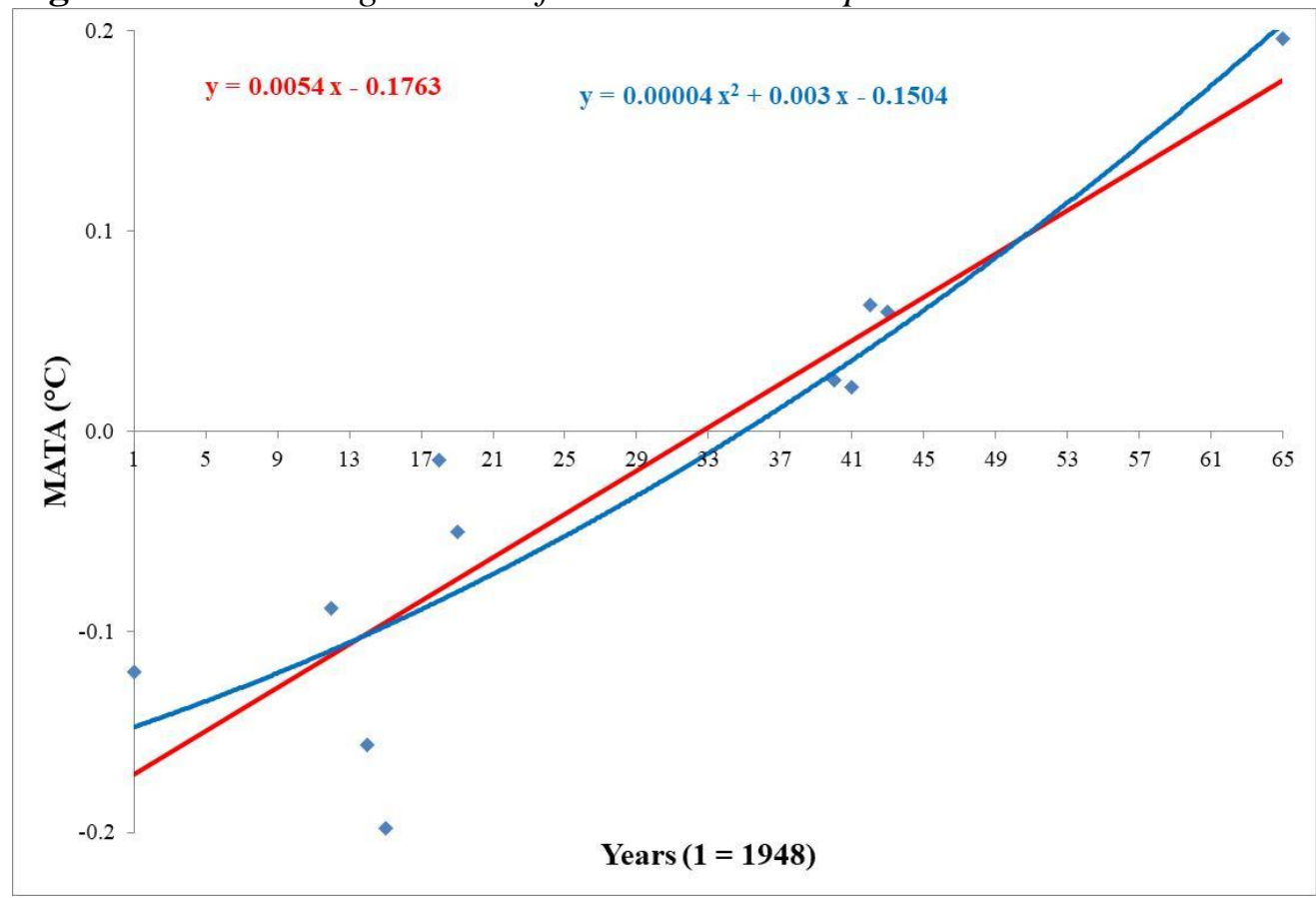

Deep Layer (1,000, 1,500 and 2,000 m Levels)

The source of formation of the deep and near-bottom waters in the Eastern Mediterranean Sea was suggested by Nielsen (1912) to be in the southern regions 
of the Adriatic and Aegean Seas. Pollak (1951) suggested only the Adriatic and that the deep outflow through the Strait of Otranto was far from continuous. Wüst (1961) noted the maximum value of dissolved oxygen content $(>4.4 \mathrm{ml} / 1)$ and minimum water temperature at the deep $(2,000 \mathrm{~m})$ levels $\left(<13.2{ }^{\circ} \mathrm{C}\right)$ to the south of the islands separating the Aegean from Levantine Seas. Maiyza (1984) concluded that formation of the deep water mass takes place to the east of Crete Island in the northern Levantine Sea. His conclusion agrees and resolves the contrast between the three mentioned results of Nielsen (1912), Pollak (1951) and Wüst (1961).

Field experiments conducted in the early 1980s in the international co-operative research programme: Physical Oceanography of the Eastern Mediterranean (POEM) demonstrated that a single homogeneous deep water body filled the entire Eastern Mediterranean below a depth of about 1,200 m (Manca et al. 2002). In the present work, the 1,000 m level is considered as the upper limit of this deep layer. It is well-observed that the MATA variations and trends at this level (Figure 6) are still following the general behaviour of a general linear increase but with a rate of $+0.001^{\circ} \mathrm{C} / \mathrm{yr}$, and with a parabolic quadratic distribution with a minimum value in 1970. The regression models of the MATA at the 1,000 m level are respectively presented by the following Equations:

$$
\begin{aligned}
& y=0.0013 x-0.0364 ; r=0.61 \\
& y=5 E-05 x^{2}-0.0022 x+0.0118 ; r=0.72
\end{aligned}
$$

The predicted half cycle at the $1000 \mathrm{~m}$ level, according to Equation (11) extended from 1953 to 1985 , i.e., 33 years.

At the $1500 \mathrm{~m}$ level (Figure 7), the linear trend of the MATA variations examined the highest rate of increase in the calculated rates, being $+0.003^{\circ} \mathrm{C} / \mathrm{yr}$. The quadratic variations, on the other hand, are still reflecting a cyclic trend with a minimum occurrence in 1969.

Figure 6. General Regressions of Deep Temperature at the $1000 \mathrm{~m}$ Level

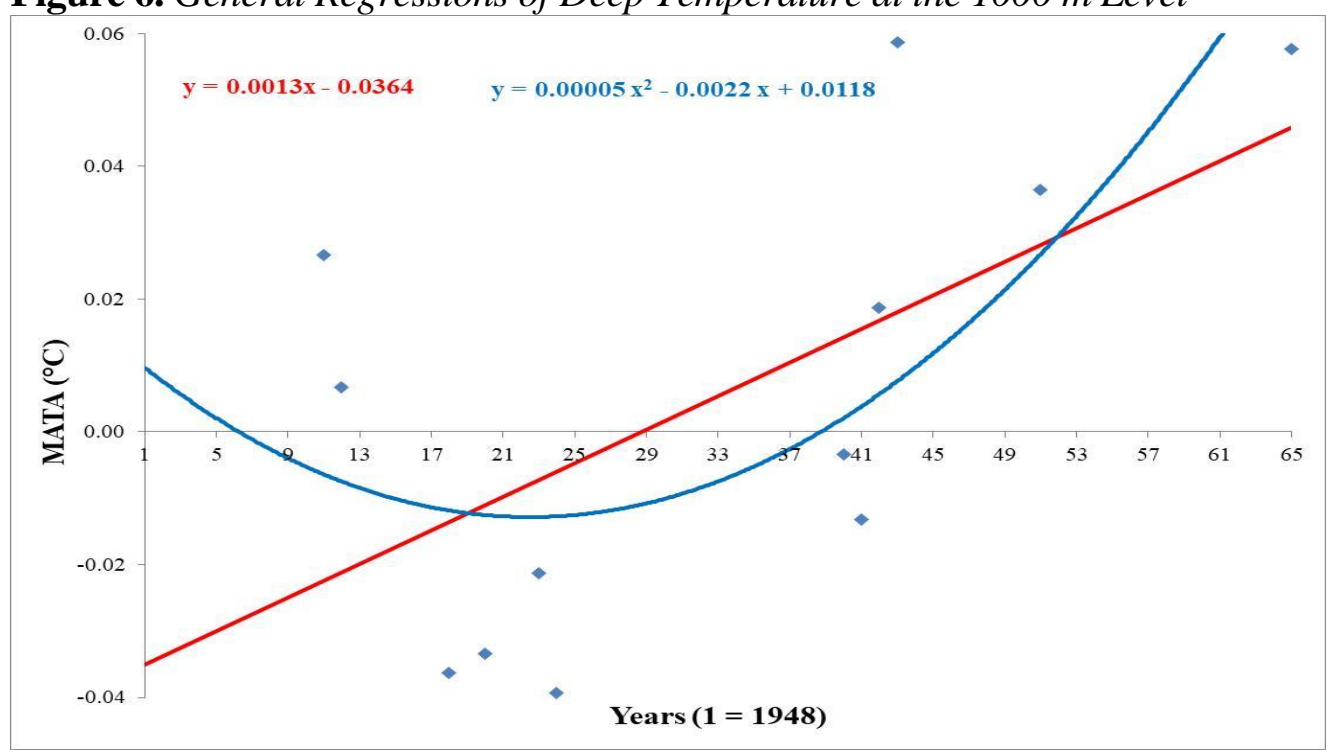


The two regression models at the $1,500 \mathrm{~m}$ level can be respectively presented by the following Equations:

$$
\begin{aligned}
& y=0.0029 x-0.1534 ; r=0.75 \\
& y=0.0002 x^{2}-0.0084 x-0.0225 ; r=0.81
\end{aligned}
$$

At the 1,500 m level, the half cycle of the MATA, roots of Equation (13), extended from 1945 to 1992 , i.e., 48 years.

Figure 7. General Regressions of Deep Temperature at the 1,500 $\mathrm{m}$ Level

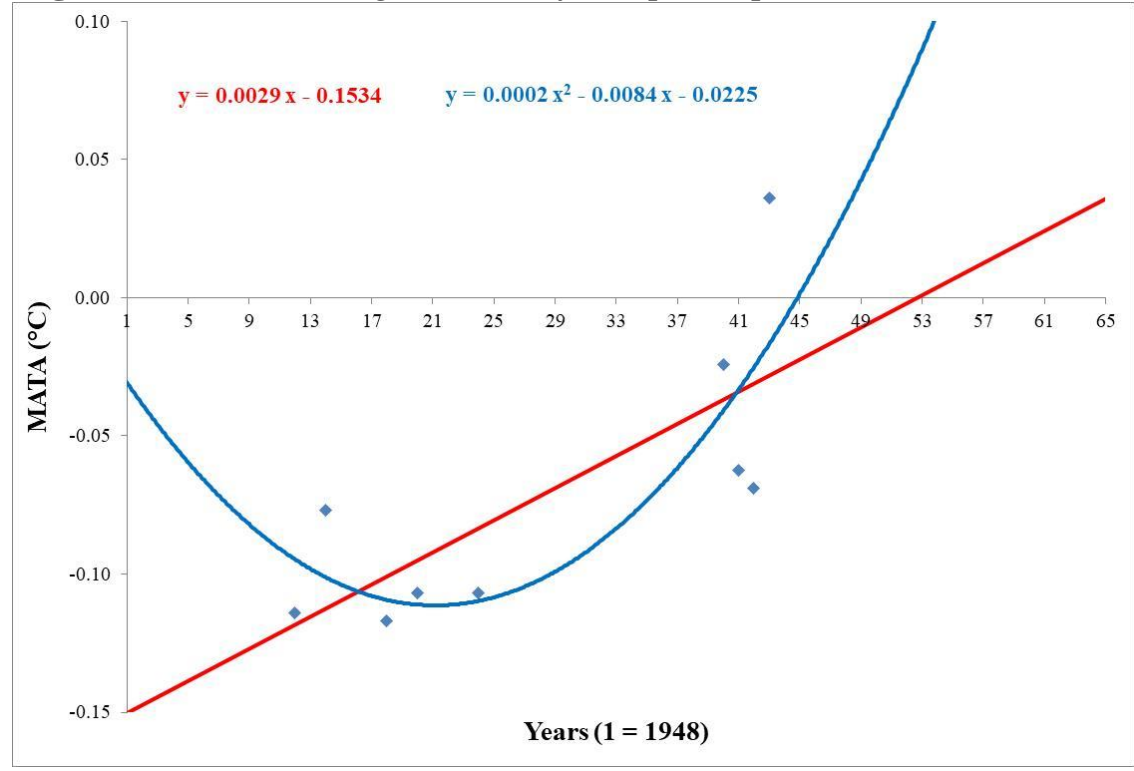

The general trends of the MATA variations in the 2,000 $\mathrm{m}$ level are shown in Figure 8 . Linearly, the same rate of increase at the $1,500 \mathrm{~m}$ level, of $+0.003^{\circ} \mathrm{C} / \mathrm{yr}$, still exists. From a quadratic point of view, there is a general decrease from 1948 to 1961 , followed by a general increase onwards. The regression models of the MATA at the 2,000 m level are respectively presented by the following Equations:

$$
\begin{aligned}
& y=0.0034 x-0.1204 ; r=0.74 \\
& y=9 E-05 x 2-0.0024 x-0.0566 ; r=0.83
\end{aligned}
$$

The roots of Equation (15) of the MATA occurrence at the 2,000 m level revealed a half cycle extending from 1934 to 1989, i.e., 56 years. 
Figure 8. General Regressions of Deep Temperature at the 2,000 $\mathrm{m}$ Level

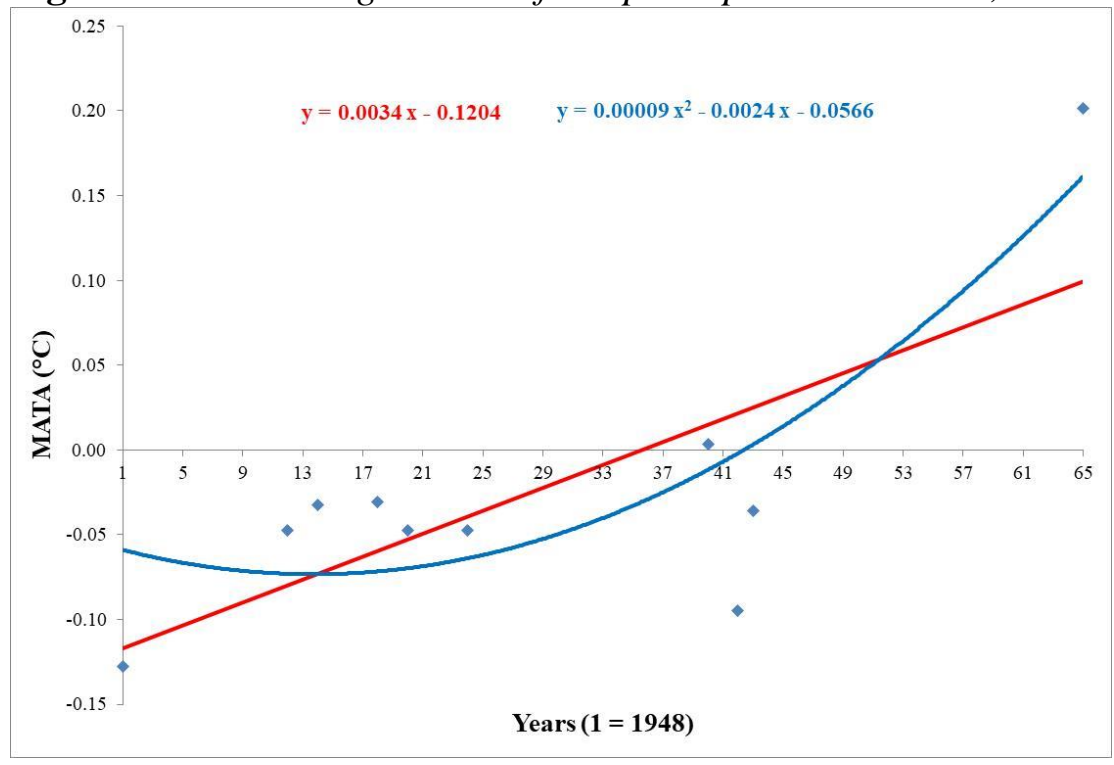

\section{Discussion}

The long-term variations in the sea surface temperature anomaly in the southeastern Mediterranean basin were previously studied by Maiyza and Kamel (2009) and Maiyza et al. (2010). Their results revealed a cyclic behaviour of variation with a minimum surface temperature anomaly in the year 1985 .

The present work is a qualitative research, which aims at drawing the general behaviour of variations in the seawater temperature within three distinctive layers in the south-eastern Mediterranean region; based on hydrographic data collected between 1948 and 2012. These are the subsurface, the intermediate and the deep layers.

All examined linear trends of MATA are of increasing behaviour except that at the $75 \mathrm{~m}$ level, which examined a decreasing trend following that concluded by Maiyza and Kamel (2009) for the surface MATA. This may lead to a conclusion on the extended thermal effect of the surface layer in the region of interest. Also, results revealed that the highest rate of increase of the MATA linear trends was $+0.02^{\circ} \mathrm{C} / \mathrm{yr}(100 \mathrm{~m} \mathrm{level})$, while all other rates varied between +0.001 and $+0.005^{\circ} \mathrm{C} / \mathrm{yr}$. This range is in agreement with that concluded by Iona et al. (2018) for the Levantine Basin.

The resultant parabolic curves for the entire levels tend to reflect a cyclic behaviour similar to that detected by Maiyza and Kamel (2009) for the sea surface temperature anomaly. However, the year of minimal MATA occurrence differs from one level to another. This observed similarity in the behaviour of MATA variations may be, partially, attributed to the thermal nature and physical property of the water column in the investigated region. The transparency of the water column within the investigated region may extend to about $30 \mathrm{~m}$ depth, which permits the sun rays to impact on the thermal expansion even to the subsurface layers. 
Figure 9. General Regression of Deep Temperature at the $2000 \mathrm{~m}$ Level for the New Extended Area of Interest

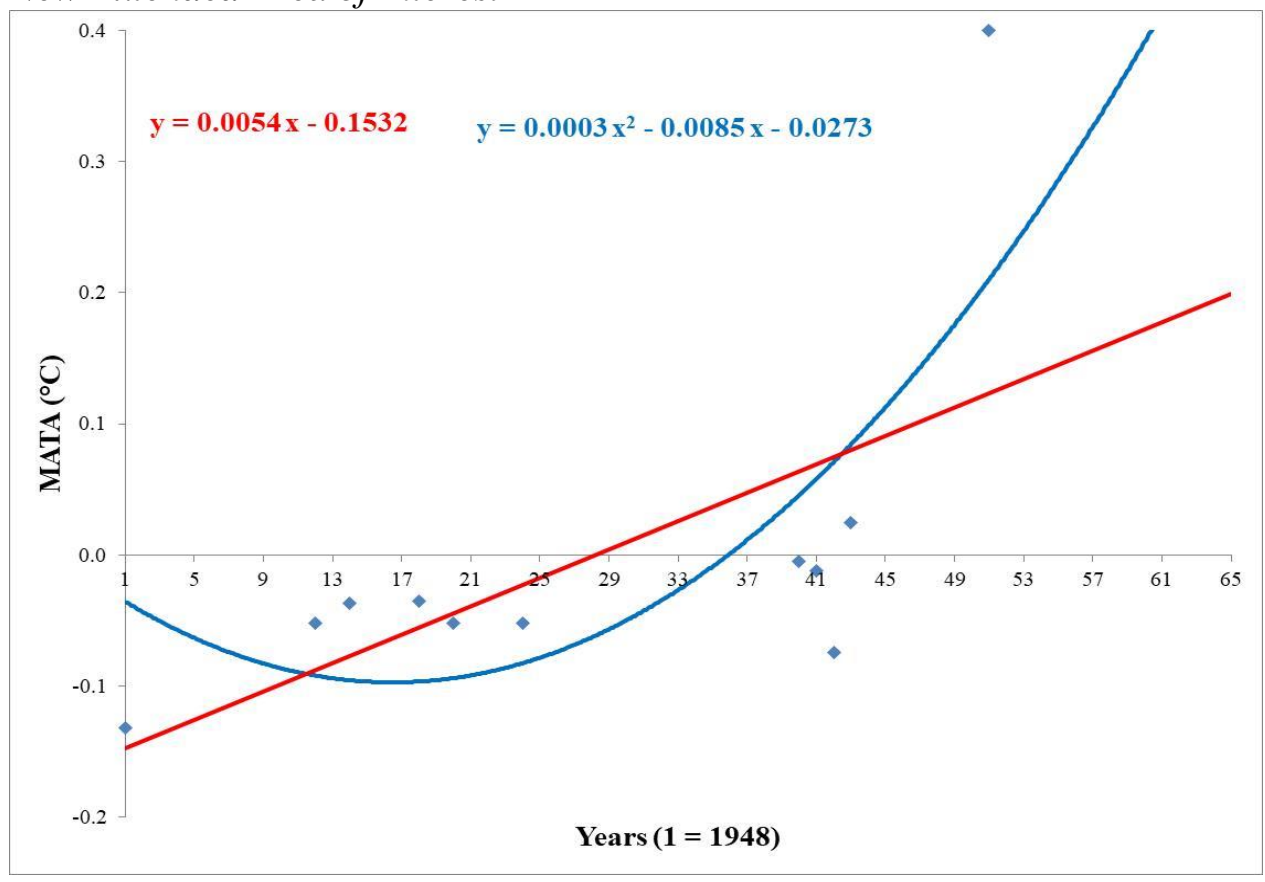

Any water mass is formed at the surface, inside or outside the basin of interest, and then sinks to the appropriate level and spreads afterward (Dobravolsky 1947, Marchall and Schott 1999). The hydrographic and atmospheric conditions within the formation areas especially during winter season are critical in defining the general characteristics and behaviour of the water formed (Schroeder et al. 2017). Hence, in order to come closer to the area of formation of the Levantine Intermediate Water, the most important water mass in the Mediterranean basin with its extended effect to the Atlantic, it has been more convenient to expand the present area of interest northward to Latitude $35^{\circ} \mathrm{N}$. The trend of the MATA has, therefore, been re-examined at the $2000 \mathrm{~m}$ level. Wüst (1961) studied the physical properties at this level and put two question marks (see Figures 5 and 7 in Wüst 1961), remarking the sinking zone of fresh surface waters characterized by maximum dissolved oxygen and minimum water temperature between Rhodes and Crete. The result of the present re-examination is shown in Figure 9, reflecting a linear trend of increase in the MATA variations with a rate of $+0.005^{\circ} \mathrm{C} / \mathrm{yr}$. The new MATA varied between a minimum of $-0.13^{\circ} \mathrm{C}$ in 1948 and a maximum of $+0.4^{\circ} \mathrm{C}$ in 1998 , with a general mean of -0.03 . The standard deviation and the variance of the new MATA are 0.13 and 0.02 , respectively. In the meantime, the resultant parabolic curve tends to follow that of the MATA variations at all overlaying layers in the present work and at the surface layer concluded by Maiyza and Kamel (2009). The predicted half cycle from the resultant quadratic equation at this extended region expanded from 1946 to 1982, i.e., 37 years. The minimum year of occurrence is 1962. This, indeed, supports the conclusion that the origin of the deep Levantine water is mainly from the modified sinking surface water. This is also consistent with the conclusions that formation of the warmer LIW is 
initiated by a transformation processes (evaporation and cooling) and sinking of the surface water either in the Levantine Basin or in the Cretan Sea (Georgopoulos et al. 1989, Rohling and Bryden 1992, Lascartos et al. 1999, Schroeder et al 2017).

\section{Conclusions}

To conclude, the general behaviour of the MATA for all levels within the south-eastern Mediterranean region: subsurface, intermediate and deep do have the same trend deduced for the surface layer, but with different magnitude and different time of occurrence. This can be attributed to the late winter vertical convection on the extreme cold and salter water column with transparency $(\sim 30$ $\mathrm{m})$ in this region. The observed trend of "cyclic" parabolic behaviour is observed at all levels and even close to region of formation of the deep water mass.

\section{References}

Adloff F, Somot S, Sevault F, Jordà G, Aznar R, Déqué M et al. (2015) Mediterranean Sea response to climate change in an ensemble of twenty first century scenarios. Climate Dynamics 45(9-10): 2775-2802.

Astraldi M, Gasparini GP, Vetrano A, Vignudelli S (2002) Hydrographic characteristics and interannual variability of water masses in the central Mediterranean: a sensitivity test for long-term changes in the Mediterranean Sea. Deep-Sea Research 49(4): 661680.

Bethoux J-P, Gentili B, Tailliez D (1998) Warming and freshwater budget change in the Mediterranean since the 1940 s, their possible relation to the greenhouse effect. Geophysical Research Letters 25(7): 1023-1026.

Dobrovolsky AD (1947) Water masses of the Pacific Ocean. Moscow: DSc Synopsis, Stepen Hydro-Geographic Institute. (In Russian)

Drakopoulos PG, Lascaratos A (1999) Modelling the Mediterranean Sea: climatological forcing. Journal of Marine Systems 20(1-4): 157-173.

El-Geziry TM (2010) Environmental impact assessment and process simulation of the tidal current energy resource in the strait of Messina. $\mathrm{PhD}$ Thesis. UK: University of Edinburgh.

El-Geziry TM, Bryden IG (2010) The circulation pattern in the Mediterranean Sea: issues for modeler consideration. Journal of Operational Oceanography 3(2): 39-46.

Fusco G, Manzella GMR, Cruzado A et al (2003) Variability of mesoscale features in the Mediterranean Sea from XBT data analysis. Annals of Geophysics 21(1): 21-32.

Georgopoulos D, Theocharis AC, Zodiatis G (1989) Intermediate water formation in the Cretan Sea (S. Aegean Sea). Oceanologica Acta 12(4): 353-359.

Iona A, Theodorou A, Sofianos S et al (2018) Mediterranean Sea climatic indices: monitoring long-term variability and climate changes. Earth System Science Data 10(4): 1829-1842.

Lascaratos A, Roether W, Nittis K, Klein B (1999) Recent changes in deep water formation and spreading in the eastern Mediterranean Sea: a review. Progress in Oceanography 44(1-3): 5-36. 
Levitus S, Antonov JI, Boyer TP, Baranova OK, Garcia HE, Locarnini RA et al. (2012) World ocean heat content and thermosteric sea level change (0-2000 m), 1955-2010. Geophysical Research Letters 39(10): L10603.

Lozier MS, Owens WB, Curry RG (1995) The climatology of the North Atlantic. Progress in Oceanography 36(1): 1-44.

Maiyza IA (1984) Long term variation of water temperature in the eastern part of the Mediterranean Sea. PhD Thesis. Russia: Moscow University. (In Russian)

Maiyza IA, Mohamed E.E., Badawi HK (1993) Climatological atlas of the Mediterranean Sea. Bulletin of National Institute of Oceanography and Fisheries 19(3VII): 1-7.

Maiyza IA, Kamel MS (2009) Climatological trend of sea surface temperature anomalies in the South Eastern Mediterranean Sea. Journal of King Abdulaziz University: Marine Sciences 20(1): 59-66.

Maiyza IA, Said MA, Kamel MS (2010) Sea surface temperature anomalies in the South Eastern Mediterranean Sea. Journal of King Abdulaziz University: Marine Sciences 21(1): 151-159.

Maiyza IA, El-Geziry TM, Maiyza HI, Kamel MS (2011) Climatological of air temperature anomalies in the South Eastern Mediterranean Sea. Journal of King Abdulaziz University: Marine Sciences 22(2): 55-65.

Manca BB, Ursella L, Scarazzato P (2002) New development of Eastern Mediterranean circulation based on hydrological observations and current measurements. Marine Ecology 23(1): 237-257.

Marshall J, Schott F (1999) Open-ocean convection: observations, theory, and models. Reviews of Geophysics 37(1): 1-64.

Millot C, Taupier-Letage I (2005). Circulation in the Mediterranean Sea. In Handbook of Environmental Chemistry: The Natural Environment and the Biogeochemical Cycles. Springer-Verlag 5(K): 29-66.

Nielsen JN (1912) Hydrography of the Mediterranean and adjacent waters. In Report of the Danish Oceanographic Expedition 1908-1910 to the Mediterranean and Adjacent Waters, 77-192. AF Host and Son.

Nykjaer L (2009) Mediterranean Sea surface warming 1985-2006. Climate Research 39(1): 11-17.

Pastor F, Valiente JA, Palau JA (2018) Sea surface temperature in the Mediterranean: trends and spatial patterns (1982-2016). Pure and Applied Geophysics 175(Jan): 4017-4029.

Pollak MI (1951) The sources of the deep water of the Eastern Mediterranean Sea. Journal of Marine Research 10(1): 128-152.

Reid JL (1979) On the contribution of the Mediterranean Sea outflow to the NorwageanGreenland Sea. Deep-Sea Research 26(11): 1199-1223.

Rohling EJ, Bryden HL (1992) Man-Induced salinity and temperature increases in Western Mediterranean Deep Water. Journal of Geophysical Research 97(C7): 11191-11198.

Said MA (1990) Horizontal circulation of the Eastern Mediterranean waters during winter and summer seasons. Acta Adriatica 31(1-2): 5-21.

Samuel-Rhoads Y, Zodiatis G, Nikolaidis A et al (2013) Climate change impacts on sea surface temperature in the Eastern Mediterranean, Levantine Basin. In Proceedings First International Conference on Remote Sensing and Geoinformatics Environment (RSCy2013) 8795: 87950N-1 - 87950N-9.

Schroeder K, Chiggiato J, Josey SA, Borghini M, Aracri S, Sparnocchia S (2017) Rapid response to climate change in a marginal sea. Science Reports 7(1): 4065.

Shaltout M, Omstedt A (2014). Recent sea surface temperature trends and future scenarios for the Mediterranean Sea. Oceanologia 56(3): 411-443. 
Sharaf El-Din SH, El-Gindy A (1987) Characteristics, spreading and mixing of the intermediate water masses and their seasonal variations in the Eastern Mediterranean. Acta Adriatica 28(1): 45-58.

Tonbol KM, El-Geziry TM (2015) The daily SST Variations within the South-eastern Mediterranean Sea. In Proceedings of the $12^{\text {th }}$ International Conference on Mediterranean Coast and Environment (MEDCOAST15) 2, 1005-1016.

Tonbol KM, El-Geziry TM, Elbessa M (2018) Evaluation of changes and trends of air temperature within the Southern Levantine Basin. Weather 73(2): 60-66.

Vargas-Yanez M, Moya F, Tel E, Garcia-Martinez M, Guerber E, Bourgeon M (2009) Warming and salting in the western Mediterranean during the second half of the $20^{\text {th }}$ century: inconsistencies, unknowns and the effect of data processing. Scientia Marina 73(1): 7-28.

Wu P, Haines K (1996) Modelling the dispersal of Levantine intermediate water and its role in Mediterranean deep water formation. Journal of Geophysical Research 101(C3): 6591-6607.

Wüst G (1961) On the vertical circulation of the Mediterranean Sea. Journal of Geophysical Research 66(10): 3261-3271. 


\title{
Pragmatic Association of the Two Evaluation Concepts of Operational Observation and Mathematical Modeling
}

\author{
By Adel Razek
}

\begin{abstract}
Recent developments in several theoretical and industrial concepts are closely associated to the relation of operational observation to mathematical modeling. The present work investigates first the interdependence of these two evaluation notions. An assessment of these notions is performed involving different analyses based on philosophical aspects as phenomenology and structural research. These analyses are also supported by illustrations from physics and quantum science. These analyses examine the autonomy limits of each of both concepts and their interdependence. The associate resulting from such interdependence is therefore studied. This involves different aspects characterizing such associate (couple) as its managing in time and its rulings. The immersion of the couple "observation-theory" is subsequently considered through the exploration of different representing cases showing the nature of the interdependence in this couple. The corroborating interdependence is illuminated in the case of coupled amended models. The matching interdependence is illustrated in the cases of the industrial digital twins concept and Bayesian brain theory in neuroscience. Finally, the imitating interdependence is pointed out in quantum and neuromorphic computing technologies. The conclusion of the paper underlines that mathematical modeling needs operational observation simply to be credible and that the second needs the first for deeper research. Additionally, the interdependence of this associate is valuable to the ideas of several research and industrial innovative concepts.
\end{abstract}

Keywords: observation-modeling associate, phenomenology, structural research, Bayesian concepts, quantum science, matching, imitating, corroborating.

\section{Introduction}

Topical occurrences in numerous academic and industrial conceptions are intimately linked to the associate observation modeling. These two evaluation concepts could be employed separately or in a complementary associate.

We can carry on the analysis of a real object and its behavior according to real environmental events by operational observation or theoretical modeling. Depending on the concerned area of investigation, researchers prefer often one of these two concepts to evaluate the behavior of the subject under discussion. Observation is traditionally employed in human and social sciences e.g. anthropology, psychology, epidemiology... It is also partially used in earth science, applied physics and chemistry... On the other hand, mathematical

*Emeritus Research Director, C.N.R.S. \& Honorary Professor, CentraleSupelec, GeePs, University of Paris-Saclay and Sorbonne University, France. 
modeling is often employed generally in "hard" sciences as general physics, chemistry... These two concepts are not in fact, independent or auto sufficient. The validity of each results from the benefit of the other. This insures deeper and/ or credible research outcomes.

A real observable object and its behavior according to real observable environmental events could be explored by operational observation. Simple tools or instruments that are more sophisticated could perform such observation; this depends on the complexity of the observation task. When the object has an inherent nature and behaving under a simple environmental event, we are tackling a simple observation task. In the contrary, when the object nature inclines to interact with the environment in an interdependence frame, the task will be more complicated. This complexity will be particularly stronger in the case of interaction of the object with multiple events that are interdependent. The last situation, where the nature of the object as well as the different environmental events, are interacting interdependently corresponds to numerous societal realistic application domains e.g. health, mobility, energy.... In such case, an observation result (point) will be valid for a given specified operational condition. The different observation points (data) could be treated by algorithmic technics to perform a more universal and complete analysis. Thus, even observation could be auto-sufficient; it still needs mathematical modeling treatments for deeper investigations.

In the case where the analyzed behavior could be governed by known and founded verified theories, another evaluation issue for this problem may be the mathematical modeling. Here we mean by modeling, using mathematical formulation based on a theory expressed under the form of mathematical expression. In general, one can consider a theory only established after validation by observation. Moreover, such a theory remains valid until disagreement with observation. Therefore, the theory-observation couple is necessarily always associated.

Founding coherent and agreeable theories habitually requires postulations that squeeze and idealize the actual context of the investigation. When the situation studied is very close to such an unrealistic context, the problem of modeling analysis could be self-sufficient. In realistic situations, to amend for idealizing approximation errors, we have to account beside the principle-studied idealized phenomenon for more phenomena concerned by the committed approximations. Thus, we will have a multiple phenomenon (events) system to model in order to approach a realistic solution.

As in the case of observation, the complexity of the task of modeling will depend on how interacts the object with its environment. Each interaction of the object with an environmental event will be considered through a consequent theoretical treatment. Therefore, the complete analysis of the behavior of the studied object could be only performed through all the theories corresponding to the different concerned events (the principle one and those corresponding to the committed approximations). Moreover, if the natures of the studied object and the environmental events are interdependent, the modeling task will go through a coupled analysis of different theories (mathematical expressions), see e.g. (Razek 2020a). Such coupling may be performed sequentially in case of linear behaviors; 
see for example in the case of electromagnetic systems (EMS), (Sekkak et al. 1994, Piriou and Razek 1990). In the general case where the events self-behaviors and/or their interdependent behaviors are non-linear, we need a simultaneous coupling; see for example again in EMS (Ren and Razek 1994).

We can have an interrogation on the self-sufficiency of each of these two issues of analysis (concepts of observation and modeling) as well as on their complementarity (Razek 2020b). The nature and field of investigation is closely related to this questioning. Observation or modeling can be self-sufficient in areas of investigation that we often consider idealized or of simple nature. In the general case of real societal landscapes, the situation is more realistic and complex. In such case we need to use the two issues of analysis in a framework of complementarity. Such association is often necessary to obtain credible and deeper investigations. Thus, the validation by observation in the case of modeling is needed for creditability (see e.g. Merleau-Ponty 1960). In addition, the extension of the research limits by modeling in the case of observation is required for deepness (see e.g. Lévi-Strauss 1958).

In the present work, an assessment of the concepts of observation and modeling is performed. This involves different analyses based on philosophical aspects as phenomenology and structural research as well as illustrations from physics and quantum science. After this assessment, we will analyze the modelobservation associate in general. This involves different aspects of the couple "theory-observation" concerns as the theory-observation managing, the rulings on theory-observation, the theory-observation couple immersion. Different illustrating cases are analyzed including amended models (coupled phenomena), digital twins concept, and Bayesian brain theory as well as quantum and neuromorphic technologies (computing).

\section{Assessment of the Concepts: Observation and Modeling}

In this part of the paper, we will examine the limits of the self-sufficiency of both concepts.

\section{Theoretical Modeling Isolated from Observation}

Examine the bounds of the autonomy of the theoretical survey, counting for the research areas, which generally require theoretical modeling, for example physical, chemical, etc. In these cases, such modeling uses mathematical formulation based on a theory expressed under the form of mathematical expression. In such situations, founding coherent and agreeable theories habitually obligates postulations that squeeze and idealize the actual context of the investigation. When the situation studied is very close to such an unrealistic context, the problem of modeling analysis could be self-sufficient. On the contrary, in most societal survey situations, this type of analysis will not be sufficient. Furthermore, for problems where the theoretical behavior (mathematical expression) is not well known or unproven, it is manifest that the use of isolated 
mathematical modeling would be hopeless and speculative; this is the case of e.g. inductive prediction (see Popper 1934).

\section{Merleau-Ponty, Phenomenology and Science}

A typical example of cases of non-self-sufficiently of modeling analysis is illustrated in several works of Maurice Merleau-Ponty (1908-1961), French philosopher and intellectual. He analyzed and commented on modeling and observation in different publications; (see for example, Merleau-Ponty 1960). Merleau-Ponty was the main academic supporter of existentialism and phenomenology. Recognized for his creative and meaningful work on incarnation, perception and ontology, he has also made important contributions to several other fields including art, history, language, and nature.

Merleau-Ponty acted a vital role in the spread of phenomenology that was initially founded by the German philosopher, Edmund Husserl (1859-1938). Phenomenology can be coarsely expressed as the maintained effort to illustrate experiences (and their own things) without theoretical inferences. Husserl advocated that only by overhanging the "natural approach", philosophy could become a distinctive and rigorous science, and he asserted that phenomenology is a science of consciousness instead of empirical things. He is one of the furthermost prominent philosophers with key adapt phenomenologists, in addition to MerleauPonty, like Heidegger, Sartre, Gadamer, Levinas, and Derrida.

The Key impacts on Merleau-Ponty philosophical thoughts include besides Edmund Husserl, Henri Bergson, Max Scheler, Martin Heidegger and Jean-Paul Sartre. In addition to this list, in fields apart of philosophy, Kurt Goldstein in neurology, Wolfgang Köhler and Kurt Koffka in Gestalt theory, as well as Marcel Proust, Paul Claudel and Paul Valéry in literary. Moreover, he inspired the poststructuralist of French thinkers after him; especially Michel Foucault, Gilles Deleuze and Jacques Derrida.

Phenomenology, in accordance with Merleau-Ponty, sets away all scientific or naturalistic explanations of phenomena in order to describe faithfully the prescientific experience that such explanations take for established. Similarly, since the world exists prior to pensive analysis or judgment, phenomenology avoids reconstructing actual experience in terms of its conditions of possibility or the activity of perception. The phenomenological reduction, on his interpretation, is not an idealistic method but an existential one, namely, the reflective effort to disclose our pre-reflective engagement with the world.

The phenomenology of Perception according to Merleau-Ponty, considers the privileging of description over scientific explanation. It stands as a philosophy that places essences back into existence and does not think that human beings and the world are comprehensible. The Phenomenology is not in opposition to the sciences that are concerned with the same phenomena, even if these disciplines approach the subject from a different perspective. Merleau-Ponty considers that science improperly forces phenomenological or perceptual classes into objective classifications. The phenomenology of perception must progress from the world categories to those under which we perceive it. Science (and particularly empiricism), incorrectly infers the world of (persons, objects, actions...), from the 
reality to an associated artifact.

Built on these thoughts, Merleau-Ponty noted in several masterpieces on the limits of theoretical investigation and more generally on the science and theoretical researchers using theories set apart from reality. The ultimate one of these oeuvres was "The eye and the spirit, Paris 1960" mentioned before. He noticed, as a Professor at "Collège de France" and at the Lyon University, concerning isolateduse of theory, that science handles things, abandons inhabiting inside and considers the world as an item of knowledge "disconnected" from the subsisting subject. In addition, he complemented with respect to the models, that they are closely contingent to their authors, that there is correlation between the model and the mind, and that the scientists perceive the world with a spirit linked to the model discounting the reality observation.

The Merleau-Ponty thoughts suggest, as mentioned before, the presence of a correspondence between the model, its author and the minds of its users. Almost fifty years later, and thanks to research in modern neuroscience, the theory of mirror neurons has confirmed this proposition. This research first showed for animals, then for humans, thanks to functional MRI brain mapping, that the zones of activated neuronal connections are similar, involving an observable and one or more observers.

\section{Parity Violation in Weak Interactions (in Physical Science)}

After the illustration of the weakness of isolated theoretical modeling from the philosophical point of view, we will consider an additional illustration relative to an example of important discovery in the 1950s in the field of subatomic elementary particles.

It is well known that symmetries play an important role in physics. In addition, parity was naturally assumed to be conserved in the four fundamental interactions: electromagnetism, gravity (long-range forces) \& strong and weak interactions (subatomic). This was believed until Lee and Yang (Nobel 1957) suggested theoretically in 1955 parity violation in weak interactions. A fast experimental confirmation (by $\mathrm{Wu}$ ) has been performed immediately after such theoretical proposal. This experimental validation was crucial for the establishment of this fact and instituted it simply credible. It may be noted that this contribution originated numerous explorations in elementary particles (subatomic) concerns.

\section{Sound Tongue of Feynman}

One more picture of the weakness of isolated modeling concerns a famous statement of Richard Phillips Feynman (1918-1988), father of Quantum electrodynamics (Nobel 1965) and one of the firsts proposing Quantum computing. The statement is: "No matter how beautiful your theory is, No matter how smart you are, No matter if you're famous ...If your theory is not in tune with experience, It is wrong. That's all".

\section{Weakness of Isolated Theoretical Modeling}

The last sections relative to the position of theoretical isolated investigations, supported largely by the philosophical point of view of Merleau-Ponty and 
reinforced by subatomic and Quantum physics research, illustrated the limits of such investigations. As a conclusion for the limits of theoretical investigation selfsufficiency, we can say that theoretical modeling used isolated could nosedive and needs observation, simply to be credible or to get equitable result.

\section{Observation Isolated from Theoretical Modeling}

Consider domains of investigations that generally call for observation. These concern traditionally human and social sciences. In such case, we need a relatively high number of observed data for deep investigations in a given situation. Despite this richness of data, the observation alone rapidly appeared limiting the extension of the field of research. Putting such observational studies in a theoretical context opens the field of exploration of the concerned situation. In addition, these theoretical "tools" make it possible to generalize a more in-depth research involving different studied situations amalgamated in the same model (theory). Consequently, these solitary observations may support into a more general structured concept illuminating real widespread phenomena and permits the enlargement from a single situation to more universal setups.

\section{Claude Lévi-Strauss and Structural Research}

A typical domain among those using observation is Anthropology. This field has used principally observation since its creation. Claude Lévi-Strauss (19082009) has illustrated the use of a theoretical structured concept (mainly mathematical) based on observational data, in "Structural Anthropology", Paris 1958, (see Lévi-Strauss 1958). Structural anthropology is one of the founding branches of the structuralist paradigm in anthropology, developed from the 1940s by Claude Lévi-Strauss, of which it constitutes the major work. This concept is indirect consequences of modern mathematics: logic, sets, groups and topology.

Important in France, the term social anthropology (general science of society), it aims to apply to this discipline the concept in the emerging age of structuralism. The object is to explain the diversity of facts by blending a limited number of logical possibilities linked to the architecture of the human brain; thus, breaking with the dominant currents of this epoch in ethno-anthropology: evolutionism, culturalism, and functionalism. It uses the general principles of understanding a society as a complex system provided with invariable independent (structural) properties arising from the relations between the individuals that compose it.

The expression structural analysis in anthropology has often been used as synonym of structural anthropology by Lévi-Strauss himself, who fixed them as the titles of several of his articles and works. Today, these different terms remain attached to its name and continue to designate its general work and its methodology. In order to assign generally the use of the structural paradigm in anthropology, among other authors, the term usually used is that of structuralism in anthropology.

Structural anthropology, resulting from various intellectual affiliations of universal orientation, will gradually develop an emerging scientific paradigm very close to the general current and to the cognitivism that were formed at the same 
time. This takes into account the dialectical structure, the relationships within and between systems, and its ambition to describe human "mental insertions".

Even that Lévi-Strauss first used the term structuralism; he firmly and very early on dissociated himself, in the 1950s, from the resumption of his methods of analysis by a vast transdisciplinary intellectual movement of formalist inspiration. In the 1970s, Lévi-Strauss abandoned all reference to the notion of structure, to mark the major paradigm difference that separated it from the politicized and ultraformalist evolution of so-called generalized structuralism.

The example of Structural Anthropology of Lévi-Strauss illustrates the fact that structural researches in the social sciences are indirect consequences of modern mathematics. This shows clearly that observation alone, even may be auto sufficient in certain situations, needs generally the modeling issue complementarity.

\section{Michael Faraday and Electromagnetic Induction}

In physical science, we can consider the example concerning the work of Michael Faraday (1791-1867) in the field of electromagnetic induction. Faraday was an excellent observer who conveyed his ideas from his experimental work in a very humble manner. His math skills, nevertheless, are limited to the unsophisticated algebra. The contributions of Faraday and others to put them in a mathematical framework and condense them into a set of equations motivated James Clerk Maxwell (1831-1879). These "Maxwell's equations" are the basis of all modern theories of electromagnetic phenomena and are the source of much scientific research in this area. This complementarity (modeling aiding observation) exists in many other fields of investigation in all disciplines of science, for example, demography, sociology, neurosciences, and physical sciences.

\section{Weakness of Isolated Observation}

The last sections relative to the position of observational isolated investigations supported largely by the structuralism of Lévi-Strauss and reinforced by the extension of Faraday work by Maxwell in electromagnetics research, illustrated the limits of such investigations. As a conclusion for the limits of observational investigation self-sufficiency, we can say that operational observation used isolated could frustrate investigations and needs theoretical modeling, obviously to permit deeper research.

\section{Theory-Observation Couple Concerns}

\section{Theory-Observation Managing and Rulings}

As discussed before, the couple theory-observation is always strongly associated. In this section, we will examine how these two associated concepts comes one to the other in time.

\section{The Usual Situation}

In the standard case the theory comes first and it is validated (or not) later by 
experience. Most of important discoveries are in this category.

We can take, for the occurrence of theory validation, as example the case of the theory of the superposition states launched (proposed) by E Schrödinger in 1930 (Nobel 1933) and validated by S Haroche \& D Wineland in 1996 (Nobel 2012). Only after such validation, this theory became established (founded) until a possible upcoming invalidation.

Concerning the theory invalidation occurrence, we can consider the example of the Hall Effect proposed by E Hall in 1879. This proposition obtained from observation (experience) has invalidated a part of the Treatise on Electricity and Magnetism proposed by JC Maxwell in 1873, concerning the relation between the force and the current in a conductor.

\section{Experience-First Situation}

Apart from the last standard case of the interiority of theory regarding experience, we can meet the situation of finding experience first and then establishing the corresponding theory afterward. In general, we meet such case in a "serendipity situation": one discover something while searching for another. A typical example is the discovery of the superconductivity by Kamerlingh Onnes (1853-1926), Nobel 1913. In this case, he was investigating problems relative to effects of low temperature on electronics without imagining the phenomenon he has observed.

\section{Simultaneous-Works Situation}

A third situation concerns simultaneous separated theoretical and experimental contributions. An emblematical case concerns the Duality Particle-Wave in quantum physics. Louis Victor de Broglie (1892-1987) Nobel 1929 has proposed the theory, and the accidental experimental validation has been simultaneously revealed by Clinton joseph Davisson (1881-1958) Nobel 1937. These two researchers ignored each the other and a third researcher (Max Born) in a conference talk has given the broadcasting of both contributions.

\section{$\underline{\text { Same-Work Situation }}$}

Another circumstance concerns the case where both theoretical and experimental works are developed in the same research. This is the other emblematic case of the discovery of Graphene and the generalizing to the Dirac cone material theory in quantum physics, work of Andre Geim \& Konstantin Novoselov Nobel 2010.

\section{Conclusions}

In all the last situations, it is worthy notable that both observation and theory encounters each, important evolutions due to the other. Moreover, "Serendipity" plays an important role in each of the two investigations concepts.

From this part, we can summarize the rulings on Theory-Observation couple as follows. In general, one can consider a theory only established after validation by observation. Moreover, such a theory remains valid until disagreement with observation. Therefore, the theory-observation couple is necessarily always 
associated.

\section{Theory-Observation Couple Immersion}

In this section, we will discuss some typical circumstances where the couple theory-observation is playing the essential role in the functioning of the phenomenon, the organ, the device...

\section{Amended Coupled Models}

One interest of theory-observation couple is the amended models accounting for more theory to fit reality. As we know, a societal observable is just, and its theoretical model is necessary. When the model does not match the societal observable, the first has to be adapted to fit better the reality. In such case, we need revised models by accounting for more theory in the model. The observed (societal) behavior is dominated by different sciences and/or involved phenomena. Therefore, a compound model will substitute the simple model. If the mathematical models concerned are particularly interdependent, only a coupled solution of these models can give an acceptable answer. The models interdependence is strongly guided by their time evolutions proximity and their self and mutual stuff behavior laws density. The degree of interdependence corresponds directly to the degree of coupling required. The limits of such degree could be defined as weak and strong. In the weak one, we consider the models individually in an iterative process linking their stuff behavior laws. In the strong, we consider a simultaneous solution of models enclosing their behavior laws. For a given degree of coupling, we need to opt for an appropriate mathematical formulation, suitable space and time scales and a proper resolution method, see e.g. (Carpes et al. 2000, Ouchetto et al. 2007, Rapetti et al. 2002).

In all cases, these amended models have to be validated by experience by means of real laboratory device, on which precise measurements can be accomplished. A typical example for such case concerns a coupled electromagnetic-mechanical model for thin conductive plate deflection analysis (Ren and Razek 1990, Razek 2020a). In this work the coupled model has been validated in two ways by analytical solution and by the TEAM (Testing Electromagnetic Analysis Methods) workshop. In the first case, an analytical solution has been developed for simple geometries and linear materials. The model has been validated using such analytical solution just for verification. The model has then been validated for the case of the TEAM Problem 12: Cantilevered beam in crossed field. It corresponds to a coupled problem with moving conductor. The device is constituted of a clamped beam, which is placed in a uniform constant magnetic field in the beam direction and a variable one exponentially decaying with time perpendicular to beam. In this case, the induced current in the beam due to the variable field will interact with the uniform field and creates a force perpinducal to the beam that will cause its movement. This TEAM problem has precisely defined dimensions, constitutive laws of materials, excitations... It is backed by a real laboratory device, on which measurements can be accomplished. 


\section{Prediction versus Observation}

Prediction is successfully operated in many consistent situations where it is associated to observation to produce accurate useful outcome. The most popular theory of the Bayesian brain in neuroscience and the concept of Digital Twins are typical illustrations of such a case, as we will see in the next sections. Furthermore, the prediction (or estimation) is often employed in the control of industrial systems and permits associated to observation (estimator-observer control), to obtain precise and quick performance, see e.g. (El Moucary et al. 2002, Baier and Meier 2020).

In contrast, the association prediction-observation has to be used with constraint in some particular situations. As mentioned before mathematical modeling can be only performed with established and validated theories. In case of problems where the theoretical behavior (mathematical expression) is not well known, or phenomenon behavior varying arbitrary, it is manifest that the use of isolated mathematical modeling would be hopeless and speculative. In such case, the use of inductive prediction: this is where one might draw a conclusion about the future using information from the past, would lead to erroneous result (Popper 1934). A typical example of such an invalid prediction could be encountered in the modeling of complex contagion behaviors such as infections by an unknown mutant virus, (Beauchemin and Handel 2011). In such a case one needs to deduce an approximated mathematical behavior (the real one is unknown) of the epidemic infection (Enserink and Kupferschmidt 2020) by the mutant unknown virus from the case of some infected subjects to apply it for future infections of others. Such methodology may help in the orientation of the observation research protocols but not in obtaining definite results. The observation will be the principle issue to solve such type of problems assisted by prediction.

These examples of the use of prediction illustrate that its use, together with observation, leads to a good end, otherwise it fails.

\section{Digital Twins Concept}

Recently the theory-observation couple has been used in a frame of the Bayesian couple of the Digital Twins concept. Digital Twins (DT) are using integrated multi-phenomena, multiscale, probabilistic approach. The concept is based on a matched real object (process, product or service) with a real-time digital (virtual) item that is a replica of the real object, and their connections (sensors, history...). The DT incorporating Internet of Thigns (IoT), Artificial Intelligence (AI), Machine Learning (ML), Software Analytics (SA)...to create living digital simulation models that update and change as their physical counterparts change. DT-assisted systems permits: Data analysis, System monitoring, Diagnostics, Problem anticipation, Future planning...

\section{Bayesian Brain}

The most popular theory relative to the functioning of the brain in neuroscience is that of the Bayesian brain. It is a typical illustration of the consistent successful use of prediction (modeling) based on observation.

In this circumstance, after a cerebral sensory observation (vision, smell, 
hearing, etc.) the predictive model creates cerebral expectations of the observed phenomenon from historical learnt data; only the error (prediction versus observation) is represented in the neuronal discharges spread out to identify the nature of such an observation. It can be noted that in this case, the predictive model is managed by a highest supercomputer (Human brain: $10^{11}$ neurons, each tied to $10^{4}$ others).

\section{Quantum and Neuromorphic Technologies (Computing)}

These two theoretical modeling tools comes directly from two observed realities belong to quantum physics and neurosciences.

In the case of quantum computing, the origin of the idea appeared at the dawn of the last century. Max Planck suggested that a "perfect black body" emits and absorbs electromagnetic waves in the form of discrete energy packages called "quanta". It was the emergence of quantum mechanics. This provided researchers by exceptional tools for the interpretation the atomic world. Later, the concept of states of quantum mechanics establishes the footing of "Quantum computers", expression invented by Richard Feynman (Feynman 1982).

A classical computer performs calculations using bits; that are 0 representing off and 1 representing on. It uses transistors to process information in the form of sequences of zeros and ones called computer binary language. More transistors correspond to more processing ability. A quantum computer uses qubits through the laws of quantum mechanics relative to the states of particles. For a qubit, a particle can be in multiple states simultaneously; this phenomenon is called superposition. Another phenomenon concerns the particles states called entanglement. This denotes when two qubits in a superposition correlate with one another; meaning the state of one depends on the state of the other. Due to these phenomena, a quantum computer can achieve 0,1 , or both states at the same time for a qubit or an entanglement of qubits. Therefore, a quantum computer with $n$ qubits can simultaneously operate on all the $2 \mathrm{n}$ possibilities, while a classical computer with $n$ bits can operate on only one of those $2 n$ possibilities at a time; thus, the first giving us more processing power. Researchers agree that quantum computers are theoretically exponentially faster and much smarter in breaking codes that are supposedly impossible for classic technology to achieve (Fedorov et al. 2018, Castelvecchi 2017).

The previous discussion shows obviously the tightened relation between the observed reality and the mathematical modeling (quantum physics - quantum computing).

Concerning neuromorphic computing, as in the case quantum computing, neuromorphic computing is not new, it is a concept advanced by Carver Mead in the end of the 1980s, relating the practice of very-large-scale integration (VLSI) systems enclosing analog circuits to mimic neuro-biological constructions existing in the nervous system (Mead 1990).

Modern advances in the AI have reintroduced attention in neuromorphic computers. The increasing attractiveness of deep learning and neural networks has encouraged a competition to develop AI hardware dedicated for neural network computations. Among the trends that have arisen in the past few years is 
neuromorphic computing, which has shown potential because of its resemblances to biological and artificial neural networks (BNN and ANN). These tools are largely used in optimization, diagnostics, images, machine learning, AI...

\section{Conclusions}

In this article, we studied the interdependence of the two evaluation notions of observation and modeling. We have proposed an evaluation of these notions involving different studies based on philosophical aspects such as phenomenology and structural research. These investigates were also supported by illustrations from physics and quantum science. They examined the limits of autonomy of each of the two concepts and their interdependence.

The associate resulting from such interdependence is therefore considered. This involved different aspects characterizing such an associate such as its management over time and its rulings. The engagement of the "observationtheory" couple was then reflected through the exploration of different illustrative cases showing the nature of the interdependence in this couple.

Corroborating interdependence has been brought to light in the case of coupled models. The matching interdependence has been illustrated in the cases of the concept of industrial digital twins and Bayesian Brain theory in neuroscience. Finally, imitating interdependence has been demonstrated in quantum and neuromorphic computing technologies.

In general, we can conclude that mathematical modeling requires operational observation simply to be credible and that the second requires the first for further research. In addition, the interdependence of this couple is valuable for the ideas of several innovative research and industrial concepts.

\section{References}

Baier NU, Meier T (2020) Using model predictive control to modulate the humidity in a broiler house and effect on energy consumption. Athens Journal of Technology and Engineering 7(3): 157-184.

Beauchemin C A, Handel A (2011) A review of mathematical models of influenza infections within a host or cell culture: lessons learned and challenges ahead. BMC Public Health 11(S1-7): 1-15.

Carpes WP Jr, Pichon L, Razek A (2000) A 3D finite element method for the modelling of bounded and unbounded electromagnetic problems in the time domain. International Journal of Numerical Modelling: Electronic Networks, Devices and Fields 13(6): 527-540.

Castelvecchi, D (2017) Quantum computers ready to leap out of the lab in 2017. Nature News 541(7635): 9-10.

El Moucary C, Mendes E, and Razek A (2002) Decoupled direct control for PWM inverter-fed induction motor drives. IEEE Transactions on Industry Applications 38(5): 1307-1315.

Enserink M, Kupferschmidt K (2020) With COVID-19, modeling takes on life and death importance. Science 367(6485): 1414-1415. 
Fedorov AK, Kiktenko EO, Lvovsky AI (2018) Quantum computers put blockchain security at risk. Nature 563(7732): 465-467.

Feynman RP (1982) Simulating physics with computers. International Journal of Theoretical Physics 21(6-7):467-488.

Lévi-Strauss C (1958) Structural anthropology. Paris.

Mead C (1990) Neuromorphic electronic systems. Proceedings of the IEEE 78(10): 16291636.

Merleau-Ponty M (1960) The eye and the spirit. Paris.

Ouchetto O, Zouhdi S, Bossavit A, Griso G, Miara B, Razek A (2007) Homogenization of structured electromagnetic materials and metamaterials. Journal of Materials Processing Technology 181(1-3): 225-229.

Piriou F, Razek A (1990), Numerical simulation of a nonconventional alternator connected to a rectifier. IEEE Transactions on Energy Conversion 5 (3): 512-518.

Popper, KR (1934) The logic of scientific discovery. English Version. London: Hutchinson.

Rapetti F, Maday Y, Bouillault F, Razek A (2002) Eddy-current calculations in threedimensional moving structures. IEEE Transactions on Magnetics 38(2): 613-616.

Razek A (2020a) The elegant theory, the observed societal reality and the potentialities of coupled models (Invited). In International Symposium on Numerical Modeling towards Digital Twin in Electrical Engineering, Beijing, China, January 5-7.

Razek A (2020b) The observable, the theory, and prospective revised models for societal concerns. Athens Journal of Sciences 7(1): 1-14.

Ren Z, Razek A (1990) A coupled electromagnetic-mechanical model for thin conductive plate deflection analysis. IEEE Transactions on Magnetics 26(5): 16501652.

Ren Z, Razek A (1994) A strong coupled model for analyzing dynamic behaviors of nonlinear electromechanical systems. IEEE Transactions on Magnetics 30(5): 32523255.

Sekkak A, Pichon L, Razek A (1994) 3-D FEM magneto-thermal analysis in microwave ovens. IEEE Transactions on Magnetics 30(5): 3347-3350. 



\title{
A Modified System of Nonlinear Fractional-Order Differential Equations in the Study of the Dynamics of Marital Relationships and their Behavioural Features
}

\author{
By Olutunde Samuel Odetunde*, Rasaki Kola Odunaike ${ }^{ \pm}$\& \\ Adetoro Temitope Talabi ${ }^{*}$
}

\begin{abstract}
Urbanization and modernization have effects on marital relationships in Nigeria which led to high divorce rate among legitimate couples prompting unstable environment. This situation design and uses scientific means to study the dynamics of marital relationships and their behavioural features to check excesses in marriage and to promote stability. A modified system of nonlinear fractional-order differential equations was used to categorize people of different personalities and different Impact Factors of Memory, using different sets of parameters. The equations predict and interpret the features of the union of different individuals with external circumstance(s). Equations were adapted to a local environment where data collections were carried out to investigate factors affecting marriages. Data collected by the use of questionnaire validate the model. An Iterative Decomposition Method was adopted to solve the fractional system in which fractional derivatives were given in the Caputo sense; the obtained results were interpreted appropriately. The modified model shows the trajectory of the couple from the state of indifference and as the impact factor memory increases it affects their togetherness making the love between them to decay easily. Numerical simulation results were presented to show the effectiveness of the model and the accuracy of the statements established.
\end{abstract}

Keywords: Differential model, dynamical system, impact factors of memory, iterative decomposition method, marital relationship

\section{Introduction}

Marital relationship can be referred to as a relationship governed by feedback, or circular causality, in which each person continually responds to the other in predictable ways that sustain patterns of interaction in the system. However, the presence of chaos in marriage is undesirable. Wauer et al. (2007) reported that romantic relationships in human can be studied via system dynamics methodology. It was reported by Weigel and Murray (2000) that to apply chaos theory to marital relationship, there should be thorough and rigorous work so that its value to marital relationships studies will come from its ability to solve problems and explain behaviours. The mathematics to the study of marital relationship was presaged by Von Bertalanffy (1968) and since then the study began to hold both the artistic imaginations and interest of various scholars in the fields of

\footnotetext{
*Senior Lecturer, Department of Mathematical Sciences, Olabisi Onabanjo University, Nigeria. ${ }^{ \pm}$Professor, Department of Physics, Olabisi Onabanjo University, Nigeria.

${ }^{\dagger}$ Lecturer II, Department of Physics, Olabisi Onabanjo University, Nigeria.
} 
Mathematics, Physics, Sociology, Biology, Neuroscience, Psychology and Anthropology (Barley and Cherif 2011). Strogatz (1988) first analyzed love affairs in his 1-page paper and later contributed to a book. Gottman et al. (2005) had applied Mathematical power to the dynamics of marriage. Experiment in studying the application of Mathematics to marital relationships has been difficult to design because marriage is difficult to quantify. However, earthly observations are the only sources of description of such relationship expressed within individuals, groups or set of people. It could be inferred that mathematical models may play a major role in studying dynamics of marital relationships by using a set of nonlinear and linear differential equations. Control of chaos in marriage promotes a peaceful co-existence and it could show the behavioural time series and phase plots (Paul et al. 2012). Modelling dynamical system or phenomena in life sciences, economics, engineering, particularly in marriage dynamics using classical integer order differential equations has attracted researchers several years ago, but there is a limit to integer order models because love is a state that is always influenced by historical information (Liu and Chen 2015). There are many excellent introductions to this general approach to qualitative nonlinear dynamic modelling and its subtopics of chaos and catastrophe theory (Morrison 1991, Beltrami 1993, Lorenz 1993, Vallacher and Nowack 1994, Baker and Gollub 1996).

\section{Nonlinear Dynamical Models in the Study of Complex Phenomena}

Vallacher et al. (2010) in a recent issue along with an American Psychologist supported the importance of dynamical systems for the modelling and study of complex phenomena using simple linear formulae. They also discussed the feature of social life that degenerate into pattern of behaviour which brings out the worst in human nature and the attractor in their work but no model and phase portraits were used to back up the work. Strogatz's aim was to teach harmonic oscillation phenomena in the classroom (Sprott 2004, Barley and Cherif 2011), but ended up by suggesting an unusual approach to the teaching of coupled integer order differential equations (Sprott 2005). His approach related to the model of marriage relationship that is time-evolution of a romantic affair between two individuals. His model was referred to as minimal model on love which explains love affairs between Romeo and Juliet. Strogatz linear model was modified by Rinaldi (1998) using two linear differential equations to describe romantic life between two individuals and considered in his work the mechanisms of love, growth and decay which he referred to as return (pleasure of being loved), instinct (reaction to the appeal of the partner) and oblivion (the forgetting process). Rinaldi's model can only be used for a short period of time (months/years) to predict if marriage will be ideal or fragile. The model is a dynamic system with two state variables, also called a typical minimal model but love is a complex mixture of different feelings (esteem, friendship, sexual satisfaction, emotional attachment, qualifications, career work, finance and so on and on) and can barely be captured by a single variable. In this model, the tensions and emotions involved in the social life of human being cannot be considered in a simple model, therefore only the 
interactions between the two individuals are modelled, while the rest of the world is kept frozen and does not participate explicitly in the structure of love dynamics (Rinaldi 1996). Dharna and Arun (2012), discovered Rinaldi's model does not consider some parameters like the effect of synergism, adaptation and learning after living together (in the case of arranged marriages in India, which have succeeded over centuries). They suggested that, the emotional interaction of two individuals must be considered in the process of modelling, that is, emotion of a particular individual with respect to another cannot increase infinitely and they assumed that emotion is proportional to $\mathrm{x}_{1} \mathrm{x}_{2}$. Dharna and Arun (2012) in their work reported that to the psychologists it is not difficult to study human behaviour but it is not easy studying it to accuracy.

Sprott (2001) disagreed with Strogatz work because the researcher did not consider appeal of the couple in his differential equation. Sprott (2001) therefore proposed a model of love and happiness which he referred to as Love model for Romeo and Juliet. Orsucci (2001) reported that, it is essential to define happiness as many emotions which includes excitement, pleasure, joy, contentment, serenity, fulfillment, and satisfaction among others. In the world today, people get married for several reasons which may include legal, social, libidinal, emotional, financial, spiritual, and religion purposes (Cynthia 2015). Kefalas et al. (2011) identified two groups of marriage namely marriage naturalists and marriage planners. In their work, Kefalas et al. (2011) defined marriage naturalists to be largely from the rural area and are eager to get married while marriage planners are based in metropolitan areas. Chaos is surely in marriages and has been defined from different perspectives namely ancient time, ancient classics, general science and religious books. It is a term used in Physics to refer to the state of extreme disorder which results due to unpredictable behaviour that depends so sensitively on the system's precise initial conditions. Nature has given us amazing different complex systems that show chaotic behaviour. For example, animal populations, the red spot of Jupiter, electrical signal in the human heart, the motion of the planets round the sun, pulsations of the brain, the stock market, the population, marriage instability and so on. All these are different complex systems with different reasons but with the help of chaos theory, the complexity of these systems can be explained to some extent. Many publications and books have been written on the subject 'chaos' as it relates to various behaviours in nonlinear dynamics, mathematics, mechanics, computer, religion, humanities, social life and other branches of science. Gleick (1987) stated that classical science stops where chaos begins.

Adenugba (2015) reported that sex is important in marriage. Sex between male and female can be described as an excited electron after the bombardment by an atom. As the excited atom is ground seeking for stability, so also a couple that is sexually aroused is yearning for sex. If the husband or the wife has the urge to meet with his or her partner and the partner is not in the mood or not aroused then such a person will not be balanced. According to Adenugba (2015) sexual tension could drive any person to misbehave, commit sexual immorality with any person including the under aged and/or go into prostitution. By the application of external force in terms of flow of electron that is, conductors allows electric current to flow through them while insulators do not allow the passage of electric current and 
Adenugba (2015) related it to impotency in human whereby the body is not charged and excited. Also, there are virtually no free electrons hence there is no electron gas and therefore no electrical conductivity. Both the male and the female shall not be attracted to each other in this case hence when they see each other, their bodies are not excited. Applications of fractional order differential (FOD) are recent research focus of interest which can be used to describe life sciences and psychological processes ( $\mathrm{Gu}$ and $\mathrm{Xu}$ 2011). Many dynamical phenomena in physics have been studied by the application of fractional-order differential equations. Liu and Chen (2015) reported in their work that the dynamics of love have not been studied properly. Due to the effectiveness of fractional order integrals and derivatives, several models in sciences and engineering have been formulated and analyzed successfully (Okyere et al. 2016). Fractional order differential operator is non local (Khan et al. 2020). This makes fractional differential equation to be veritable tools for modelling marital relations. The theory of FOD was first constrained to the field of pure theoretical mathematics three centuries ago which is useful to both the theoretical Physicists and Mathematicians only (Mohammadi 2014). Also, it has been successfully used in modelling many physical phenomena nowadays such as nonlinear oscillation of earthquake, acoustics, electromagnetism, electrochemistry, diffusion process, fluid flow, polymer physics, mathematical biology and several areas of science and technology (Alawad et al. 2013, Odetunde and Taiwo 2015, Ahmad et al. 2020). In solving fractional order differential equation efficiently, several methods have been applied such as Taylor Collocation Method (TCM) (Noeiaghdam et al. 2020), Variational Iteration Method (VIM) (Vilu et al. 2019), Iterative Decomposition Method (IDM), Adomian Decomposition Method (ADM) (Thabet and Kendre 2018), Homotopy Analysis Method (HAM) (Mohammadi 2014). However, most nonlinear fractional order differential equations cannot be solved analytically but numerical methods can be used in solving them.

Recently, decomposition methods receive more attention as efficient techniques for the solution of deterministic or stochastic, nonlinear, linear, partial differential equations (Osilagun and Taiwo 2011). Talabi et al. (2019) applied Adams Predictor-Corrector Method (APCM) to test the chaoticity of the system and was confirmed via numerical simulations. Many researchers put efforts into the studies of chaotic dynamics and control of fractional order differential system but no research has been done in applying iterative decomposition method in solving love model. Nonlinear coupled dynamical fractional model of romantic and interpersonal relationships using fractional variation iteration method (FVIM) and fractional homotopy perturbation transform method (FHPTM) was applied to inspect the dynamics of love affairs among couples (Goyal et al. 2019). Owolabi (2019) modelled a new fractional-order love dynamics equation using the CaputoFabrizio (exponential decay-law), Caputo (power-law) and Atangana-Baleanu (Mittag-Leffler-law) fractional operators and Adams-Bash forth new fractional schemes was utilize for the approximation of these derivatives. Koca and Yaprakdal (2019) reported that mathematical modeling is a very important work in applied sciences and considered mathematical modeling of nuclear family model with fractional order Caputo derivative in their work. Zhang (2018) uses the 
coincidence degree theory, to get result for a coupled system of nonlinear fractional differential equations with multi-point boundary conditions at resonance.

According to Ahmad and El-Khazali (2007) it was emphasized that modelling psychological phenomena is more complex than engineering systems due to many parameters involved in the phenomena. The parameters used in psychological phenomena is time varying. Recently, it has been noticed by some researchers that relationships do not always follow patterns of linear change. Some relationships end and are then reborn in a new form while others begin and end. Therefore this makes it difficult to identify any stable sequence.

This work compels evidence of the power of nonlinear dynamical models for understanding complex psychological phenomena which will give people different ideas of love in couples. Song and Yang (2009) described real world processes as the most likely fractional order system and numerical simulations are often used to investigate the behaviour of these systems.

\section{Methodology and Mathematical Model}

Survey (using questionnaire), was conducted among young and old married men/women and the questionnaire was designed to get views from different angles to help find answers to the research questions. Two different states were used as the sample studies which are Lagos and Ogun states of Nigeria because of the settlement pattern (urbanization and modernization), population and environmental dynamics. The focus of this study is based on micro-experiment, the statistics techniques used was Point Pattern Analysis (PPA) and the criteria chosen were random sampling. The research was not limited to controlled environment but respondent were picked from different locations in the study areas. The study areas had been under survey for two years to better understand the way of living in that environment and gain access to participants.

However, in this work; all items in the research data set were labeled for proper identification whereby data from the field were transformed into numbers so that the computer software can understand after listing all the variables to be measured. For the close ended questions all the categories had been decided and common responses were ascribed the same code.

Barley and Cherif (2011) proposed a general model on couples dynamics to show the behavioural features of romantic relationship but only showed the phase plot of ideal relationship in their work where they considered $\varepsilon=0$. The model of consideration in this work is an improvement of the existing model of Barley and Cherif which was modified to fractional nonlinear differential equation that uses the result of the data analysis as its parameters. It describes the time-variation displayed by individuals in their marriages under certain external circumstance(s) which is given as: 
$\left\{\begin{array}{l}\frac{d^{q} x}{d t^{q}}=-a x+b x\left(1-e y^{2}\right)+\sin t \\ \frac{d^{q} y}{d t^{q}}=-c y+d y\left(1-e x^{2}\right)+\sin t .\end{array}\right.$

For convenience of interpretation, some practical physical meanings were imposed on the parameters such as $\mathrm{a}, \mathrm{b}, \mathrm{c}, \mathrm{d}, \mathrm{e}, \mathrm{x}, \mathrm{y}, \sin (t)$ and $\mathrm{q}$ as shown in eq. (1). The parameters used in this study are to categorize people with different personality in marriage, a; maltreatment, b; loneliness, c; wrong advice, d; phone calls, e; fission (external influence), measure of disorderliness in marriage of individual 1 and $2(\mathrm{x}(\mathrm{t})$ and $\mathrm{y}(\mathrm{t}))$, sin $(\mathrm{t})$ is a time dependent forcing function representing ones external circumstances. The order $\mathrm{q}$ represents the Impact Factor of Memory (IFM) of the couple, that is, as the value of $q$ increases from 0 to 1 , the IFM of an individual increases correspondingly. The derivative is of the order $0<q \leq 1$. The system can produce chaos according to different competition coefficients (Figure $1)$.

Figure 1. Strange Attractor and Time Series Plot from the Nonlinear FractionalOrder Love System in (1) with $\alpha=0.75$
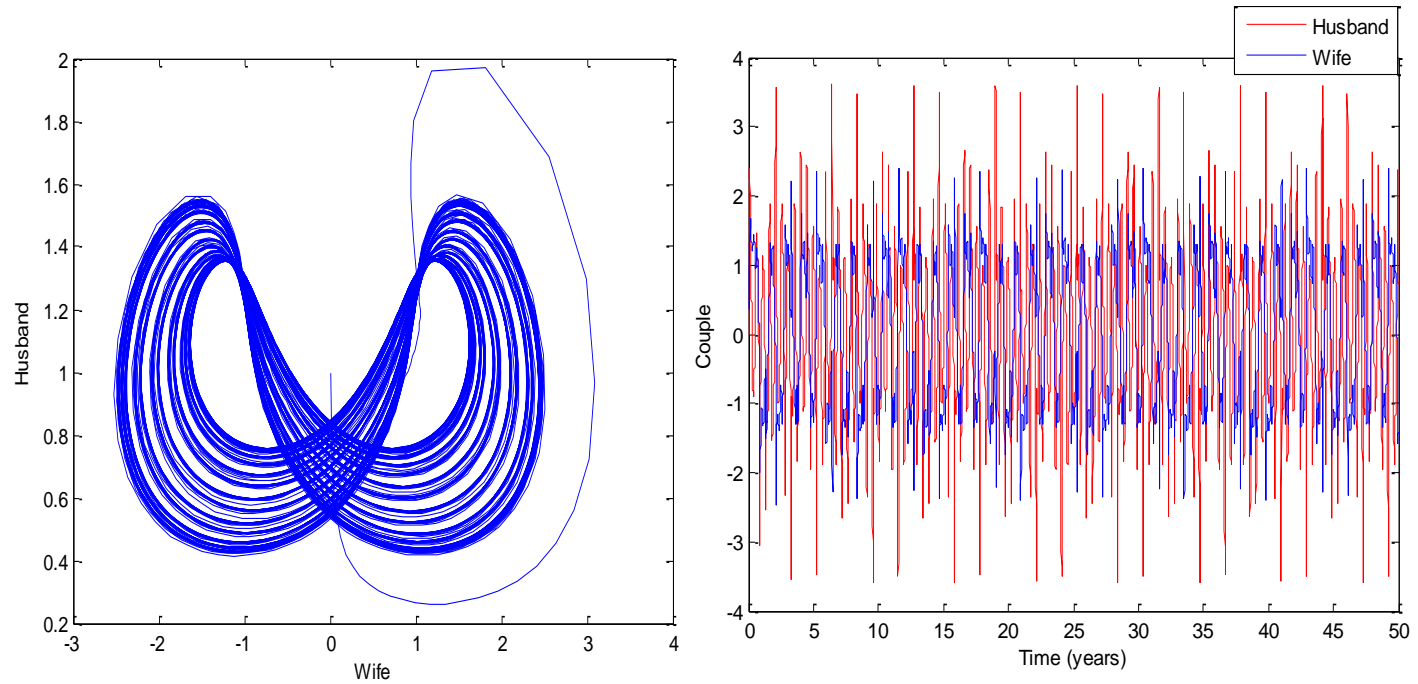

There are several definitions of fractional derivatives but this study uses the Caputo-type fractional derivative defined by Caputo (1967). Caputo's definition is a modification of the Riemann-Liouville definition and has the merit of dealing properly with initial value problems. It is more favoured because of its ease in adaptability to initial conditions for physical problems whereby the initial conditions are given in terms of the field variables (Odibat and Momani 2008). The fractional derivative in the Caputo sense is defined as

$$
D^{\alpha} y(x)=J^{m-\alpha} y^{(m)}(x), \alpha>0
$$


where $m=[\alpha]$ is the value $\alpha$ rounded up to the nearest integer, $y^{m}$ is the ordinary $m t h$ derivative of $\mathrm{y}$, and

$J^{\beta} f(x)=\frac{1}{\Gamma(\beta)} \int_{0}^{x}(x-t)^{\beta-1} f(t) d t$,

Is the Riemann-Liouville integral operator of order $\beta>0$ where $\Gamma(\beta)$ is the gamma function.

To illustrate the suitability of the proposed method.

$$
\left\{\begin{array}{l}
D^{\alpha} x(t)=-a x+b x\left(1-e y^{2}\right)+\sin t \\
D^{\alpha} y(t)=-c y+d y\left(1-e x^{2}\right)+\sin t .
\end{array}\right.
$$

where $0<\alpha<1$, the fractional-order $\alpha$ will be determined later, to point out that the order $\alpha$ has its practical physical meanings which represents the impact factor of memory of an individual, with initial condition $y(0)=x(0)=0.1$,

We consider the equation

$$
D^{\alpha} x(t)=-a x+b x-e b x y^{2}+\sin t .
$$

$\sin t$ in equation (5) can be decomposed into infinite series as follows

$$
D^{\alpha} x(t)=t-\frac{t^{3}}{3 !}+\frac{t^{5}}{5 !}-\frac{t^{7}}{7 !}+b x-a x-e b x y^{2} .
$$

By applying the operator $J^{\alpha}$ to both sides of (6), we have

$x(t)=\frac{\Gamma(2) t^{\alpha+1}}{\Gamma(\alpha+2)}-\frac{\Gamma(4) t^{\alpha+3}}{6 \Gamma(\alpha+4)}+\frac{\Gamma(6) t^{\alpha+5}}{120 \Gamma(\alpha+6)}-\frac{\Gamma(8) t^{\alpha+7}}{5040 \Gamma(\alpha+8)}+J^{\alpha}\left\{b x_{o}-a x_{o}-e b x_{o}\right\}$.

Take $x_{o}$ to be

$x_{o}=\frac{\Gamma(2) t^{\alpha+1}}{\Gamma(\alpha+2)}-\frac{\Gamma(4) t^{\alpha+3}}{6 \Gamma(\alpha+4)}+\frac{\Gamma(6) t^{\alpha+5}}{120 \Gamma(\alpha+6)}-\frac{\Gamma(8) t^{\alpha+7}}{5040 \Gamma(\alpha+8)}$

and

$x_{1}=J^{\alpha}\left\{b x_{o}-a x_{o}-e b x_{o}\right\}$

On substituting equation (8) into equation (9), we have 
$x_{1}=J^{\alpha}\left\{\begin{array}{l}\frac{b \Gamma(2) \Gamma(\alpha+2) t^{2 \alpha+1}}{\Gamma(\alpha+2) \Gamma(2 \alpha+2)}-\frac{b \Gamma(4) \Gamma(\alpha+4) t^{2 \alpha+3}}{6 \Gamma(\alpha+4) \Gamma(2 \alpha+4)}+\frac{b \Gamma(6) \Gamma(\alpha+6) t^{2 \alpha+5}}{120 \Gamma(\alpha+6) \Gamma(2 \alpha+6)}+\frac{b \Gamma(8) \Gamma(\alpha+8) t^{2 \alpha+7}}{5040 \Gamma(\alpha+8) \Gamma(2 \alpha+8)}- \\ \frac{a \Gamma(2) \Gamma(\alpha+2) t^{2 \alpha+1}}{\Gamma(\alpha+2) \Gamma(2 \alpha+2)}+\frac{a \Gamma(4) \Gamma(\alpha+4) t^{2 \alpha+3}}{6 \Gamma(\alpha+4) \Gamma(2 \alpha+4)}-\frac{a \Gamma(6) \Gamma(\alpha+6) t^{2 \alpha+5}}{120 \Gamma(\alpha+6) \Gamma(2 \alpha+6)}-\frac{a \Gamma(8) \Gamma(\alpha+8) t^{2 \alpha+7}}{5040 \Gamma(\alpha+8) \Gamma(2 \alpha+8)}- \\ \frac{e b \Gamma(2) \Gamma(\alpha+2) t^{2 \alpha+1}}{\Gamma(\alpha+2) \Gamma(2 \alpha+2)}+\frac{e b \Gamma(4) \Gamma(\alpha+4) t^{2 \alpha+3}}{6 \Gamma(\alpha+4) \Gamma(2 \alpha+4)}-\frac{e b \Gamma(6) \Gamma(\alpha+6) t^{2 \alpha+5}}{120 \Gamma(\alpha+6) \Gamma(2 \alpha+6)}-\frac{e b \Gamma(8) \Gamma(\alpha+8) t^{2 \alpha+7}}{5040 \Gamma(\alpha+8) \Gamma(2 \alpha+8)}\end{array}\right\}$.

$x_{0}+x_{1}=\left\{\begin{array}{l}\frac{\Gamma(2) t^{\alpha+1}}{\Gamma(\alpha+2)}-\frac{t^{\alpha+3}}{\Gamma(\alpha+4)}+\frac{t^{\alpha+5}}{\Gamma(\alpha+6)}+\frac{t^{\alpha+7}}{\Gamma(\alpha+8)}+\frac{b \Gamma(2) t^{2 \alpha+1}}{\Gamma(2 \alpha+2)}-\frac{b t^{2 \alpha+3}}{\Gamma(2 \alpha+4)}+\frac{b t^{2 \alpha+5}}{\Gamma(2 \alpha+6)}+\frac{b t^{2 \alpha+7}}{\Gamma(2 \alpha+8)}-\frac{a \Gamma(2) t^{2 \alpha+1}}{\Gamma(2 \alpha+2)}+\frac{a t^{2 \alpha+3}}{\Gamma(2 \alpha+4)}- \\ \frac{a t^{2 \alpha+5}}{\Gamma(2 \alpha+6)}-\frac{a t^{2 \alpha+7}}{\Gamma(2 \alpha+8)}-\frac{e b \Gamma(2) t^{2 \alpha+1}}{\Gamma(2 \alpha+2)}+\frac{e b t^{2 \alpha+3}}{\Gamma(2 \alpha+4)}-\frac{e b t^{2 \alpha+5}}{\Gamma(2 \alpha+6)}-\frac{e b t^{2 \alpha+7}}{\Gamma(2 \alpha+8)}\end{array}\right\}$.

By applying the operator $J^{\alpha}$ on equation (11) we have

$x_{2}=J^{\alpha}\left\{b\left(x_{o}+x_{1}\right)-a\left(x_{o}+x_{1}\right)-e b\left(x_{o}+x_{1}\right)\right\}-J^{\alpha}\left\{b x_{o}-a x_{o}-e b x_{o}\right\}$.

On integrating equation (12) we obtained.

$x_{2}=\left\{\begin{array}{l}\frac{b^{2} \Gamma(2) t^{3 \alpha+1}}{\Gamma(3 \alpha+2)}-\frac{b^{2} t^{3 \alpha+3}}{\Gamma(3 \alpha+4)}+\frac{b^{2} t^{3 \alpha+5}}{\Gamma(3 \alpha+6)}+\frac{b^{2} t^{3 \alpha+7}}{\Gamma(3 \alpha+8)}-\frac{2 a b \Gamma(2) t^{3 \alpha+1}}{\Gamma(3 \alpha+2)}+\frac{2 a b t^{3 \alpha+3}}{\Gamma(3 \alpha+4)}-\frac{2 a b t^{3 \alpha+5}}{\Gamma(3 \alpha+6)}-\frac{2 a b t^{3 \alpha+7}}{\Gamma(3 \alpha+8)}- \\ \frac{2 e b^{2} \Gamma(2) t^{3 \alpha+1}}{\Gamma(3 \alpha+2)}+\frac{2 e b^{2} t^{3 \alpha+3}}{\Gamma(3 \alpha+4)}-\frac{2 e b^{2} t^{3 \alpha+5}}{\Gamma(3 \alpha+6)}-\frac{2 e b^{2} t^{3 \alpha+7}}{\Gamma(3 \alpha+8)}+\frac{a^{2} \Gamma(2) t^{3 \alpha+1}}{\Gamma(3 \alpha+2)}-\frac{a^{2} t^{3 \alpha+3}}{\Gamma(3 \alpha+4)}+\frac{a^{2} t^{3 \alpha+5}}{\Gamma(3 \alpha+6)}+\frac{a^{2} t^{3 \alpha+7}}{\Gamma(3 \alpha+8)}+ \\ \frac{2 e a b \Gamma(2) t^{3 \alpha+1}}{\Gamma(3 \alpha+2)}-\frac{2 e a b t^{3 \alpha+3}}{\Gamma(3 \alpha+4)}+\frac{e^{2} b^{2} \Gamma(2) t^{3 \alpha+1}}{\Gamma(3 \alpha+2)}-\frac{e^{2} b^{2} t^{3 \alpha+3}}{\Gamma(3 \alpha+4)}+\frac{e^{2} b^{2} t^{3 \alpha+5}}{\Gamma(3 \alpha+6)}-\frac{e^{2} b^{2} t^{3 \alpha+7}}{\Gamma(3 \alpha+8)}\end{array}\right\}$

Then, $x(t)$ is approximated as

$$
x(t)=x_{0}+x_{1}+x_{2}
$$

Therefore,

$x(t)=\left\{\begin{array}{l}\frac{\Gamma(2) t^{\alpha+1}}{\Gamma(\alpha+2)}-\frac{t^{\alpha+3}}{\Gamma(\alpha+4)}+\frac{t^{\alpha+5}}{\Gamma(\alpha+6)}+\frac{t^{\alpha+7}}{\Gamma(\alpha+8)}+\frac{b \Gamma(2) t^{2 \alpha+1}}{\Gamma(2 \alpha+2)}-\frac{b t^{2 \alpha+3}}{\Gamma(2 \alpha+4)}+\frac{b t^{2 \alpha+5}}{\Gamma(2 \alpha+6)}+\frac{b t^{2 \alpha+7}}{\Gamma(2 \alpha+8)}-\frac{a \Gamma(2) t^{2 \alpha+1}}{\Gamma(2 \alpha+2)}+\frac{a t^{2 \alpha+3}}{\Gamma(2 \alpha+4)}- \\ \frac{a t^{2 \alpha+5}}{\Gamma(2 \alpha+6)}-\frac{a t^{2 \alpha+7}}{\Gamma(2 \alpha+8)}-\frac{e b \Gamma(2) t^{2 \alpha+1}}{\Gamma(2 \alpha+2)}+\frac{e b t^{2 \alpha+3}}{\Gamma(2 \alpha+4)}-\frac{e b t^{2 \alpha+5}}{\Gamma(2 \alpha+6)}-\frac{e b t^{2 \alpha+7}}{\Gamma(2 \alpha+8)}+\frac{b^{2} \Gamma(2) t^{3 \alpha+1}}{\Gamma(3 \alpha+2)}-\frac{b^{2} t^{3 \alpha+3}}{\Gamma(3 \alpha+4)}+\frac{b^{2} t^{3 \alpha+5}}{\Gamma(3 \alpha+6)}+\frac{b^{2} t^{3 \alpha+7}}{\Gamma(3 \alpha+8)}- \\ \frac{2 a b \Gamma(2) t^{3 \alpha+1}}{\Gamma(3 \alpha+2)}+\frac{2 a b t^{3 \alpha+3}}{\Gamma(3 \alpha+4)}-\frac{2 a b t^{3 \alpha+5}}{\Gamma(3 \alpha+6)}-\frac{2 a b t^{3 \alpha+7}}{\Gamma(3 \alpha+8)}-\frac{2 e b^{2} \Gamma(2) t^{3 \alpha+1}}{\Gamma(3 \alpha+2)}+\frac{2 e b^{2} t^{3 \alpha+3}}{\Gamma(3 \alpha+4)}-\frac{2 e b^{2} t^{3 \alpha+5}}{\Gamma(3 \alpha+6)}-\frac{2 e b^{2} t^{3 \alpha+7}}{\Gamma(3 \alpha+8)}+\frac{a^{2} \Gamma(2) t^{3 \alpha+1}}{\Gamma(3 \alpha+2)}-\frac{a^{2} t^{3 \alpha+3}}{\Gamma(3 \alpha+4)}+ \\ \frac{a^{2} t^{3 \alpha+5}}{\Gamma(3 \alpha+6)}+\frac{a^{2} t^{3 \alpha+7}}{\Gamma(3 \alpha+8)}+\frac{2 e a b \Gamma(2) t^{3 \alpha+1}}{\Gamma(3 \alpha+2)}-\frac{2 e a b t^{3 \alpha+3}}{\Gamma(3 \alpha+4)}+\frac{e^{2} b^{2} \Gamma(2) t^{3 \alpha+1}}{\Gamma(3 \alpha+2)}-\frac{e^{2} b^{2} t^{3 \alpha+3}}{\Gamma(3 \alpha+4)}+\frac{e^{2} b^{2} t^{3 \alpha+5}}{\Gamma(3 \alpha+6)}-\frac{e^{2} b^{2} t^{3 \alpha+7}}{\Gamma(3 \alpha+8)}\end{array}\right\}$.

We then consider $\mathrm{x}(\mathrm{t})$ for particular cases $\alpha=0.25,0.50,0.75$ and 1.00 , the numerical simulations are shown below.

From equation (4) 
$D^{\alpha} y(t)=-c y+d y-e d y x^{2}+\sin t$

To solve for (16), same procedure used in solving (6) was applied to establish the accuracy and efficiency of the method.

Therefore,

$y(t)=\left\{\begin{array}{l}\frac{\Gamma(2) t^{\alpha+1}}{\Gamma(\alpha+2)}-\frac{t^{\alpha+3}}{\Gamma(\alpha+4)}+\frac{t^{\alpha+5}}{\Gamma(\alpha+6)}+\frac{t^{\alpha+7}}{\Gamma(\alpha+8)}+\frac{d \Gamma(2) t^{2 \alpha+1}}{\Gamma(2 \alpha+2)}-\frac{d t^{2 \alpha+3}}{\Gamma(2 \alpha+4)}+\frac{d t^{2 \alpha+5}}{\Gamma(2 \alpha+6)}+\frac{d t^{2 \alpha+7}}{\Gamma(2 \alpha+8)}-\frac{c \Gamma(2) t^{2 \alpha+1}}{\Gamma(2 \alpha+2)}+\frac{c t^{2 \alpha+3}}{\Gamma(2 \alpha+4)}- \\ \frac{c t^{2 \alpha+5}}{\Gamma(2 \alpha+6)}-\frac{c t^{2 \alpha+7}}{\Gamma(2 \alpha+8)}-\frac{e d \Gamma(2) t^{2 \alpha+1}}{\Gamma(2 \alpha+2)}+\frac{e d t^{2 \alpha+3}}{\Gamma(2 \alpha+4)}-\frac{e d t^{2 \alpha+5}}{\Gamma(2 \alpha+6)}-\frac{e d t^{2 \alpha+7}}{\Gamma(2 \alpha+8)}+\frac{d^{2} \Gamma(2) t^{3 \alpha+1}}{\Gamma(3 \alpha+2)}-\frac{d^{2} t^{3 \alpha+3}}{\Gamma(3 \alpha+4)}+\frac{d^{2} t^{2 \alpha+5}}{\Gamma(3 \alpha+6)}+\frac{d^{2} t^{3 \alpha+7}}{\Gamma(3 \alpha+8)}- \\ \frac{2 c d \Gamma(2) t^{3 \alpha+1}}{\Gamma(3 \alpha+2)}+\frac{2 c d t^{3 \alpha+3}}{\Gamma(3 \alpha+4)}-\frac{2 c d t^{3 \alpha+5}}{\Gamma(3 \alpha+6)}-\frac{2 c d t^{3 \alpha+7}}{\Gamma(3 \alpha+8)}-\frac{2 e d^{2} \Gamma(2) t^{3 \alpha+1}}{\Gamma(3 \alpha+2)}+\frac{2 e d^{2} t^{3 \alpha+3}}{\Gamma(3 \alpha+4)}-\frac{2 e d^{2} t^{3 \alpha+5}}{\Gamma(3 \alpha+6)}-\frac{2 e d^{2} t^{3 \alpha+7}}{\Gamma(3 \alpha+8)}+\frac{c^{2} \Gamma(2) t^{3 \alpha+1}}{\Gamma(3 \alpha+2)}-\frac{c^{2} t^{3 \alpha+3}}{\Gamma(3 \alpha+4)}+ \\ \frac{c^{2} t^{3 \alpha+5}}{\Gamma(3 \alpha+6)}+\frac{c^{2} t^{3 \alpha+7}}{\Gamma(3 \alpha+8)}+\frac{2 e c d \Gamma(2) t^{3 \alpha+1}}{\Gamma(3 \alpha+2)}-\frac{2 e c d t^{3 \alpha+3}}{\Gamma(3 \alpha+4)}+\frac{e^{2} d^{2} \Gamma(2) t^{3 \alpha+1}}{\Gamma(3 \alpha+2)}-\frac{e^{2} d^{2} t^{3 \alpha+3}}{\Gamma(3 \alpha+4)}+\frac{e^{2} d^{2} t^{3 \alpha+5}}{\Gamma(3 \alpha+6)}-\frac{e^{2} d^{2} t^{3 \alpha+7}}{\Gamma(3 \alpha+8)}\end{array}\right\}$.

For the particular case $\alpha=0.25$

The results for $\mathrm{y}(\mathrm{t})$ was then solved for different cases when $\alpha=0.25,0.50,0.75$ and 1.00 . The parameters used (c, $\mathrm{d}$ and e) were taken from the data analysis; the data of the results when $\alpha=0.25,0.50,0.75$ and 1.00 were used to show the time series plots.

\section{Results}

Based on the Iterative Decomposition Method results above, the results of the fractional order love model can be proved by computer simulations. According to what have been discussed above, Numerical simulations were conducted on both the modified and the existing models using the fractional differential equation. The following are the plots of the results of our investigations for various cases studied

Table 1. Numerical Results $x(t), y(t)$ in Equation 15 and 17 for Case $1 a$

\begin{tabular}{|l|c|c|c|c|}
\hline & $\mathbf{x}(\mathbf{t})$ for $\boldsymbol{\alpha}=\mathbf{0 . 2 5}$ & $\mathbf{y}(\mathbf{t})$ for $\boldsymbol{\alpha}=\mathbf{0 . 2 5}$ & $\mathbf{x}(\mathbf{t})$ for $\boldsymbol{\alpha}=\mathbf{0 . 2 5}$ & $\mathbf{y}(\mathbf{t})$ for $\boldsymbol{\alpha}=\mathbf{0 . 2 5}$ \\
\hline $\mathbf{( t )}$ & Modify & Modify & Existing & Existing \\
\hline 0 & $0.000000000 \mathrm{E}+00$ & $0.000000000 \mathrm{E}+00$ & $1.000000000 \mathrm{E}+00$ & $1.000000000 \mathrm{E}+00$ \\
\hline 0.1 & $7.304214356 \mathrm{E}-01$ & $4.244793214 \mathrm{E}-01$ & $-2.892194748 \mathrm{E}-01$ & $2.751858042 \mathrm{E}+00$ \\
\hline 0.2 & $2.515290497 \mathrm{E}+00$ & $1.463791253 \mathrm{E}+00$ & $-2.219194574 \mathrm{E}+00$ & $2.360731075 \mathrm{E}+00$ \\
\hline 0.3 & $5.163624373 \mathrm{E}+00$ & $3.009833545 \mathrm{E}+00$ & $-3.813756018 \mathrm{E}+00$ & $1.969697227 \mathrm{E}+00$ \\
\hline 0.4 & $8.569007204 \mathrm{E}+00$ & $5.001575057 \mathrm{E}+00$ & $-5.212717650 \mathrm{E}+00$ & $1.596293123 \mathrm{E}+00$ \\
\hline 0.5 & $1.264557709 \mathrm{E}+01$ & $7.389417875 \mathrm{E}+00$ & $-6.478279693 \mathrm{E}+00$ & $1.240875821 \mathrm{E}+00$ \\
\hline 0.6 & $1.731469709 \mathrm{E}+01$ & $1.012770811 \mathrm{E}+01$ & $-7.644869554 \mathrm{E}+00$ & $9.016065644 \mathrm{E}-01$ \\
\hline 0.7 & $2.250004977 \mathrm{E}+01$ & $1.317196466 \mathrm{E}+01$ & $-8.734018027 \mathrm{E}+00$ & $5.765295815 \mathrm{E}-01$ \\
\hline 0.8 & $2.812551189 \mathrm{E}+01$ & $1.647766682 \mathrm{E}+01$ & $-9.760299237 \mathrm{E}+00$ & $2.639340799 \mathrm{E}-01$ \\
\hline 0.9 & $3.411420844 \mathrm{E}+01$ & $1.999969842 \mathrm{E}+01$ & $-1.073414431 \mathrm{E}+01$ & $-3.761458280 \mathrm{E}-02$ \\
\hline 1.0 & $4.038813691 \mathrm{E}+01$ & $2.369210174 \mathrm{E}+01$ & $-1.166333600 \mathrm{E}+01$ & $-3.293112943 \mathrm{E}-01$ \\
\hline
\end{tabular}


Table 2. Numerical Results $x(t), y(t)$ in Equation 15 and 17 for Case $1 b$

\begin{tabular}{|c|c|c|c|c|}
\hline & $\mathbf{x}(\mathbf{t})$ for $\boldsymbol{\alpha}=\mathbf{0 . 5}$ & $\mathbf{y}(\mathbf{t})$ for $\boldsymbol{\alpha}=\mathbf{0 . 5}$ & $\mathbf{x}(\mathbf{t})$ for $\boldsymbol{\alpha}=\mathbf{0 . 5}$ & $\mathbf{y}(\mathbf{t})$ for $\boldsymbol{\alpha}=\mathbf{0 . 5}$ \\
\hline$(\mathbf{t})$ & Modify & Modify & Existing & Existing \\
\hline 0 & $0.000000000 \mathrm{E}+00$ & $0.000000000 \mathrm{E}+00$ & $1.000000000 \mathrm{E}+00$ & $1.000000000 \mathrm{E}+00$ \\
\hline 0.1 & $-1.033244507 \mathrm{E}-01$ & $-1.237625056 \mathrm{E}-01$ & $3.904169924 \mathrm{E}+00$ & $3.569993597 \mathrm{E}+00$ \\
\hline 0.2 & $-5.695277085 \mathrm{E}-01$ & $-7.014697501 \mathrm{E}-01$ & $4.167967943 \mathrm{E}+00$ & $4.232027564 \mathrm{E}+00$ \\
\hline 0.3 & $-1.532946223 \mathrm{E}+00$ & $-1.915567443 \mathrm{E}+00$ & $3.729735120 \mathrm{E}+00$ & $4.465458881 \mathrm{E}+00$ \\
\hline 0.4 & $-3.094919015 \mathrm{E}+00$ & $-3.901556392 \mathrm{E}+00$ & $2.823869996 \mathrm{E}+00$ & $4.432357257 \mathrm{E}+00$ \\
\hline 0.5 & $-5.344811772 \mathrm{E}+00$ & $-6.775299939 \mathrm{E}+00$ & $1.554224406 \mathrm{E}+00$ & $4.201095971 \mathrm{E}+00$ \\
\hline 0.6 & $-8.366875547 \mathrm{E}+00$ & $-1.064183329 \mathrm{E}+01$ & $-1.953058719 \mathrm{E}-02$ & $3.809487942 \mathrm{E}+00$ \\
\hline 0.7 & $-1.224377152 \mathrm{E}+01$ & $-1.559977739 \mathrm{E}+01$ & $-1.858204951 \mathrm{E}+00$ & $3.281599784 \mathrm{E}+00$ \\
\hline 0.8 & $-1.705872195 \mathrm{E}+01$ & $-2.174397089 \mathrm{E}+01$ & $-3.933846720 \mathrm{E}+00$ & $2.634148296 \mathrm{E}+00$ \\
\hline 0.9 & $-2.289694736 \mathrm{E}+01$ & $-2.916720295 \mathrm{E}+01$ & $-6.225369636 \mathrm{E}+00$ & $1.879461044 \mathrm{E}+00$ \\
\hline 1.0 & $-2.984667663 \mathrm{E}+01$ & $-3.796142903 \mathrm{E}+01$ & $-8.716208328 \mathrm{E}+00$ & $1.027033337 \mathrm{E}+00$ \\
\hline
\end{tabular}

Table 3. Numerical Results $x(t), y(t)$ in Equation 15 and 17 for Case $2 a$

\begin{tabular}{|l|c|c|c|c|}
\hline & $\mathbf{x}(\mathbf{t})$ for $\boldsymbol{\alpha}=\mathbf{0 . 2 5}$ & $\mathbf{y}(\mathbf{t})$ for $\boldsymbol{\alpha}=\mathbf{0 . 2 5}$ & $\mathbf{x}(\mathbf{t})$ for $\boldsymbol{\alpha}=\mathbf{0 . 5}$ & $\mathbf{y}(\mathbf{t})$ for $\boldsymbol{\alpha}=\mathbf{0 . 5}$ \\
\hline$(\mathbf{t})$ & Modify & Modify & Existing & Existing \\
\hline 0 & $0.000000000 \mathrm{E}+00$ & $0.000000000 \mathrm{E}+00$ & $1.000000000 \mathrm{E}+00$ & $1.000000000 \mathrm{E}+00$ \\
\hline 0.1 & $1.312525905 \mathrm{E}-01$ & $3.046455524 \mathrm{E}-01$ & $1.867862502 \mathrm{E}+00$ & $6.109091020 \mathrm{E}-01$ \\
\hline 0.2 & $4.422230900 \mathrm{E}-01$ & $1.049177774 \mathrm{E}+00$ & $1.389765176 \mathrm{E}+00$ & $-6.670279515 \mathrm{E}-01$ \\
\hline 0.3 & $9.034316491 \mathrm{E}-01$ & $2.157795048 \mathrm{E}+00$ & $9.547245161 \mathrm{E}-01$ & $-1.738535113 \mathrm{E}+00$ \\
\hline 0.4 & $1.497833906 \mathrm{E}+00$ & $3.587340842 \mathrm{E}+00$ & $5.551577841 \mathrm{E}-01$ & $-2.685604756 \mathrm{E}+00$ \\
\hline 0.5 & $2.211302685 \mathrm{E}+00$ & $5.302565504 \mathrm{E}+00$ & $1.833011644 \mathrm{E}-01$ & $-3.546431545 \mathrm{E}+00$ \\
\hline 0.6 & $3.030650803 \mathrm{E}+00$ & $7.270909162 \mathrm{E}+00$ & $-1.663435073 \mathrm{E}-01$ & $-4.342625903 \mathrm{E}+00$ \\
\hline 0.7 & $3.942899115 \mathrm{E}+00$ & $9.460568568 \mathrm{E}+00$ & $-4.976899938 \mathrm{E}-01$ & $-5.087888882 \mathrm{E}+00$ \\
\hline 0.8 & $4.934957495 \mathrm{E}+00$ & $1.183965175 \mathrm{E}+01$ & $-8.136157012 \mathrm{E}-01$ & $-5.791583973 \mathrm{E}+00$ \\
\hline 0.9 & $5.993479581 \mathrm{E}+00$ & $1.437579136 \mathrm{E}+01$ & $-1.116304024 \mathrm{E}+00$ & $-6.460461401 \mathrm{E}+00$ \\
\hline 1.0 & $7.104798537 \mathrm{E}+00$ & $1.703597419 \mathrm{E}+01$ & $-1.407457430 \mathrm{E}+00$ & $-7.099586297 \mathrm{E}+00$ \\
\hline
\end{tabular}

Table 4. Numerical Results $x(t), y(t)$ in Equation 15 and 17 for Case $2 b$

\begin{tabular}{|l|c|c|c|c|}
\hline & $\mathbf{x}(\mathbf{t})$ for $\boldsymbol{\alpha}=\mathbf{0 . 7 5}$ & $\mathbf{y}(\mathbf{t})$ for $\boldsymbol{\alpha}=\mathbf{0 . 7 5}$ & $\mathbf{x}(\mathbf{t})$ for $\boldsymbol{\alpha}=\mathbf{0 . 7 5}$ & $\mathbf{y}(\mathbf{t})$ for $\boldsymbol{\alpha}=\mathbf{0 . 7 5}$ \\
\hline$(\mathbf{t})$ & Modify & Modify & Existing & Existing \\
\hline 0 & $0.000000000 \mathrm{E}+00$ & $0.000000000 \mathrm{E}+00$ & $1.000000000 \mathrm{E}+00$ & $1.000000000 \mathrm{E}+00$ \\
\hline 0.1 & $6.155577598 \mathrm{E}-03$ & $2.895632885 \mathrm{E}-03$ & $1.970623848 \mathrm{E}+00$ & $2.191082404 \mathrm{E}+00$ \\
\hline 0.2 & $5.219094311 \mathrm{E}-03$ & $-1.845667942 \mathrm{E}-02$ & $2.414176187 \mathrm{E}+00$ & $2.594006269 \mathrm{E}+00$ \\
\hline 0.3 & $-9.639837374 \mathrm{E}-02$ & $-1.007135085 \mathrm{E}-01$ & $2.657487129 \mathrm{E}+00$ & $2.674349279 \mathrm{E}+00$ \\
\hline 0.4 & $-2.342601224 \mathrm{E}-01$ & $-2.804235074 \mathrm{E}-01$ & $2.761154513 \mathrm{E}+00$ & $2.523544203 \mathrm{E}+00$ \\
\hline 0.5 & $-2.342601224 \mathrm{E}-01$ & $-5.955334252 \mathrm{E}-01$ & $2.754112656 \mathrm{E}+00$ & $2.186316953 \mathrm{E}+00$ \\
\hline 0.6 & $-4.554791476 \mathrm{E}-01$ & $-1.085750764 \mathrm{E}+00$ & $2.653686938 \mathrm{E}+00$ & $1.689915427 \mathrm{E}+00$ \\
\hline 0.7 & $-7.798133170 \mathrm{E}-01$ & $-1.792775141 \mathrm{E}+00$ & $2.471556839 \mathrm{E}+00$ & $1.052956970 \mathrm{E}+00$ \\
\hline 0.8 & $-1.227804269 \mathrm{E}+00$ & $-2.760511951 \mathrm{E}+00$ & $2.216200694 \mathrm{E}+00$ & $2.891050823 \mathrm{E}-01$ \\
\hline 0.9 & $-1.820895223 \mathrm{E}+00$ & $-4.035291009 \mathrm{E}+00$ & $1.894093963 \mathrm{E}+00$ & $-5.911083376 \mathrm{E}-01$ \\
\hline 1.0 & $-2.581543730 \mathrm{E}+00$ & $-5.666093907 \mathrm{E}+00$ & $1.510369287 \mathrm{E}+00$ & $-1.579269656 \mathrm{E}+00$ \\
\hline
\end{tabular}


Table 5. Numerical Results $x(t), y(t)$ in Equation 15 and 17 for Case $3 a$

\begin{tabular}{|l|c|c|c|c|}
\hline & $\mathbf{x}(\mathbf{t})$ for $\boldsymbol{\alpha}=\mathbf{0 . 2 5}$ & $\mathbf{y}(\mathbf{t})$ for $\mathbf{\alpha}=\mathbf{0 . 2 5}$ & $\mathbf{x}(\mathbf{t})$ for $\boldsymbol{\alpha}=\mathbf{0 . 2 5}$ & $\mathbf{y}(\mathbf{t})$ for $\boldsymbol{\alpha}=\mathbf{0 . 2 5}$ \\
\hline$(\mathbf{t})$ & Modify & Modify & Existing & Existing \\
\hline 0 & $0.000000000 \mathrm{E}+00$ & $0.000000000 \mathrm{E}+00$ & $1.000000000 \mathrm{E}+00$ & $1.000000000 \mathrm{E}+00$ \\
\hline 0.1 & $7.769339754 \mathrm{E}-02$ & $2.069033088 \mathrm{E}-01$ & $2.411166256 \mathrm{E}+00$ & $3.651986618 \mathrm{E}+00$ \\
\hline 0.2 & $2.498818864 \mathrm{E}-01$ & $7.086550603 \mathrm{E}-01$ & $2.437305294 \mathrm{E}+00$ & $3.912897698 \mathrm{E}+00$ \\
\hline 0.3 & $5.011067765 \mathrm{E}-01$ & $1.455661253 \mathrm{E}+00$ & $2.411906698 \mathrm{E}+00$ & $4.044918132 \mathrm{E}+00$ \\
\hline 0.4 & $8.225614617 \mathrm{E}-01$ & $2.419428702 \mathrm{E}+00$ & $2.368621031 \mathrm{E}+00$ & $4.123406017 \mathrm{E}+00$ \\
\hline 0.5 & $1.206893805 \mathrm{E}+00$ & $3.576535993 \mathrm{E}+00$ & $2.317264752 \mathrm{E}+00$ & $4.172723969 \mathrm{E}+00$ \\
\hline 0.6 & $1.647197834 \mathrm{E}+00$ & $4.905259900 \mathrm{E}+00$ & $2.261861399 \mathrm{E}+00$ & $4.203850215 \mathrm{E}+00$ \\
\hline 0.7 & $2.136647029 \mathrm{E}+00$ & $6.384333950 \mathrm{E}+00$ & $2.204369407 \mathrm{E}+00$ & $4.222658726 \mathrm{E}+00$ \\
\hline 0.8 & $2.668338185 \mathrm{E}+00$ & $7.992421331 \mathrm{E}+00$ & $2.145846553 \mathrm{E}+00$ & $4.232649343 \mathrm{E}+00$ \\
\hline 0.9 & $3.235224058 \mathrm{E}+00$ & $9.707897187 \mathrm{E}+00$ & $2.086904413 \mathrm{E}+00$ & $4.236068325 \mathrm{E}+00$ \\
\hline 1.0 & $3.830088010 \mathrm{E}+00$ & $1.150878607 \mathrm{E}+01$ & $2.027913104 \mathrm{E}+00$ & $4.234438406 \mathrm{E}+00$ \\
\hline
\end{tabular}

Table 6. Numerical Results $x(t), y(t)$ in Equation 15 and 17 for Case $3 b$

\begin{tabular}{|l|c|c|c|c|}
\hline & $\mathbf{x}(\mathbf{t})$ for $\boldsymbol{\alpha}=\mathbf{0 . 5}$ & $\mathbf{y}(\mathbf{t})$ for $\boldsymbol{\alpha}=\mathbf{0 . 5}$ & $\mathbf{x}(\mathbf{t})$ for $\mathbf{\alpha}=\mathbf{0 . 5}$ & $\mathbf{y}(\mathbf{t})$ for $\mathbf{\alpha}=\mathbf{0 . 5}$ \\
\hline$(\mathbf{t})$ & Modify & Modify & Existing & Existing \\
\hline 0 & $0.000000000 \mathrm{E}+00$ & $0.000000000 \mathrm{E}+00$ & $1.000000000 \mathrm{E}+00$ & $1.000000000 \mathrm{E}+00$ \\
\hline 0.1 & $-1.462256518 \mathrm{E}-03$ & $3.760936169 \mathrm{E}-03$ & $2.332430963 \mathrm{E}+00$ & $3.046080610 \mathrm{E}+00$ \\
\hline 0.2 & $-4.805752367 \mathrm{E}-02$ & $-2.019925049 \mathrm{E}-03$ & $2.750177860 \mathrm{E}+00$ & $3.759430869 \mathrm{E}+00$ \\
\hline 0.3 & $-1.609068464 \mathrm{E}-01$ & $-1.425974674 \mathrm{E}-02$ & $2.979204591 \mathrm{E}+00$ & $4.215282038 \mathrm{E}+00$ \\
\hline 0.4 & $-3.534475222 \mathrm{E}-01$ & $-2.906783061 \mathrm{E}-02$ & $3.095651948 \mathrm{E}+00$ & $4.522951241 \mathrm{E}+00$ \\
\hline 0.5 & $-6.367567758 \mathrm{E}-01$ & $-4.393004618 \mathrm{E}-02$ & $3.130878072 \mathrm{E}+00$ & $4.726647193 \mathrm{E}+00$ \\
\hline 0.6 & $-1.020812528 \mathrm{E}+00$ & $-5.799756505 \mathrm{E}-02$ & $3.101880974 \mathrm{E}+00$ & $4.849958463 \mathrm{E}+00$ \\
\hline 0.7 & $-1.515062564 \mathrm{E}+00$ & $-7.221543975 \mathrm{E}-02$ & $3.019292920 \mathrm{E}+00$ & $4.907432408 \mathrm{E}+00$ \\
\hline 0.8 & $-2.128746296 \mathrm{E}+00$ & $-8.940831237 \mathrm{E}-02$ & $2.890386777 \mathrm{E}+00$ & $4.908892795 \mathrm{E}+00$ \\
\hline 0.9 & $-2.871100573 \mathrm{E}+00$ & $-1.143429875 \mathrm{E}-01$ & $2.720452974 \mathrm{E}+00$ & $4.861401914 \mathrm{E}+00$ \\
\hline 1.0 & $-3.751501770 \mathrm{E}+00$ & $-1.537720040 \mathrm{E}-01$ & $2.513516669 \mathrm{E}+00$ & $4.770275003 \mathrm{E}+00$ \\
\hline
\end{tabular}

Figure 2a. Time Series Plot of Case 1a Depicts the Optimal Height where the Love Reached Before Depreciating After Three Years of Togetherness. The Plot Compares the Existing and Modified Model where $\alpha=0.25$

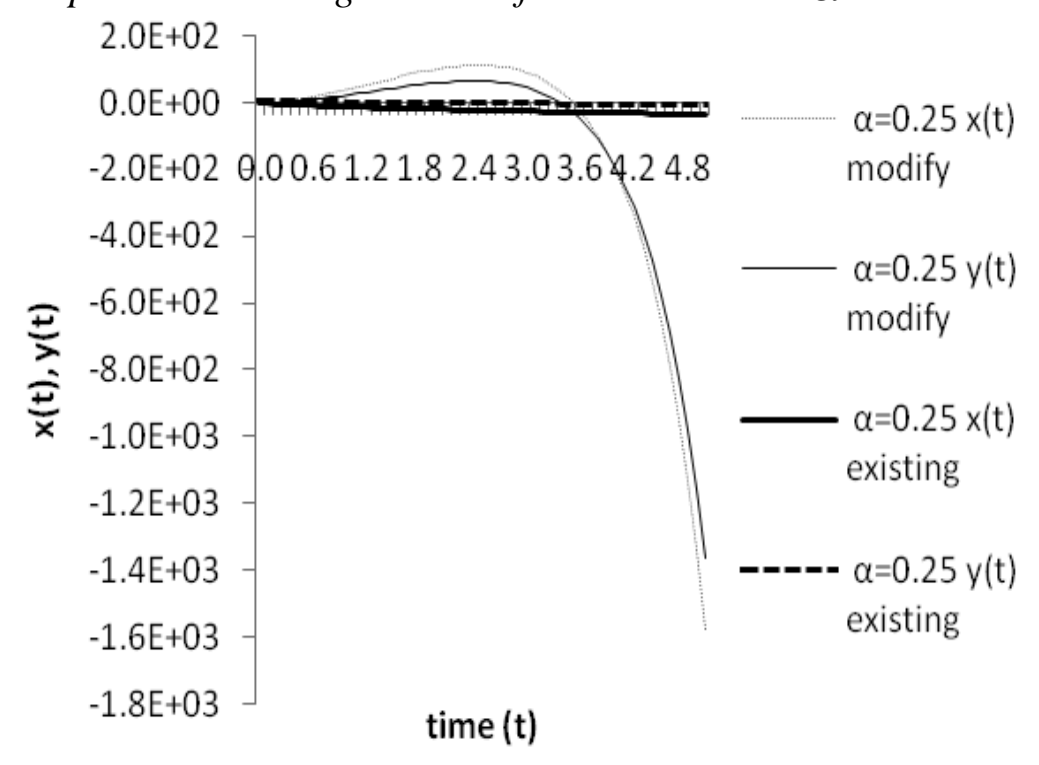


Figure 2b. Time Series Plot of Case 1a Depicts Rapid Drop in the Love Life of the Couple due to Increase in the Impact Factor Memory where $\alpha=0.50$

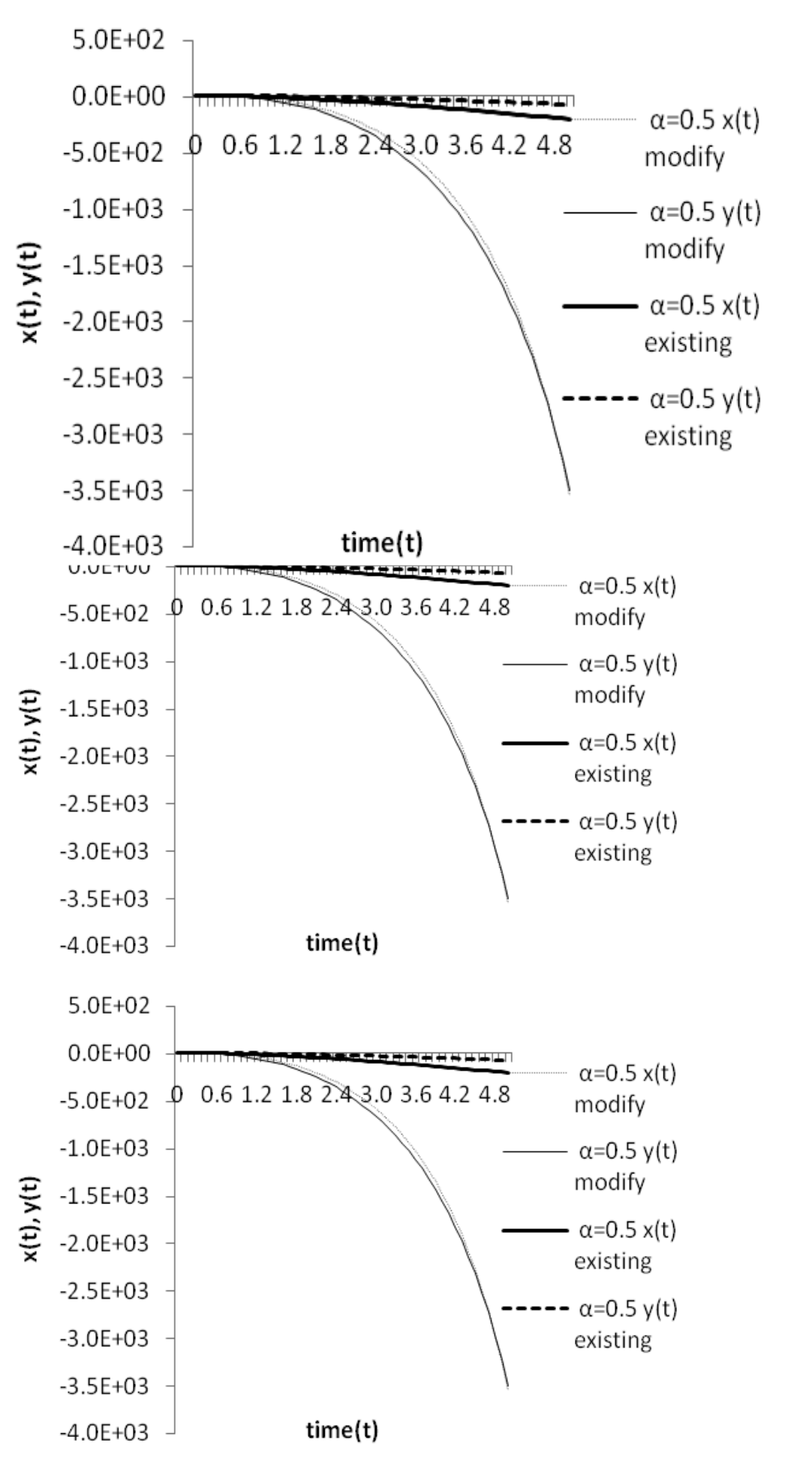


Figure 3a. Time Series Plot of Case 3 Depicts the Optimal Height where the Love Reached Before Depreciating After Three Years of Togetherness where $\alpha=0.25$

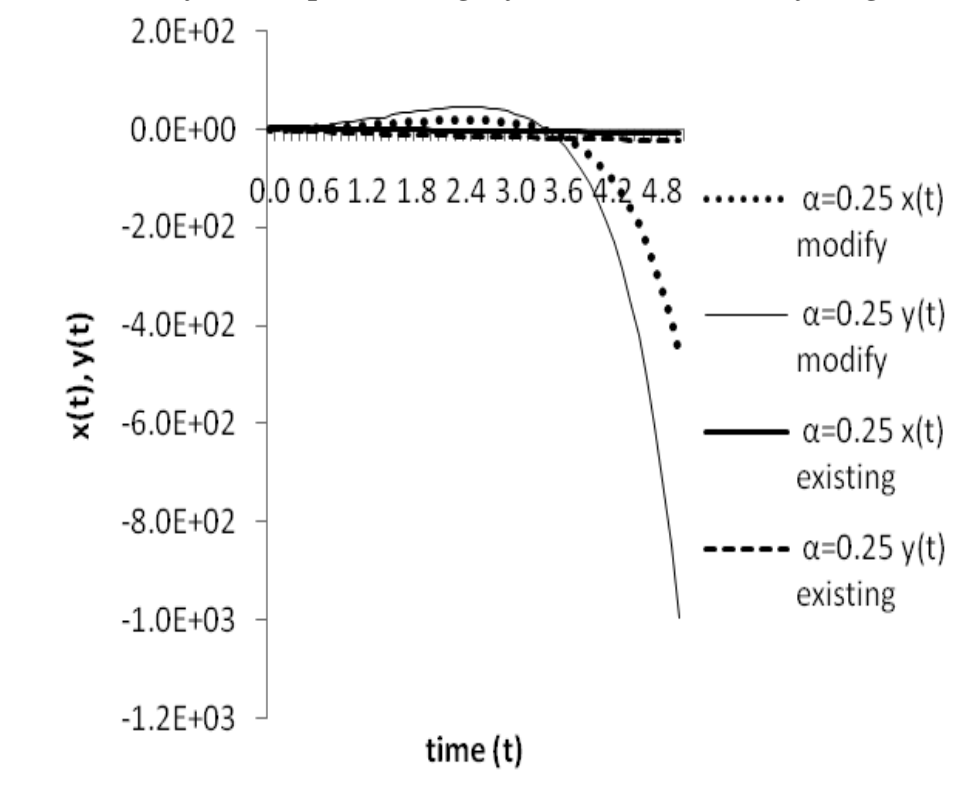

Figure 3b. Time Series Plot of Case 3 Depicts Rapid Drop in the Love Life due to Increase in the Impact Factor Memory where $\alpha=0.75$

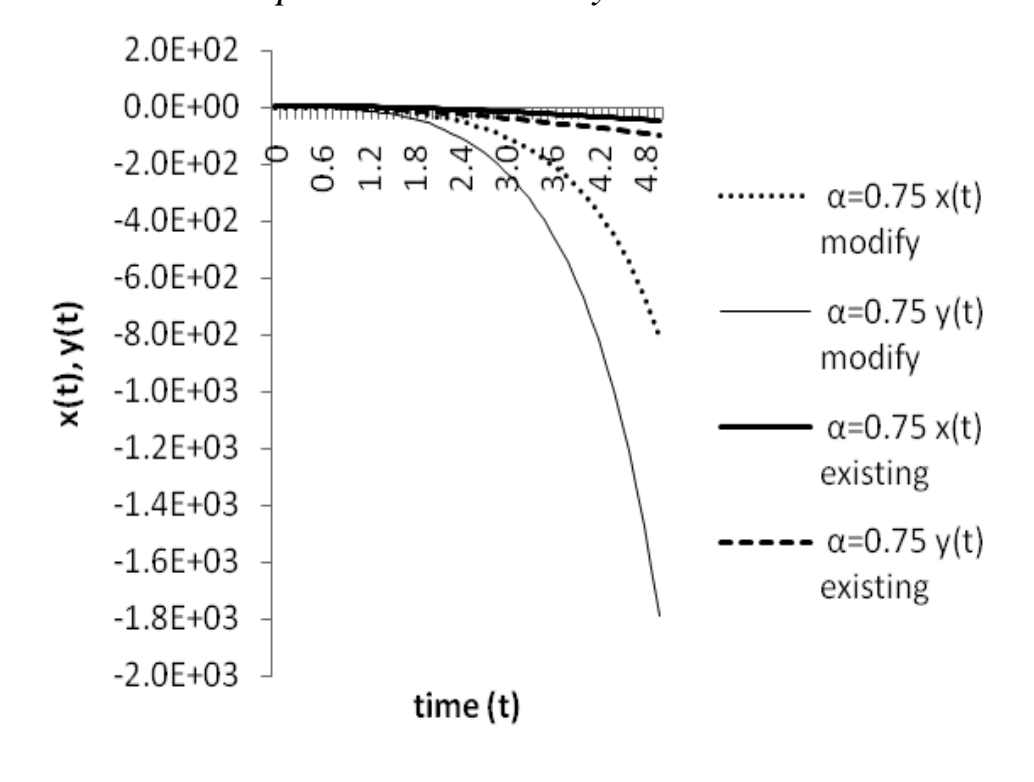


Figure 4a. Time Series Plot of Case 3a Depicts the Optimal Height where the Love Reached Before Depreciating After Three Years of Togetherness where $\alpha=0.25$

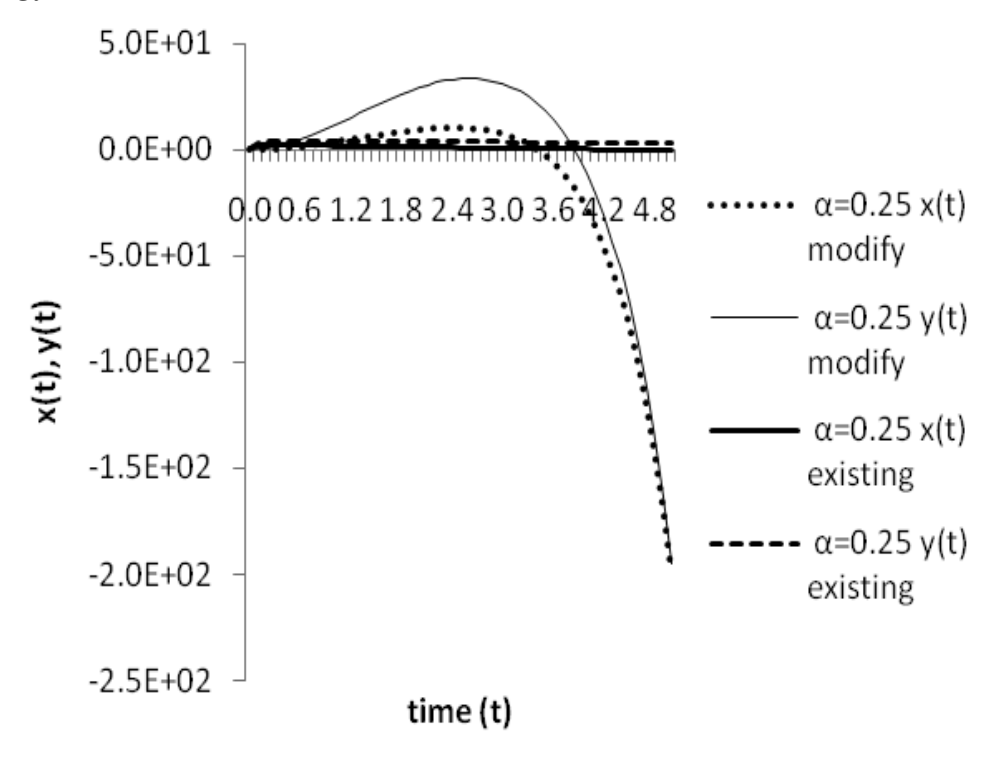

Figure 4b. Time Series Plot of Case $3 b$ Depicts Drop in the Love Life of the Couple due to Increase in the Impact Factor Memory where $\alpha=0.5$

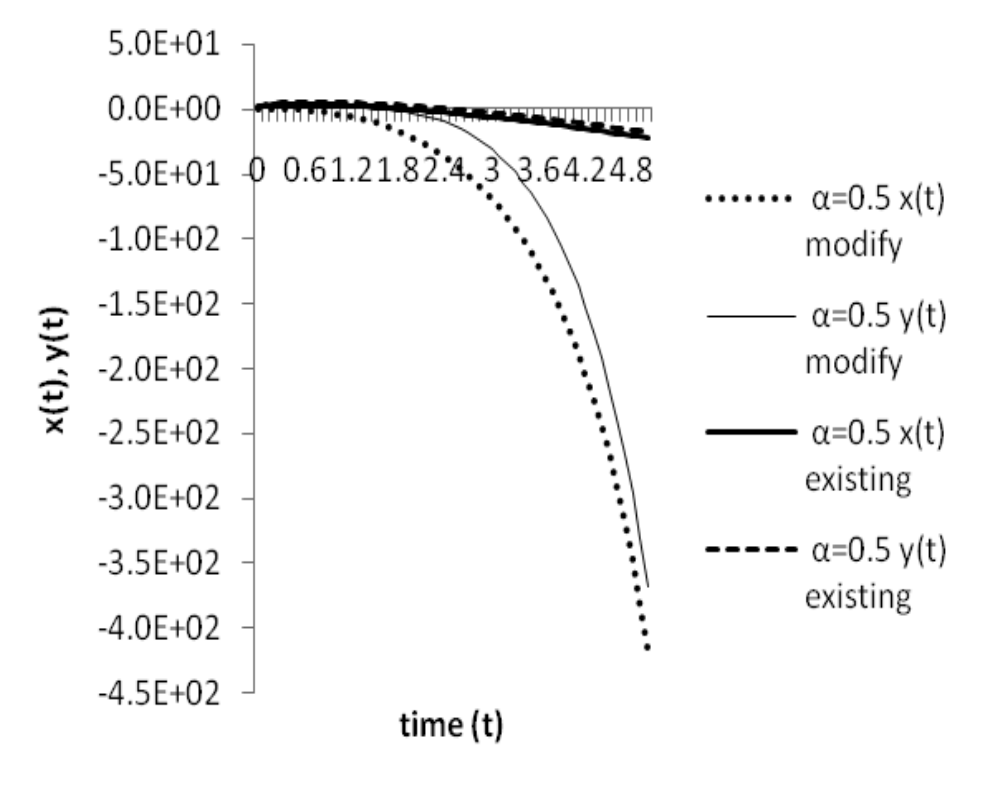

\section{Discussion}

Case 1

This case implies that the love story between case 1a enters into the dynamics of antagonist, when two lovers first meet at time $\mathrm{t}=0$, we say they are completely indifferent to each other (Rinaldi and Gragnani 1998). The parameters used were 
from the analysis of lover 1 while Tables 1 and 2 showed the data from the analysis for order 0.50 and 0.25 respectively. Figure $2 \mathrm{a}$ allows us to deduce the qualitative shape of the solutions, the time response of the love between individual moves faster and faster until it reaches the optimal height. The love depreciated after three years of togetherness and then moved to negative feelings. Comparing the existing and modified model shows that the trajectory for the existing model for the case reached the optimal height almost at the same time and the love did not start from the state of indifference but for the modified model; the love started from the state of indifference in accordance with Rinaldi and Gragnani (1998) where they are just trying to know each other and the husband love $(y(t))$ for the wife $(x(t))$ moved at a faster rate than that of $\mathrm{x}(\mathrm{t})$ before the feeling towards each other crept to the negative feelings with order 0.25 .

Figures $2 \mathrm{a}$ and $\mathrm{b}$ allow us to deduce the qualitative shape of the solutions, lovers 1 were together for few years before divorce and they started experiencing troubles within a year in their marriage. The plots showed that when the impact memory factor increased (the moment they allowed their past to take over their present), right from the beginning of their love life they have no feeling towards each other. The love depreciated within a year of their togetherness and moved to negative feelings. Comparing the existing and modified model, it shows that the trajectory for the existing model for the love did not start from the state of indifference but for the modified model, it shows the systematic dropped in the love life of both couple. The love started from the state of indifference with order $0.25,0.05$ and 0.75 .

\section{Case 2}

In this case, the parameters used were from the analysis of lover 3. Iterative decomposition method was used in solving the problem, the numerical results from Tables 3 and 4 were plotted and the graphs were also interpreted.

Figures $3 \mathrm{a}$ and $\mathrm{b}$ allow us to deduce the qualitative shape of the solutions, the time response of the love between individual moves faster and faster until it reaches the optimal height. At the optimal height, the love dropped a little before picking again and followed a parabolic part. After few years of their togetherness, the love depreciated and moved to negative feelings. Comparing the existing and modified model shows that the trajectory for the existing model for the couple did not start from the state of indifference (the state when they first met each other) but for the modified model; the love started from the state of indifference where they are just trying to know each other but the love for each other later creeped to the negative feelings with order $0.25,0.50$ and 0.75 .

\section{Case 3}

In this case, the parameter values used were from the analysis of couple 8 while Tables 5 and 6 showed the data from the analysis for order 0.25 and 0.50 respectively. Iterative decomposition method was used in solving the problem, the numerical results were plotted and the graphs were similarly interpreted. 
Figure 4a allows us to deduce the qualitative shape of the solutions, the time response of the love between individual moves faster and faster until it reaches the optimal height. The love depreciated after few years of togetherness and moved to negative feelings. Figure $4 \mathrm{~b}$ depicts rapid drop in the love life of the lovers due to increase in the impact factor memory. The plot compares the existing and modified model time response of the lover in their marriage with order 0.5 .

\section{Conclusions}

In the present work, linear love dynamic model was modified by introducing nonlinear terms to become nonlinear fractional order differential equations. The model was used to interpret the dynamics of most marriages. According to Sprott (2005) he reported that simple linear models of happiness can produce surprisingly complex dynamics, much of which rings true to common experience. When there are periodic external events, simple nonlinearities can produce chaos. The existence of chaos in relationship implies a degree of unpredictability. Numerical simulations were shown to illustrate the effectiveness and applicability of this design. The integer-order love model is extended to a fractional-order pattern through the comparison between the existing and modified model, which is found to be more suitable to depict the marriage behaviour. It is noteworthy that the conception of IFM proposed here is to denote a measurement of how influenced an individual is by his/her past experiences. When one's IFM is low, his/her past experiences may have little influence on his/her present and future life; while when IFM is high, it might be difficult for him/her to escape from past experiences, in despite of nightmares or sweet memories.

Moreso, this research was carried out to look into the reason behind the increasing divorce rate among young lovers these days which is causing societal decadency making it unbearable for friendly environment. However, the work also focuses on analyzing data with the aid of questionnaires and to interpret the result with the aid of phase plots, time series plots and charts. Finding solutions to the problems young lovers are facing is a problem with required solution that the current research work is attempting to un-ravel to allow reasonable stability to enhance marriage so that the socio-economic growth and development in the nation can be improved upon.

Also, fractional order model has been used in this work because of its memory effect compared to integer-order model. The model describes the dynamical behaviour of the couples in their marital affair. The dynamics of the proposed system was studied numerically using Iterative Decomposition Method with different order. The method is easily applied as the terms of the approximating series are easy to compute. It was demonstrated via numerical simulations by showing that fractional order model of marriage can exhibit irregular pattern using an appropriate set of parameters gotten from analysis of the survey results. From the time series and phase plots acquired using computer simulation, it was recognized that there is a clear difference in the results of modified and existing model. The modified model shows the trajectory of the couple from the state of 
indifference which implies that the status of love between the couples can be affected by various parameters like opinions of parents, maltreatment, loneliness etc. As the impact factor memory increases, it also affects their togetherness making the love between them to decay easily.

\section{References}

Adenugba DA (2015) The physics of identical unions and excitation. International Journal of Computer Applications 110(14): 11-18.

Ahmad WM, El-Khazali R (2007) Fractional-order dynamical models of love. Chaos, Solitons and Fractals 33(4): 1367-1375.

Ahmad M, Jiang J, Zada A, Shah SO, Xu J (2020) Analysis of coupled system of implicit fractional differential equations involving Katugampola-Caputo fractional derivative. Complexity 2020(4): 1-11.

Alawad FA, Yousif EA, Arbab IA (2013) A new technique of Laplace iteration method for solving space-time fractional telegraph equations. International Journal of Differential Equations 2013. Article ID 256593.

Baker GL, Gollub JP (1996) Chaotic dynamics: an introduction. $2^{\text {nd }}$ Edition. New York: Cambridge University Press.

Barley K, Cherif A (2011) Stochastic nonlinear dynamics of interpersonal and romantic relationships. Applied Mathematics and Computation 217(13): 6273-6281.

Beltrami E (1993) Mathematical models in the social and biological sciences. Boston: Jones and Bartlett Publishers.

Caputo M (1967) Linear models of dissipation whose Q is almost frequency independent. Geophysical Journal of the Royal Astronomical Society 13(5): 529-539.

Cynthia LH (2015) Critical response to Stefani Engelstein's "Allure of wholeness": traditional marriage and the beauty of holiness. Critical Inquiry 41(2): 443-450.

Dharna S, Arun KS (2012) Dynamics of love and happiness: a mathematical analysis. International Journal of Modern Education and Computer Science 4(5): 31-37.

Gleick J (1987) Chaos: making a new science. New York: Viking Press.

Gottman JM, Murray JD, Swanson CC, Tyson R, Swanson KR (2005) The mathermatics of marriage. Cambridge, MA: MIT Press.

Goyal M, Prakash A, Gupta S (2019) Numerical simulation for time-fractional nonlinear coupled dynamical model of romantic and interpersonal relationships. Pramana Journal of Physics 92(5): 82.

Gu R, Xu Y (2011) Chaos in a fractional-order dynamical model of love and its control. In S Li, X Wang, Y Okazaki, J Kawabe, T Murofushi, L Guan (eds), 349-356. Nonlinear Mathematics for Uncertainty and its Applications. Advances in Intelligent and Soft Computing. Berlin, Heidelberg: Springer.

Kefalas MJ, Furstenberg FF, Carr PJ, Napolitano L (2011) Marriage is more than being together: the meaning of marriage for young adults. Journal of Family Issues 32(7): 845-875.

Khan H, Khan A, Al Qurashi M, Baleanu D, Shah R (2020) An analytical investigation of fractional-order biological model using an innovative technique. Complexity 2020(3): $1-13$.

Koca I, Yaprakdal P (2019) A new approach for nuclear family model with fractional order Caputo derivative. Applied Mathematics and Nonlinear Sciences 5(1): 393404. 
Liu W, Chen K (2015) Chaotic behavior in a new fractional-order love triangle system with competition. Journal of Applied Analysis and Computation 5(1): 103-113.

Lorenz E (1993) The essence of chaos. Seattle: University of Washington Press.

Mohammadi F (2014) Numerical solution of Bagley-Tovik equation using Chebyshev operational matrix of fractional derivative. International Journal of Advances in Applied Mathematics and Mechanics 2(1): 83-91.

Morrison F (1991) The art of modeling dynamical systems: forecasting for chaos, randomness and determinism. New York: Wiley Interscience.

Noeiaghdam S, Sidorov DN, Sizikov VS, Sidorov NA (2020) Control of accuracy on Taylor-collocation method to solve theweakly regular Volterra integral equations of the first kind by using the CESTAC method. Applied and Computational Mathematics 19(1): 87-105.

Odetunde OS, Taiwo OA (2015) An algorithm for the approximation of fractional differential-algebraic equations with Caputo-type derivatives. Journal of Applied \& Computational Mathematics 4(Jan): 242.

Odibat ZM, Momani S (2008) An algorithm for the numerical solution of differential equations of fractional order. Journal of Applied Mathematics and Informatics 26(12): $15-27$.

Okyere E, Oduro FT, Amponsah SK, Dontwi IK, Frempong NK (2016) Fractional order SIR model with constant population. British Journal of Mathematics and Computer Science 14(Jan): 1-12.

Orsucci F (2001) Happiness and deep ecology: on noise, harmony and beauty in the mind. Nonlinear Dynamics, Psychology and Life Sciences 5(1): 65-76.

Osilagun JA, Taiwo OA (2014) A modified iterative decomposition method for solving boundary layer problem in unbounded domain. International Journal of Differential Equations and Applications 13(1): 17-25.

Owolabi KM (2019) Mathematical modelling and analysis of love dynamics: a fractional approach. Physical A 525(Jul): 849-865.

Paul RP, Larry SL, John MG, Michael DN, Jessica S (2012) A mathematical model of psychotherapy: an investigation using dynamic non-linear equations to model the therapeutic relationship. Psychoterapy Research 22(1): 40-55.

Rinaldi S (1996) Love dynamics: the case of linear couples. International Institute for Applied Systems Analysis Working Paper. WP-96-068.

Rinaldi S (1998) Love dynamics: the case of linear couples. Applied Mathematics and Computation 95(2-3): 181-192.

Rinaldi S, Gragnani A (1998) Love dynamics between secure individuals: a modeling approach. Nonlinear Dynamics Psychology and Life Sciences 2(Oct): 283-301.

Song L, Yang J (2009) Chaos control and synchronization of dynamical model of happiness with fractional order. Conference Proceedings of the $4^{\text {th }}$ IEEE Conference on Industrial Electronics and Applications (ICIEA). Institute of Electrical and Electronics Engineers, Inc., 919-924.

Sprott JC (2001) Dynamics of love and happiness, chaos and complex systems. Seminar. Madison, Wisconsin.

Sprott JC (2004) Dynamical models of love. Nonlinear Dynamics Psychology and Life Sciences 8(3): 303-313.

Sprott JC (2005) Dynamical models of happiness. Nonlinear Dynamics, Psychology and Life Science 9(1): 23-36.

Strogatz SH (1988) Love affairs and differential equations. Mathematics Magazine 61(1): 35.

Talabi AT, Odunaike RK, Odetunde OS, Omoteso KA (2019) A modified fractional differential love model. Moroccan Journal of Pure and Applied Analysis 5(1): 37-45. 
Thabet H, Kendre SD (2018) New modification of Adomian decomposition method for solving a system of nonlinear fractional partial differential equations. International Journal of Advances in Applied Mathematics and Mechanics 6(3): 1-13.

Vallacher RR, Nowack A (1994) Dynamical systems in social psychology. New York: Academic Press.

Vallacher RR, Coleman PT, Nowak A, Bui-Wrzosinska L (2010) Rethinking intractable conflict: the perspective of dynamical systems. American Psychologist 65(4): 262278.

Vilu S, Ahmad RR, Din UKS (2019) Variational iteration method and Sumudu transform for solving delay differential equation. International Journal of Differential Equations 2019(1): 1-6.

Von Bertalanffy L (1968) General system theory: foundations, development. New York: George Braziller.

Wauer J, Schwarzer D, Cai GO, Lin YK (2007) Dynamical models of love with timevarying fluctuations. Applied Mathematics and Computation 188(2): 1535-1548.

Weigel D, Murray C (2000) The paradox of stability and change in relationships: what does chaos theory offer for the study of romantic relationships? Journal of Social and Personal Relationships 17(3): 425-449.

Zhang Y (2018) Existence results for a coupled system of nonlinear fractional multi-point boundary value problems at resonance. Journal of Inequalities and Applications 2018(1): 198. 



\title{
Theory of Bioenergy Accumulation and Transformation: Application to Evolution, Energy, Sustainable Development, Climate Change, Manufacturing, Agriculture, Military Activity and Pandemic Challenges
}

\begin{abstract}
By Armen B Avagyan*
Our theory includes generalized explanations of how nature works, confirmed by pieces of evidence, cover predictions for further technological developments towards economically and environmentally sustainable industrial processes as well as provides the role of bioenergy accumulation and transformation for improved understanding about evolution, influences of anthropogenic activity, decision-makers errors, technological choices, pandemics prevention and the necessary skills toward the innovation algae-based system. The possibility of origination and evolution of the landforms of life were the results of bioenergy accumulation by microalgae and at present, the contribution of algae remains dominant in reducing $\mathrm{CO}_{2}$ and maintaining $\mathrm{O}_{2}$ level in the atmosphere. Population growth stimulates the accumulation of air carbon and bioenergy. The production and application of fertilizers originated large GHG emissions and it is a big conceptual need to shift on organic agriculture including algae fertilization of soil to contribute long-term sustainability. The used technologies for $1 G$ biofuels production, as well as microalgae to biofuel based on biomass phototrophic growth by the use of fertilizers, are induced aggressively increasing $G H G$ emission instead of their mitigation. Microalgae biofuel has big potential in case the use of wastewaters and food waste for biomass growth. The priority strategy for dealing with future pandemics treats such as COVID19, etc. must be increasing the stability of immunity system of humans and animals to infections and due to a high concentration of physiologically active compounds in microalgae they application can be the best decision. Analyses of the Kyoto Protocol, Paris Climate Agreement, etc. results provide that their application has many disadvantages. The New policy must be founded on the admitting of the Life Conserve industry as the new part of the production.
\end{abstract}

Keywords: bioenergy, biofuel, environmental policy evaluation, evolution, climate change, Malthusian theory, microalgae, agriculture, pandemics, waste

\begin{abstract}
Abbreviations: CCS - carbon capture and storage, $\mathrm{CO}_{2} \mathrm{e}-$ carbon dioxide equivalent for a gas, dw - dry weight, GHG - greenhouse gases, GDP - global gross domestic product, GDP - gross domestic product, GHG - greenhouse gases, ha - hectare, L - liter, LCA - Life Cycle Assessment, MJ - megajoule, NDS - National Determined Contributions, $\mathrm{NO}_{\mathrm{x}}$ - oxides of nitrogen, ppmv parts per million by volume, $\mathrm{ppb}$ - part per billion by volume, $\mathrm{t}-\mathrm{ton}, \mathrm{UV}-$ ultraviolet light
\end{abstract}

\footnotetext{
"President, Research \& Industry Center of Photosynthesizing Organisms, Feed Additives and Physiologically Active Compounds, Armenia.
} 


\section{Introduction}

According to the First law of thermodynamics, energy cannot be created or destroyed and only changed from separate specific form to another and applies to biological (Roach et al. 2018). The Sun is the largest reservoir of energy received by the planet (Ashok 2020). Energy is the capacity for doing work as with the following differentiation by types: Stored (potential) energy and Working (kinetic) energy (EIA 2019, Encyclopaedia 2020). It exists as heat, light, motion (kinetic), electrical, chemical, nuclear and gravitational energies. Humans and animals eat the food contained accumulated bioenergy in the form of chemical energy and then it is used as kinetic energy.

Atmospheric oxygen $\left(\mathrm{O}_{2}\right)$ increased in stages, at first through photolysis, and then the major impact on the growth of its content has been originated by the accumulation of bioenergy in algae photosynthesis which reduced the $\mathrm{CO}_{2}$ content of the atmosphere (Albany University 2020, Berkowit 2014, Samson 2018, Sayre 2010). At the first stage, the free $\mathrm{O}_{2}$ reacted with iron dissolved in the oceans, and only after saturation of its oxidizable rock it spread in Earth's atmosphere 2.3 billion years ago (Berkowit 2014). Plants complete converting the energy of sunlight into the biomass true bioenergy which has stored in the form of chemical energy. $\mathrm{O}_{2}$ level had archived a rate of $35 \%$ and later declined to $14 \%$ during a period of 120 million years and then (the Cambrian period) reached to current $21 \%$ (if the $\mathrm{O}_{2}$ share of $15 \%$ - fires would not burn, $25 \%$ - the wet organic matter would burn freely) (Samson 2018). Under the sun's ultraviolet rays (UV) form single oxygen atoms from $\mathrm{O}_{2}$ which with $\mathrm{O}_{2}$ generate ozone molecules $\left(\mathrm{O}_{3}\right)$. Due to absorbing Sun UV rays $\mathrm{O}_{3}$ layer of the atmosphere protecting the life forms from harsh and biologically lethal UV radiation (wavelengths of 200-300 nanometers). Earth's atmosphere and clouds absorb or scatter about $54 \%$ of the received sunlight energy and the other part reaches the planet surface (Ashok 2020). Stabilization of $\mathrm{O}_{2}$ to current $21 \%$ as well as formed stratospheric $\mathrm{O}_{3}$ layer allowed the rapid evolution of the life landforms and large animals which has evolved 600 million years ago (HHMI 2020). The total Sun energy captured by photosynthesis in green plants is around $2 \times 10^{23}$ joules/year or $4 \%$ of the total energy of sunlight (Akihiko and Oikawa 2004). Hence, processes were lead to the capture and storage of solar energy and chemical elements in living matter that are generalized explanations of how Life works.

The Second law on the production of entropy is not respected for life forms as they are hierarchical networks of informed energy flows and have the ability of homeostatic and environmental regulation as well as to reproduce by building an own energy transformation for evolution by natural selection (Roach et al. 2018). Natural selection and random mutation are the main arguments of Darwin's theory of evolution which is mainly the overcome scientific awareness (Burkeman 2010). However, the most past of Earth life has been the history of microorganisms which through the horizontal transfer can get $10 \%$ of its genes from other organisms and more than 200 of identified human genes is looked as the result of the horizontal transference of the bacteria genes (without evolution natural selection transition process) that was arguments for the initial foundation of the theory named the 
Conditional Evolution of Life. Simultaneously, Darwin never claimed that natural selection was the exceptional mechanism of evolution and its theory more applicable to the most modern complex forms of life. Besides, modern NeoDarwinism still has not demonstrated specific statistical distribution follow random mutations but under certain allowances, the method of evolution using random mutations or modifications can be admissible. Thus, Darwin's theory cannot describe all uncertainties.

Influenza pandemic includes the dissemination of a new strain of the virus which may infect humans when their most parts have no immunity and which can transmit efficiently from person to person around the world. Infectious diseases have repossessed as the leading cause of death compared to non-communicable diseases such as cardiovascular diseases or mental illness (WEF 2020a). The past (WHO 2020) and new virus COVID-19 pandemic affecting societies and economies at a high scale and humans face the hard challenges that require new managing and technological decisions (UN 2020). The vaccines versus pandemics are not always effective (Avagyan 2010a). Therefore, the priority strategy for dealing with future pandemics treats must be increasing the immunity system of humans and animals to infections.

On the other hand, the UN Secretary-General António Guterres in the UN's $75^{\text {th }}$ anniversary year indicated "four horsemen" (Geopolitical tensions (devastating conflicts continue to cause widespread misery, the nuclear menace is growing), The climate crisis (rising temperatures continue to melt records, the world is edging closer to the point of no return, etc.), Global mistrust, and The dark side of technology which are estimated as looming threats and imperils of 21st-century possibilities (Guterres 2020). So, the world is meeting a growing number of complex and interconnected challenges (Guterres 2020) and humans come to the future with considerable uncertainty about its ability to curb wellbeing and sustainable development. However, science is constantly evolving with expanding our understanding of life's important issues. Our theory provides the role of bioenergy accumulation and transformation for improved understanding about evolution, influences of anthropogenic activity, decision-makers errors, technological choices, and the necessary skills toward the innovation algae-based system addressed to the circular and green economy and pandemics challenges.

\section{Discussion}

\section{Where we stand regarding Global Challenges and Climate Change}

In the Archean Eon (4.0 billion to 2.5 billion years ago), hydrocarboncontaining fossil fuels (coal, petroleum, natural gas, oil shales, bitumens, tar sands, and heavy oils) were arises as an effect of geologic developments acting on the remains of organic matter produced by photosynthesis (most parts formed before the Devonian Period (back 419.2 million to 358.9 million years) from algae and bacteria (Kopp 2020, Nunez 2019). Thus, fossil fuels are a result of a former accumulation of Sun energy in living organisms and its future transformation. 
Yearly, more than $80 \%$ of the produced energy is generated through the combustion of fossil fuels (Koop 2020, Sayre 2010). The fossil coal had been used as a fuel since 1,000 B.C., but only since the Industrial Revolution began to replace biomass as the primary source of energy and a large consumption of oil and natural gas started in the late 1800s and early 1900s and at large scale the rice of theirs utilizing promoted greenhouse gases (GHG) emission with a growing speed (EPA 2018, Kopp 2020, Theodoropoulos 2011). GHG absorb infrared radiation and reradiates it back to the surface that causing planet warmer and Climate change (EPA 2016, 2018, Kopp 2020, UNEP 2019). As a result of anthropogenic activity connected with the combustion of fossil fuel and land-use change atmospheric $\mathrm{CO}_{2}$ vacillated from 275 to 290 parts per million by volume (ppmv) of dry air between the $10^{\text {th }}$ century and at the late increased up to 416 ppmv by 2020, $\mathrm{CH}_{4}$ concentration (sources: incorporate natural gas and petroleum systems, agricultural activities, land use, land-use change and forestry, landfills, coal mining, wastewater treatment, stationary and mobile combustion, and certain industrial processes) increase from 722 parts per billion (ppb) from 1750 to 1,859 ppb by $2018, \mathrm{~N}_{2} \mathrm{O}$ atmospheric concentration has risen by approximately $22 \%$ (sources: biological processes in soil and water and a variety of anthropogenic activities in the agricultural, energy, industrial, and waste management fields) $\left(\mathrm{CO}_{2}\right.$.Earth 2020, EPA, 2016, 2018, Kopp 2020, WEF 2020a). Currently, total GHG emissions by shares of the economic activities are the following: Industry $32.1 \%$, Agriculture $-26.8 \%$ (mostly from agriculture and deforestation), Heat and Electricity Production - 25\% (burning of coal, natural gas, and oil for electricity), and other - 23.5\% (WEF 2020b). Oil is the world's leading fuel and in 2018 oil production and consumption increased by 159 million liters (L)/day, natural gas consumption rose by 195 billion cubic meters, coal consumption - by $1.4 \%$, double its 10-year average growth, electricity generation - above 3.7\% and GHG emission archived maximal level for 7 years British Petroleum 2019). In 2018, total energy investment was nearly $\$ 1.85$ trillion, shares of oil and gas were $\$ 477$ billion and transport biofuel - $\$ 6$ billion (80\% from ethanol production) (IEA 2019a). On whole, fossil energy-related emissions from energy use and industry, which prevail in total GHG emissions, reaching a historical maximum of 37.5 $\mathrm{GtCO}_{2} \mathrm{e}$ in 2018 (IEA 2019a). GHG emission growing stimulates also subsidies to fossil fuels which were $\$ 4.9$ trillion or $6.5 \%$ of global gross domestic product (GDP) in 2013 and later increased to $\$ 5.3$ trillion in 2015 (Cody et al. 2015). Governments subsidizing fossil fuel have several objectives such as declining the cost of fossil fuel energy production and raise/declining the price of energy producers (Avagyan 2018a). Two-thirds of subsidies are realized in the forms of tax expenditures (tax reduction or exemption), accelerated depreciation and capital allowances as well as royalty concessions. The detrimental consequence of fossil fuel subsidies induces the decreasing necessary other expenses such as health, social spending, clean energy, energy access for the poor, etc. Eliminating fossil fuel harmful subsidies will promote the expansion of a green economy and all recognize also that government support should be limited by the WTO Agreement on Subsidies and Countervailing Measures. On the other hand, it will be an arduous agreement as the world oil demand from approximately 14.3 billion L/day 
in 2014 will increase to $16.5-19.1$ billion L/day by 2040 but continuing extraction and combustion of fossil fuels will generate serious environmental threats (Avagyan 2018a). Thus, the record consumption of previously accumulated bioenergy transformed into fossil fuel is the main driver causing Global warming.

The current global land area is 13.2 billion hectares (ha), which only 1.6 billion ha (12\%) is used for cultivation of crops, 3.7 billion ha (28-30\%) - under forest, and 4.6 billion ha (35\%) - comprises grasslands and woodland ecosystems, another part - unsuitable for agriculture (FAO 2011). Agricultural land (includes arable land and pastures) more than $50 \%$ is located in 10 countries and the largest areas are in China, the US, and Australia (OECD-FAO 2017). In 2015, the OECD countries used agricultural land by $34.3 \%$ of their total land (FAO 2018a). Nonetheless, global agricultural land usage decreased by 62 Mha over the past 10 years, which as expected will continue in the followed decade (about 24 Mha) (FAO 2018a). Decreasing of organics, excessive irrigation, exploitation of lowquality water, abuse of synthetic fertilizers, and pesticides are resulting in a reduction of agricultural soil fertility, its dirtying, and reduction. Fertilizer consumption leads also to water pollution and an increase in GHG emissions from chemicals (Avagyan 2018a, WEF 2020b). Due to soil erosion and desertification global suitable land is lost by 19-23 ha per minute (FAO 2011, 2017, 2018a, Zabel et al. 2014). Each year soil erosion and other forms of farming land degradation rate reach capacity of 5-7 million ha, and the application of current technologies could lead to the reduction of $95 \%$ of the agricultural land by 2050 (WEF 2020b). Simultaneously, agriculture and food systems are generated 25$27 \%$ of GHG emissions, $70 \%$ of freshwater exiting (water consumption should double by 2050), and 60-70\% of biodiversity deprivation (FAO 2017, 2018a). On the other hand, a third of global food manufacturing is wasted with the economy lost at $\$ 936$ billion annually and generates $4.4 \mathrm{GtCO}_{2} \mathrm{e}$ or about $8 \%$ of total anthropogenic GHG emissions (FAO 2015, WEF 2020b, 2020c). Simultaneously, Food systems must adapt to a rising global population (Table 1) which can reach around 10 billion by 2050 (FAO 2017).

Table 1. World Population by Year

\begin{tabular}{|l|c|}
\hline Year & World Population \\
\hline 2020 & $7,794,798,739$ \\
\hline 2010 & $6,958,169,159$ \\
\hline 2000 & $6,145,006,989$ \\
\hline 1990 & $5,330,943,460$ \\
\hline 1980 & $4,458,411,534$ \\
\hline 1970 & $3,700,577,650$ \\
\hline 1960 & $3,033,212,527$ \\
\hline 1927 & $2,000,000,000$ \\
\hline 1900 & $1,600,000,000$ \\
\hline 1850 & $1,200,000,000$ \\
\hline 1760 & $770,000,000$ \\
\hline 1700 & $610,000,000$ \\
\hline
\end{tabular}




\begin{tabular}{|l|c|}
\hline 1600 & $500,000,000$ \\
\hline 1500 & $450,000,000$ \\
\hline 1400 & $350,000,000$ \\
\hline 1200 & $360,000,000$ \\
\hline 1000 & $320,000,000$ \\
\hline 900 & $275,000,000$ \\
\hline 800 & $240,000,000$ \\
\hline 700 & $220,000,000$ \\
\hline 600 & $210,000,000$ \\
\hline 200 & $200,000,000$ \\
\hline-200 & $190,000,000$ \\
\hline-500 & $150,000,000$ \\
\hline-1000 & $100,000,000$ \\
\hline-2000 & $50,000,000$ \\
\hline-3000 & $27,000,000$ \\
\hline-4000 & $14,000,000$ \\
\hline-5000 & $7,000,000$ \\
\hline
\end{tabular}

Source: Worldometers 2020.

Malthusian theory predicted the geometric growth of a population and arithmetic rise in food supply (the size of a population is determined by the availability of food) (Agarwal 2020, Chand 2011, Seth 2018, Shermer 2016). However, technological successes have made an important breakthrough and will allow contributing to further overcoming problems to address current food challenges (Dupont 2019, FAO 2018b, USDA 2016a). From 1960 to 2008, the world population has more than doubled (Table 1) but over the last 40 years the production of cereals, oil crops, sugar, horticulture, eggs, and meat increase more than the population growth rate (food consumption per capita increased from an average of $2280 \mathrm{kcal} / \mathrm{person} /$ day at the $1960 \mathrm{~s}$ to $2800 \mathrm{kcal} / \mathrm{person} /$ day) in case that cultivated land area was increased only on 30\% (Wik et al. 2008). From 1960 up to 2015 agricultural production was raised 3 times due to boosting productivity and a substantial increasing in the use of land, water, and other natural resources for agricultural goals (FAO 2015). So, it allows concluding that population growth contributes to a decrease in Global warming due to the accumulation of bioenergy in agricultural products which leads to the capture and storage of carbon in living matter. In most of the economic articles was shown that population growth promotes overall GDP growth and leads to its growth per person (Peterson 2017). In low-income countries, accelerated population increasing is predisposed to be adverse in the short and medium period as can reduce well-being but in the longer period, it can be a positive as an augmenting population will make an effective contribution in economic progress. In the emerging Asian economies, the high grown rate of the population is archive significant advancement in GDP per capita. The Chinese government was introduced the one-child policy as an action to raising the economy and multiplying living standards but as a consequences, since 
1970, 400 million births were prevented (sex-selective abortion) which originated a deficit of 40 million female babies as well as the acceleration of the aging of the population which potentially treat for their economy with a far-ranging global scale (Fifield 2019, Kuo and Wang 2019). On the other hand, a small population reproduction in high-income countries is also to generate social and economic obstacles (Peterson 2017). Migration from low-income countries helps to adjust these imbalances but is opposed by some socioeconomic uncertainties (Peterson 2017). However, economic researches on the relationship between population and economic growth (Peterson 2017) have generated often contradictory results. Therefore, this relationship required description through the direct analysis of the carbon cycle to take in attention that Earths carbon moves between the following reservoirs (Table 2).

Table 2. Amount of Carbon Stored in Different Reservoirs

\begin{tabular}{|l|c|}
\hline Carbon Reservoir & Amount in Gt \\
\hline Atmosphere & 720 \\
\hline Ocean (surface layer) & 670 \\
\hline Ocean (deep layer) & 36,730 \\
\hline Lithosphere (sedimentary rocks) & $60,000,000$ \\
\hline Lithosphere (kerogens) & $15,000,000$ \\
\hline Biosphere (living) & $600-1,000$ \\
\hline Biosphere (dead) & 1,200 \\
\hline Fossil fuels (coal) & 3,510 \\
\hline Fossil fuels (oil) & 230 \\
\hline Fossil fuels (gas) & 140 \\
\hline Fossil fuels (other) & 250 \\
\hline
\end{tabular}

Source: Falkowski et al. 2000.

Human body includes roughly $18 \%$ of carbon by dry weight (dw) (Helmenstine 2019, IPFS 2016, Singer 2012), animals body: 18-25\% (Johnstone 1932), higher plants: 35.8-47.9\% (Ma et al. 2018, Mroczek et al. 2011) and microalgae: 45-70\% (Avagyan 2012, Raja et al. 2014, Schlesinger and Bernhardt 2020). Consequently, any growth of living biomass with the accumulation of bioenergy is a contribution to air carbon removal.

The G20 countries add $78 \%$ of global GHG emissions (UNEP 2019). Their military sectors are one of the sources for these emissions. So, the GHG emission of the US military sector is too many than other developed countries (Ketchell 2019, McCarthy 2019). The military protection of supertankers in the Persian Gulf was contributed $34.4 \mathrm{MtCO}_{2} \mathrm{e}$ per year, the Iraq war result was $43.3 \mathrm{MtCO}_{2} \mathrm{e}$ annually (Bannerman 2018, Liska and Perrin 2010). From 2003 to 2007, the war generated at least $141 \mathrm{MtCO}_{2} \mathrm{e}$ (Liska and Perrin 2010). The conventional and nuclear, etc. warms escalation is one of a top threat as can cause significant shortand long-term decreasing accumulation of bioenergy and conservation of carbon in a living matter as well as the growth of military sectors will stimulating the rising of GHG emissions. Simultaneously, the use of a 15-kilotonne nuclear bomb will result in 17 million deaths and the GHG emission of $690 \mathrm{MtCO}_{2} \mathrm{e}$ (Jacobson 2019). Therefore, world politics must take steps against approaches of present or 
future such warms escalations which are in some doctrines (Tannenwald et al. 2018). Such escalations will influence on the bioenergy accumulation and living standards of current and future populations through the boomerang effect based on Climate change around the world.

Analysis Traces on Formation and Application of Policy and Financial Tools for Mitigation of GHG Emission

The world community must make a Systems analysis to look by all aspects of the policy adopted tools, financial investments, and subsidies as well as priorities of R\&D to define its goals or purposes and discover operations/tools for accomplishing Natural (formed by Nature) and anthropogenic activity systems (Avagyan 2017, 2018a, b, c, 2019). The Kyoto Protocol fixed objectives and obligations of countries that have mandatory legal force but a blunder in environmental results. The Paris Climate Agreement was established only on the accord of countries based on voluntary nationally determined contributions (NDCs). It does not implement any new fundamental global instrument to GHG emission reduction and leaves the choice of measures to national policy-makers. In realness, the Paris Climate Agreement promotes, mostly, instruments of the Kyoto Protocol without well-understood problems and did not give the crucial policy ability to cut down on pollution (expectations of favorable scenarios have a small probability of 50-66\% that can be estimated as an equal probability of arising/no arising). Analyses by results of the Kyoto Protocol and Paris Climate Agreement provide global ineffective management as at their period of action GHG emission was increased by about 52 billion $\mathrm{tCO}_{2} \mathrm{e} /$ year or up to $58 \%$ from 1990 to 2018 (Avagyan 2017, 2018a, Rogelj et al. 2016). Investigation of environmental policy tools such as Carbon pricing, Emissions Trading System, etc. showed that their application has many disadvantages that discourage significantly decreasing pollution (Avagyan 2018a). In 2017, total GHG emission was estimated at 51.9 $\mathrm{GtCO}_{2} \mathrm{e} /$ year and for the $2{ }^{\circ} \mathrm{C}$ emissions gap full implementation required $11-13.5$ $\mathrm{GtCO}_{2} \mathrm{e}$ mitigation by 2030 but in 2018 it reached a record of $55.3 \mathrm{GtCO}_{2} \mathrm{e}$ as well as in case of the current policies it will be $60 \mathrm{GtCO}_{2} \mathrm{e}$ by 2030 (UNEP 2019). In case of the full fulfillment of both unconditional and conditional NDCs, the GHG emission gap will be reduced by about only on 2-3 $\mathrm{GtCO}_{2} \mathrm{e}$, and presented forecast provide that global GHG emissions of 2020 are likely to be at the high rate by the scenarios for the $2^{\circ} \mathrm{C}$ and $1.5^{\circ} \mathrm{C}$ which makes problematic to archive the 2030 and end of the century emission goals (UNEP 2019, WEF 2020a). In such circumstances, the deterioration actions and the Global environmental risks will be growing as the Paris Climate Agreement can only some reduce than eliminate severe Climate change impacts (Avagyan 2018a). If the current GHG emission movement will continue, in the future it expected further upward pressure of emission, and Global temperature would increase between 3 and $4{ }^{\circ} \mathrm{C}$ (Rogelj et al. 2016) as well as the advancing degradation of the global environment (WEF 2020a). In order to restrict global temperature growth to $1.5^{\circ} \mathrm{C}$ GHG emissions necessary drop rapidly to $25 \mathrm{GtCO}_{2} \mathrm{e}$ in 2030 (UNEP 2019). 
Adaptive System responds to the change must be an improvement for human well-being (Avagyan 2018a). The UNEP hoped for big investments for climate action, predominantly from the private sector in case that their investments were only $\$ 81$ billion in 2016 (UNEP 2016) and its approach is not business sound (Avagyan 2017, 2018a). The main attention of investors is on short-term business results prevailing on long-term decarbonization targets (WEF 2020c). According to the ISO/TS 14067 product is any goods or service and, consequently, mitigation of pollution is a product which has high demand from the public (Avagyan 2017, 2018a). For such circumstances, the relation ought on the economic Law of Supply and Demand. Any company, which actions decrease pollution, must get cash for its Life Conserve product. The New policy must admit the Life Conserve industry as the sovereign branch of production (Avagyan 2011, 2017, 2018a). Starting fund of disbursements for Life Conserve results can be created from the incomes of environmental taxes, programs, etc. (Avagyan 2017, 2018a). For this goal, compliance of the common rules and norms will promote rising initiatives and investments in the Global Life Conserve industry, supporting overcome market barriers, developing new environmental business strategies and originating jobs, etc. The indexes for payments can be set by the UNEP data (UNEP 2016) for emission reduction cost of $\$ 100 / \mathrm{tCO}_{2} \mathrm{e}$, elimination of $\mathrm{N}, \mathrm{P}$, etc. from wastewaters - the equivalent cost for their removal of a Water treatment plant, for solid waste costs of anaerobic digestion, etc. that can promote the practicality of such production and draw investments (Avagyan 2017, 2018a). Thus, only the new design of environmental policy to promote an alliance between the economics and environmental policy and applicable innovative financial instruments that can archive adequate investments for GHG reduction (Avagyan 2018a). Hence, the world meets insufficiency and critical governance errors in the development of efficient legislation based on the common guidelines, laws, etc. for the development Live Conserve industry (Avagyan 2017, 2018a).

Policy was formed but can its Tools Fundamentally Reduce GHG Emission? How do we succeed in Circular and Green Economy?

The Paris Climate Agreement as branches for GHG mitigation was noted agriculture, buildings, energy, forestry, industry through stopping deforestation \& forest restoration, restoration of degraded lands, soil carbon enhancement, biochar application, efficient appliances, and passenger cars, solar and wind energy with emission reduction potential up to $22 \mathrm{GtCO}_{2} \mathrm{e} /$ year (UNEP 2016). Improving forest management was its bio-carbon capture and storage (CCS) approach which potential has been estimated at $3 \mathrm{GtCO}_{2} \mathrm{e} /$ year in 2030 (UNEP 2016). The forest is one of the important drivers for the accumulation of bioenergy but the average contribution of forests for the accumulation of air carbon has fallen from 2.8 annually by the 1990 s to $1.8 \mathrm{GtCO}_{2} \mathrm{e}$ in 2014 (FAO 2017). Many states, along with lion's share of G20 members, have declared the goal of net-zero deforestation but often were not maintained intangible works (UNEP 2019). Simultaneously, weighing between this CCS with population growth, effectively land use and food insecurity was not analyzed (Avagyan 2018a). The Paris Climate Agreement CCS 
application of forest developments is inexperienced and could be dubious for the arguments as public acceptance based on forest competition with food production by land and water (Rogelj et al. 2016, Boysen et al. 2017). Terrestrial plants have fixed 500 billion $\mathrm{tCO}_{2}$ /year, but the $\mathrm{CO}_{2}$ capture by planting forests and such capture in agriculture is an insufficient solution as their contribution equals around 3-6\% of fossil fuel GHG emissions (Skjanes et al. 2007). The forests have low photosynthetic efficiency and harvest small power densities (Smil 2016). Thus, the hope on the air $\mathrm{CO}_{2}$ sequestration model by using forest plantations is not an essential workable (Avagyan 2018a, Boysen et al. 2017) that provides also abovelisted small forest CCS potential compared with the aggressive growth of GHG emission of various branches as above listed. On the other hand, the fast growth of wind and solar energy generation for electricity cannot have also an essential influence on the indicator of Global sustainable energy as electricity represents only $20 \%$ of energy consumption (IBRD-WB-IEA 2017). In these circumstances, innovation applications to environmental goals have remained passive, and longterm incentives are needed (UNEP 2019). Hence, primary objectives are shortterm actions by above listed new market-based policy aimed to create incentives for pollution mitigation (Avagyan 2017, 2018a) and a revolution in technologies directs (Avagyan 2011).

The anthropogenic excess of $\mathrm{CO}_{2}$ in the atmosphere mitigated from the atmosphere by carbon sinks in land and ocean (algal) ecosystems (Stocker et al. 2013). The first photosynthetic prokaryotes Cyanobacteria by the morphological structure are not classically algae as having no nucleus and chloroplasts but they are tolerance to various stresses factors such as UV radiation, desiccation, high or low temperatures, and high concentration of salty (Avagyan 2012, 2018a, Pathak et al. 2018) that promoted its bioenergy accumulation and production of $\mathrm{O}_{2}$ in the condition of harsh and biologically lethal UV radiation at start of life evolution. Eukaryotic green algae evolved from Cyanobacteria metabolism which can be only if the level of $\mathrm{O}_{2}$ was archive about $0.2-1.0 \%$ of its present ampleness that occurred by 2.5-1.0 billion years ago (Avagyan 2012, 2018a, Samson 2018, Stocker et al. 2013). Microalgae activity provides $1 / 3$ of total biomass around Earth and more than $50 \%$ of atmospheric $\mathrm{O}_{2}$ (Avagyan 2012, 2018a). They have prevailed as the most effective tool for the primary accumulation of bioenergy compared with higher plants and have the following benefits (Avagyan 2012, 2018a): 1) more efficient accumulating bioenergy (yield/ha) (terrestrial crops have much lesser photosynthetic conversion efficiency (microalgae: 0.25-0.75\%, sugarcane: $0.16 \%$, wheat: $0.024-0.03 \%$, rapeseed: $0.034 \%$ and palm: $0.15 \%$ ), originate large quantities of proteins and lipids and have harvesting cycles of days, 2) can absorb $\mathrm{CO}_{2}$ by 450 t/acre and historically approved by the ability to fix $\mathrm{CO}_{2}$ with efficiency at 10-50 times more compared to terrestrial plants. Due to an advanced tolerance to high $\mathrm{CO}_{2}$ concentrations up to $20 \%$ in the flue gases $\left(\mathrm{CO}_{2}\right.$ part in the atmosphere is around $0.03 \%$ ), the exhaust gases may be applicable for aeration, heating and as nutrients source with a reduction of $\mathrm{CO}_{2}$ share as well as for prolongation (also exhaust steam) of the industrial period. It is a widespread vision that some industrial companies such as cement, steel, etc. have barriers for a transition to low- or zero-carbon technologies (WEF 2020c). Simultaneously, it 
was offered diversification strategy to the growth of the sales for cement, thermoelectric power, and chemical industry as well as for Canadian oil sands operators through the coherent policy of microalgae production aimed to prevent environmental air pollution and improvement of economic indicators of companies (Avagyan 2008a, 2017, 2018a). The US emitted annually more than 6.7 billion metric tons of $\mathrm{CO}_{2}$ and natural gas-fired plants share is 2.1 billion t/year (US Department of Energy 2016). Thus, 1.4 billion tons of algal biomass could be produced by the use of their total $\mathrm{CO}_{2}$ amount of exhaust gas (Langholtz et al. 2016), 3) water demand of open ponds per unit area is analogous to cotton or wheat requirements but less compared to corn. Species can grow in phototrophic, heterotrophic or mixotrophic conditions. Microalgae water consumption and the use of fertilizers can be decreased by the cleaning and reuse of wastewaters and polluted groundwater. Also, the influence of water evaporation as a limiting factor for microalgae commercial manufacturing must be exaggerated (Avagyan 2018a), 4) microalgae cultivation out of agricultural land, farms, and forests allow exclude land limitation for their production (Avagyan 2018a), 5) production is an environmentally preferable process with a low waste content in comparison with other microorganisms and plants. The use of pesticides is eliminated, 6) uniform cell structures allowing more efficient and easier to extract value-added products from biomass.

Biofuels producing based on the transformation accumulated bioenergy of biomass to various fuels (Avagyan 2018a, Avagyan and Singh 2019). At vesicle, combustion liquid biofuels do not produce any sulfur oxides or nitrous oxides as well as $\mathrm{CO}$ emission, polycyclic aromatic hydrocarbons, and particulate matter is less compared with diesel and petrol (Avagyan 2010a, 2012, 2018a). Their market is growing fast (Avagyan 2012, 2018a). In 2018, the biofuels market reached 154.4 billion L or $3.7 \%$ of transport fuel demand (share of bioethanol is $74.5 \%$, biodiesel, and hydrotreated vegetable oil: $27.6 \%$, and other: $0.9 \%$ ) with forecast to boost $25 \%$ to 2024 (IEA 2019b). Currently, the production of the first-generation (1G) biofuel based on using the following main raw material: for ethanol - maize $(17 \%)$, sugarcane (19\%), and for biodiesel production - vegetable oils accounts a considerable share (13\%) of demand (Avagyan 2018a, Avagyan and Singh 2019, OECD-FAO 2017). EU ethanol is originated in general from wheat, maize, and sugar beet, biodiesel - from rapeseed oil (over 50\%) (EC 2017). Biofuel production targets have been subsidized through market price support mechanisms and more 50 countries have its mandated demand (only Brazil is no used such policy as in the main states condition favor to hydrous ethanol production) as well as mixed with other instruments such as tax incentives, etc. (Avagyan 2018a). For energy crops, the US established many support-programs (Avagyan 2018a, TCS 2014). The US taxpayers payments are about $\$ 0.62$ for every dollar of a producerselected crop insurance premiums (Federal Crop Insurance Premium program). $80 \%$ of federal crop insurance premium subsidies allocated to the production 3 major crops - corn, soybeans, and wheat for biofuels of the US and accounted 0.12 cent $/ \mathrm{L}$ subsidies for the mature corn directed to the ethanol industry. The EU member states in 2018 allowed the continuation of subsidies to crop-based biofuels for later 12 years (Keating 2018). In contrast, algae biofuel have not 
adequate support and subsidies similar to oil and crop biofuels as well as committees lobbyists and government actions to modify the risk (Avagyan 2008b, 2017, 2018a). As obstacles for commercialization of algae biofuel are marked the large capital investment, operation costs of biomass production (fertilizers, energy, and freshwater) and technological problems (Avagyan 2008b, 2017, 2018a) (Avagyan 2018a). However, 1) there is an analytical error as compared to the outlay of microalgal biofuel production with the subsided price of oil fuel and $1 \mathrm{G}$ biofuel, 2) macro- and microalgae biomass to biofuels transformation technologies have developed substantially over the past 1-2 decades. Simultaneously, analysis of proposed main approaches to "overcome supposed" economic challenges of algae to biofuels such as nitrogen or phosphate starvation/depletion, genetic engineering, polycultures, and biorefinery showed many uncertainties that arise from the lack of practical application (Avagyan 2018a). On the other hand, many analyzed big data programs and Life Cycle Assessments (LCA) are established on the application of fertilizers for the cultivation of microalgae (Avagyan 2018a). Our analysis of the more well-designed project of US National Renewable Energy Laboratory by the microalgae to biofuel based on phototrophic growth of in open unlined pond of 2,020 ha by the use of anhydrous ammonia $\left(\mathrm{NH}_{3}, 10 \mathrm{t} /\right.$ day $)$ and diammonium phosphate $\left(\mathrm{NH}_{4}\right)_{2} \mathrm{HPO}_{4}, 5 \mathrm{t}$ /day) and with the 10 -acre pond annual average productivity of $25 \mathrm{~g} / \mathrm{m}^{2} /$ day (biomass yield of $38 \mathrm{ton} / \mathrm{acre} / \mathrm{year}$ ) (Davis et al. 2016). Leaning on the ISO/TS 14067, we evaluated the product full Life cycle by daily GHG emission values due to the use of nitrogen fertilizers (Avagyan 2018a). The result showed that only their production realized $63.56 \mathrm{kgCO}_{2} \mathrm{e}$ for each $\mathrm{kg}$ of biotechnologically originated microalgae biomass that exceeding sum of mitigation by algae cultivation $\mathrm{CCS}-1.83 \mathrm{kgCO}_{2} \mathrm{e}$ per $\mathrm{kg}$ biomass, differences between gasoline and diesel emissions by combustion in motor vehicles (gasoline is realized 2.29, biofuel $\mathrm{E} 10-2.21$ and $\mathrm{E} 85-1.61 \mathrm{kgCO}_{2} / \mathrm{L}$, diesel $-2.7 \mathrm{kgCO}_{2} / \mathrm{L}$, biodiesel $\mathrm{B} 5-2.65$ and $\mathrm{B} 20-2.62 \mathrm{kgCO}_{2} / \mathrm{L}$ ) as well as the amount of crude oils extraction-to-refining (4 to $50 \mathrm{gCO}_{2} \mathrm{e} /$ megajoule $(\mathrm{MJ}$ ) and combustion in motor vehicle emissions of $73 \mathrm{gCO}_{2} \mathrm{e} / \mathrm{MJ}$ ). Our evaluation confirms - nitrogen fertilizers in which production is consumed a large volume of natural gas should not be used in the production of microalgae biomass, as well as commercial biomass phototrophic growth technology based on the application of only fertilizers, cannot provide GHG emission mitigation (Avagyan 2018a). Unfortunately, this NPEL design originates also the uncertainties connected with the planned productivity of microalgae, construction of unlined ponds, and the probability of polluting groundwater by fertilizers as well as the safety of staff and environment. Simultaneously, our research on the many wastewater contents, food waste, etc. was shown that their microalgae bioremediation conjugate with their profitable biomass manufacturing has a high unrestricted potential which unaccustomed (Avagyan 2008b, c, 2010a, 2011, 2012, 2013, 2018a). Besides, the use of food waste as a nutrient for microalgae biomass producing may originate GHG emission reduction equal to $3.3 \mathrm{GtCO}_{2} \mathrm{e} /$ year or $8 \%$ of overall emissions as a result of reducing its origin (Avagyan 2018a).

In total, the manufacturing of fertilizers, food storage, and packaging make 1/3 of wholly anthropogenic GHG emissions (whole food system: 9,800-16,900 
$\mathrm{MtCO}_{2} \mathrm{e}$; fertilizer manufacturing: $575 \mathrm{MtCO}_{2} \mathrm{e}$, and refrigeration: $490 \mathrm{MtCO}_{2} \mathrm{e}$ ) (Gilbert 2012) as well as consumes 1\% of the world's energy and for soil fertilization, the US farmers expend $3 \mathrm{kcal}$ of fossil energy or on a par with $20.8 \mathrm{~L}$ of fossil fuels/acre/year to produce $1 \mathrm{kcal}$ of food energy (Connelly 2011). The fertilizers using promote progressive degradation of soil organic matter, and water (Avagyan 2018a, European Environment Agency 2018, Gilbert 2012, Xie et al. 2017). It is well known that nitrogen fertilizers production originates large GHG emission of 3.6-3.7 $\mathrm{tCO}_{2} \mathrm{e}$ to each ton of nitrogen amount, potash fertilizer production creates GHG emission at $0.095-0.161 \mathrm{tCO}_{2} \mathrm{e}$ per ton, as well as an emission factor of phosphate fertilizer plants equal $0.57 \mathrm{~kg} \mathrm{CO}_{2} \mathrm{e} / \mathrm{kg} \mathrm{P}_{2} \mathrm{O}_{5}$ (Avagyan 2018a, Avagyan and Singh 2019). Our stressed issue (Avagyan 2018a) is the fact that in 2016, $1 \mathrm{G}$ biofuel production promoted expansion of fertilizer industry and nitrogen fertilizer consumption directed to biofuels manufacturing was the following: in the US - maize to ethanol - 2.2, Europe - rapeseed to biodiesel -0.6 , Brazil - sugarcane to ethanol -0.3 and other countries -0.4 million tons (Yara 2018) corresponding to about 3.2\% of global nitrogen fertilizer consumption (Yara 2020). To address this challenge, we recommended that manufacturers of IG biofuel must make displacement to the use of feedstock originating by the Principles of Organic Agriculture (Avagyan 2018a) with avoiding the use of fertilizers, pesticides, etc. (EC 2020a, IFOAM 2020, USDA 2016b). Simultaneously, microalgae Chlorella suspension watering of the agricultural plant (wheat, rice, etc.) improve the soil's mineral and organic composition, increase the content of $\mathrm{O}_{2}$, water binding, etc. in soil with producing of good environmental impact and was caused 10-20\% growth of the various crops yields in large scale field trials (Avagyan 2010a, 2012, 2018a) fertilization of dried Chlorella biomass improves crop production compared to a commercially available inorganic fertilizer: increase $21 \%$ taller and yielded $25 \%$ more (Connelly 2011) as well as it was recommended the application of microalgae in the hydroponic system as biostimulants and biofertilizers (Ronga et al. 2019).

At the same time, the UK Royal Academy of Engineering and 181 Holland scientists concluded that manufacturing of several biofuels from food crops such as biodiesel, etc. originated more GHG emissions and have much an unfavorable impact on climate, nature, and peoples compared to diesel arisen from fossil fuels (Lane 2017, UK Royal Academy of Engineering 2017). Their analyses were based on the estimations of the Direct and Indirect Land Use Change. However, the published researches of Land Use Changes have a weighty fluctuation in the results (UK Royal Academy of Engineering 2017). Therefore, we evaluated direct agro-chemicals influence on rapeseed biodiesel production (Avagyan and Singh 2019). From rapeseed feedstock, it can be produced biodiesel of about $1000 \mathrm{~L} / \mathrm{ha}$ (Avagyan and Singh 2019, EC 2020b, Farm Energy 2019, Nickel 2011). Nitrogen requirements for rapeseed feedstock range from $135-183 \mathrm{~kg} / \mathrm{ha}(\mathrm{EU})$ to $112-168$ $\mathrm{kg} / \mathrm{ha}$ (US), phosphorus fertilizer: $29-69 \mathrm{~kg} / \mathrm{ha}$ and potassium fertilizer: $110-160$ $\mathrm{kg} / \mathrm{ha}$ (Avagyan and Singh 2019). The summary production of these fertilizers creates $\mathrm{GHG}$ emission of $0.9-1.2 \mathrm{kgCO}_{2} \mathrm{e} / \mathrm{L}$ biodiesel. Moreover, it was indicated that using fertilizers originates an additional emission, exceeding the emission of their production at 2.0-5.5 times (Fertilizers Europe 2015). GHG emission of 
land-use changes (for fossil diesel is $0.13 \mathrm{kgCO}_{2} \mathrm{e} / \mathrm{GJ}$ and for rapeseed biodiesel is $0.016 \mathrm{kgCO}_{2} \mathrm{e} / \mathrm{GJ}$ (HHV) (IEA 2015). Fossil diesel combustion emission is 2.7 and biodiesel B100 is $2.5 \mathrm{~kg} \mathrm{CO}_{2} \mathrm{e} / \mathrm{L}$ (Anderson 2011, Avagyan and Singh 2019, British Columbia Ministry of Environment 2014, IEA 2015). Hence, the manufacturing and use of fertilizers for the growth of rapeseed feedstock intended for biodiesel manufacturing generate more GHG emission compared with GHG emission mitigation by biodiesel at motor combustion.

The principal dilemma in the use of $1 \mathrm{G}$ biofuels is their influence on the food security, challengers of land and water accessibility as well as the impact on the food and feed prices (Avagyan 2008b, 2010a, 2012, 2018a, UK Royal Academy of Engineering 2017). In 2013, for producing of 86 million tons of $1 \mathrm{G}$ biofuels were used area of about 41.3 Mha or $4 \%$ of the global arable area and 216 billion cubic meters of water or $3 \%$ of the worldwide water uptake for food production (Rulli et al. 2016). The placement of policy for bioenergy crop for growth of biofuel production could require up to 54 Mha by 2030 or up to $3.8 \%$ of available arable land as well as 1.5 billion ha could be under biofuel crops by 2050, equivalent to current total global farmland (FAO 2020) as well as 700 Mha by the end of the century and converting such massive area of land to monocultures has clear unfavorable consequences for food production and nature (WEF 2020a). Currently, for producing $1 \mathrm{G}$ biofuels it has consumed $5.5 \%$ of world cereals and $8 \%$ of world vegetables (Searchinger 2020). It follows that the above-listed data are required a mandatory downward revision of planning volume and technology of producing $1 \mathrm{G}$ biofuel.

It was offered a conglomerate diversification strategy for Canadian oil sand operators including also microalgae biofuel manufacturing based on the use of their effluent gases as well as food waste (Avagyan 2017). Microalgae biomass has great market potential in many niches that allow a firm to add related products or markets in addition to biofuel. At present, about 9,200-13,600 tons dw of microalgae are annually produced worldwide (almost exclusively in open ponds) in general as additives for human consumption, perfumery, and aquaculture (Avagyan 2018a). The microalgae market was estimated at $€ 3.5-5$ billion in 2014 (Chy 2017) and is expected to achieve \$44.6 billion in 2023 (García et al. 2017). Macro- and microalgae commercial installations are worldwide: Europe has 430 micro- and 132 macroalgae companies with an economic value of more than $€ 1.69$ billion/year), North America: 105, Asia: 26, Oceania: 2 and Middle East: 7), macroalgae production is 19-23 million ton $\mathrm{dw}$ and their market are estimated at \$5-6 billion (Avagyan 2018a).

Presently, fruits and vegetables incorporate little key nutrients such as proteins (on $6 \%$ ), vitamin $\mathrm{B}_{2}$ (on $38 \%$ ), vitamin $\mathrm{C}$, phosphorus, calcium, iron, etc. compared to past (Avagyan 2008d, 2012, 2018a, Davis et al. 2004). This can also have its contribution on registered non-communicable diseases such as cardiovascular or mental illness substitution by infectious illnesses which currently the leading cause of death (WEF 2020a) as well as increase probability of pandemics linked to low-quality diets (Avagyan 2008d, 2010b). For increasing the immunity system of humans and animals to infections, long-term priorities must be the use of microalgae bioenergy in diets as they have high quantities of proteins 
(50-70\%, $15-17 \%$ in wheat, and up to $50 \%$ in meat), amino acids, a fairly big quantities of vitamins $\mathrm{B}_{1}, \mathrm{~B}_{2}, \mathrm{~B}_{3}, \mathrm{~B}_{6}, \mathrm{~B}_{12}, \mathrm{E}, \mathrm{K}, \mathrm{D}$, up to $30 \%$ lipids, 8-10\% carotene, macro- and microelements, etc., in comparison with other plants or animals and algae applied in the human diet for thousands of years (Avagyan 2010a, b, 2012, 2018a). Their biomass is used also for at large scale production of carotenoids and astaxanthin as well as microalgae biomass can be used for a variety Biopharma product developments such as omega-3-fatty acids, arachidonic, eicosapentaenoic acids, stimulator of T-cells which largely improving the protecting ability of the immune system toward diseases like cancer, hypoglycemia, and bacteria, etc. (Avagyan 2010b, 2012, 2018a). Researches of the epidemiology of influenza and COVID-19 showed that vitamins B, C, D, zinc, etc. which may have influences on how people immune system works to fight off infections can be a useful tool to reduce risk (CDC 2020, Grant et al. 2020, Maghbooli et al. 2020, MedicineNet 2020, Narayanan and Nai 2020). Hence, microalgae have a high potential for present and future food security and human health.

In 2015-2017 the worldwide demand for feed was 1.6 billion tons and is supposed to increase up to 1.9 billion tons in 2027 with an annual growth rate of around 1.7\% (OECD-FAO 2018). Throughout past years, the commercial goal of farmers was to gain the feed high assimilability which mainly was achieved by supplementation of cellulose hydrolysis enzymes as well as using small concentrations of powdered activated carbon (Avagyan 2008d, 2012). This unilateral formulation promotes decreasing product quality and the ability of animals immune system toward diseases. As a result growth of the mass epidemics amid animals and poultries in many states were evidenced. Since the 1970s, the former USSR established the industrial cultivation of microalgae (more than five hundred installations) for the production of microalgal feed additives (Avagyan 2008d, 2012, 2018a). On a large scale, it was shown that Chlorella suspension, pasta, and powder act as excellent feed supplements and boost the middle daily weight of cattle, sheep, poultry, fish, etc. on 11-20\%; cow milk production on 17$20 \%$; and poultry egg-laying on 10-20\%. The account showed that producing of microalgae biomass of 417,659 t/year for addition like $1 \%$ feed additive can costeffectively satisfy the demand of Top 6 high feed consumed countries for total feed additive by China at $23.2 \%$, the US - at $21.1 \%$, Russia - at $143.5 \%$, Germany - at $174.8 \%$, Japan - at $178.5 \%$, and France - at $417.7 \%$ or they total feed additive demand of broiler branch - at $32.3 \%$ as well as common feed additive demand of aquaculture at 216.4\% (Avagyan 2017, 2018a). Simultaneously, the expected fishmeal demand in 2025 will be $5.1 \mathrm{Mt}$ and in case of fishmeal substitution by microalgae, it will allow mitigation of $9.33 \mathrm{MtCO}_{2} \mathrm{et} / \mathrm{year}$ (Avagyan 2018a, WEF 2018). On the other hand, up to 2030, the global animal protein consumption replacement by alternative proteins (such as microalgae) on $10-15 \%$ will have the consequence of GHG emission reducing up to 550-950 $\mathrm{MtCO}_{2} \mathrm{e} /$ year (WEF 2018). At the same time, antibiotics use in animal production results in arisen antibiotic-resistant bacteria that are pathogenic to humans and animals, and therefore many countries removed antibiotic growth promoters from animal diets (Avagyan 2008d, 2010a, 2012, 2018a). As an antibiotic alternative, it was offered organic acids and the use of essential or botanical oils. In this context, the use of 
microalgae Chlorella additive may be the better decision as incorporate natural organic acids: hexadecatetraenoic $\left(\mathrm{C}_{16} \mathrm{H}_{24} \mathrm{O}_{2}\right)$ up to 7-8\% of total fatty acid content and octadecatetrienoic $\left(\mathrm{C}_{18} \mathrm{H}_{30} \mathrm{O}_{2}\right)$ acid together with oxy, aldehyde, and keto acids (Avagyan 2008d, 2012, 2018a). Due to the content of these acids, Chlorella has applied also for feed storage.

\section{Conclusions}

The possibility of origination and evolution of the life landforms were the results of bioenergy accumulation by microalgae which promoted decreasing $\mathrm{CO}_{2}$ and the growth of $\mathrm{O}_{2}$ contents (up to $35 \%$ ) in the atmosphere that facilitates also creating stratospheric $\mathrm{O}_{3}$ layer protecting the life from biologically lethal Sun UV radiation. In the Archean Eon, bioenergy accumulation by plants and its biomass further geologic transformation to fossil fuel which consumption in energy, industry, and agriculture since the late 1800s and early 1900s increase with a growing speed GHG emission inducing Climate change. Simultaneously, as a result of anthropogenic activities fixed lost forests and their role in accumulation air carbon and bioenergy, degradation of agricultural land, and water resource. What is the most hopeful and conceptual tool for sustainable development and move to the circular economy? Our former theory (Avagyan 2008b, 2012) is modeled from reality which has a history of some million years of implementation and devoted to life existence and solving problems of anthropogenic activity with the transition toward a bioeconomy and must the use in decision-making as algorithms to build the future. At present, the contribution of algae remains dominant in reducing $\mathrm{CO}_{2}$ and maintaining $\mathrm{O}_{2}$ level in the atmosphere. Historically, microalgae are the better organisms for the active accumulation of bioenergy compared with higher plants, have a high potential for the present and future food security and human health, can be cultivated away from agricultural land, for cleaning wastewaters and groundwater, improve the soil's mineral composition through increase content of organics, oxygen, water binding, etc. with the shift towards the elimination of the use of fertilizers, can cost-effectively satisfy the demand in high-quality feed additives and increasing product yields of agricultural animals as well as serving as feed antibiotic alternative and means against pandemics. Population growth and its needs in foods stimulate the accumulation of air carbon and bioenergy. However, the application of fertilizers, certainly, was promoted to a growing volume of agricultural production and population but their production and use originated large GHG emissions. Consequently, there is a big conceptual need to shift on organic agriculture including algae fertilization of soil to contribute to decreasing environmental degradation and long-term sustainability.

In the Energy branch, the current situation is unwanted in the area of biofuels policy as the collected data provides that currently used technology for $1 \mathrm{G}$ biofuels production as well as microalgae to commercial biofuel technology based on biomass phototrophic growth by the use of fertilizers is induced aggressive increasing GHG emission instead of their mitigation. Any decision-makers, experts, or journalists can account and get the obvious results that the governments 
subsided oil and $1 \mathrm{G}$ biofuel technologies which are increased GHG emissions. Microalgae biofuel has big potential in case the use of wastewaters and food waste for biomass growth towards sustainable system configuration. Such an approach will be the best solution for mitigation GHG emissions, restoration of water resources, and reuse materials as well as engage a diversification strategy as a way for boosting the companies' growth rate. Decision-makers need better verification and inventory data by the production of raw material to the final product such as $1 \mathrm{G}$ biofuel, to set measurable targets, design, and monitor implementation by ISO 14064 for biofuels and food security initiatives. System analyses provide that the main obstacle to the implementation of algae biofuel potential is unproductive policies that make complications in the connection of the goals of economic development and environmental activity.

In this context, the conventional and nuclear warms escalation is one of a top threat as can cause decreasing accumulation of bioenergy and conservation of carbon in organisms as well as the development of military sectors to move to the rising of GHG emissions.

Analyses of the Kyoto Protocol, Paris Climate Agreement, Emissions Trading system, carbon prices, etc. results provide that their application has many disadvantages which discourage significantly decrease pollution and environmental failures. It was fixed that the world is edging closer to the point of no return (Guterres 2020) but the member-parties of the Paris Climate Agreement unlearning lessons from the low effectiveness by solving large-scale environmental problems. The UNEP hoped to attract enough private investment for climate action, but its offered approach is not business sound. A philanthropic approach to environmental issues can take place, but the severity of the challenges requires the creation of economic incentives to ensure the preservation of life conditions. For such circumstances, the relation ought on the economic Law of Supply and Demand. The New policy must be founded on the acceptance of the Life Conserve industry that will allow mobilizing private finance to climate actions. Summarizing the issues described above, the world community must start preparing a tougher new arrangement with a change in organizational, political, financial, and technological choices.

Our theory includes generalized explanations of how nature works, confirmed by pieces of evidence, cover predictions for further technological developments towards economically and environmentally sustainable industrial processes as well as provides the role of bioenergy accumulation and transformation for improved understanding about evolution, influences of anthropogenic activity, decisionmakers errors, technological choices, pandemics prevention, and the necessary skills toward the innovation algae-based system. Microalgae are the most optimal and productive means for accumulating excess solar radiation, transforming it into bioenergy with a direct effect on mitigation of global warming and Climate change, removal of GHG emission as well as promoting food, feed, and energy security and human health. Therefore, the conceptual shift of the world community must be the advancement of algae system technologies worldwide application for fostering sustainable development. 


\section{References}

Agarwal P (2020) Malthusian theory of population. Intelligent Economist. Retrieved from: https://www.intelligenteconomist.com/malthusian-theory/. [Accessed 2 March 2020]

Akihiko I, Oikawa T (2004) Global mapping of terrestrial primary productivity and light-use efficiency with a process-based model. In M Shiyomi et al. (eds.), Global Environmental Change in the Ocean and on Land, 343-358. Tokyo: TERRAPUB.

Albany University (2020) Formation of the ozone layer. Retrieved from: https://www.al bany.edu/faculty/rgk/atm101/ozone.htm. [Accessed 1 June 2020]

Anderson LG (2011) Effects of biodiesel fuel use on vehicle emissions. In World Renewable Energy Congress, Sweden, 8-13 May.

Ashok S (2020) Solar energy. Encyclopaedia Britannica. Retrieved from: https://www.bri tannica.com/science/solar-energy. [Accessed 1 June 2020]

Avagyan A (2008a) Global prospects for microalgae production for biofuels and for the preservation of nature. Global Fuel Magazine 2(Feb): 22-27.

Avagyan AB (2008b) A contribution to global sustainable development: inclusion of microalgae and their biomass in production and bio cycles. Clean Technologies and Environmental Policy 10(4): 313-317.

Avagyan A (2008c) Microalgae production development global prospects and profitable technology wasterwater purification by the use microalgae. Water World 9. Retrieved from: https://bit.ly/31c17Di. [Accessed 1 June 2020]

Avagyan A (2008d) Microalgae: big feed potential in a small package. Feed International, 16-18. Retrieved from: http://www.wattagnet.com/articles/368-microalgae-big-feedpotential-in-a-small-package. [Accessed 1 June 2020]

Avagyan AB (2010a) New design \& build biological system addressed to global environment management and sustainable development through including microalgae and their biomass in production and bio cycles. Journal of Environmental Protection 1(2): 183-200.

Avagyan AB (2010b) New design of biopharmaceuticals through the use of microalgae addressed to global geopolitical and economic changes. Are you ready for the new development in biopharma? Pharmacology \& Pharmacy 1(1): 33-38.

Avagyan AB (2011) Water Global recourse management through the use of microalgae addressed to new design \& build biological system and sustainable development. Clean Technologies and Environmental Policy 13(3): 431-445.

Avagyan AB (2012) Theory of global sustainable development based on including of microalgae in bio and industrial cycles. New design and building of biological system. CreateSpace Independent Publishing Platform. Amazon.

Avagyan AB (2013) Theory of global Sustainable development based on microalgae in Bio and Industrial cycles, management-changing decisions in areas of Climate change and waste management. Journal of Sustainable Bioenergy Systems 3(4): 287-297.

Avagyan AB (2017) Environmental building policy by the use of microalgae and decreasing of risks for Canadian oil sand sector development. Environmental Science and Pollution Research 24(25): 20241-20253.

Avagyan AB (2018a) Algae to energy and sustainable development. technologies, resources, economics and system analyses. New design of global environmental policy and live conserve industry. Amazon.

Avagyan AB (2018b) The use of microalgae for biofuel production and need in improvements of global environmental policy. Journal of Fundamentals of Renewable Energy and Applications 8(Jul): 93. 
Avagyan AB (2018c) Climate change, necessities of change in global environmental policy and microalgae application. Journal of Earth Science \& Climatic Change 9.

Avagyan AB (2019) Truly coherent policies of microalgae with food technologies. Journal of Nutrition \& Food Sciences 8(Sep).

Avagyan AB, Singh B (2019) Biodiesel: Feedstocks, technologies, economics and barriers. Assessment of environmental impact in producing and using chains. Springer.

Bannerman S (2018) Is climate the worst casualty of war? Common Dreams. Retrieved from: https://www.commondreams.org/views/2018/07/31/climate-worst-casualtywar. [Accessed 31 July 2018]

Berkowit R (2014) New and old ideas about earth's oxygen history. Physics Today.

Boysen LR, Lucht W, Gerten D, Heck VT, Lenton MH, Schellnhuber J (2017) The limits to global-warming mitigation by terrestrial carbon removal. Earth Future 5(5): 463-474.

British Columbia Ministry of Environment (2014) Best practices methodology for quantifying greenhouse gas emissions. Retrieved from: https://bit.ly/3dw96Qi. [Accessed 5 June 2014]

British Petroleum (2019) 2018 at a glance. Retrieved from: https://on.bp.com/37bBG8L. [Accessed 5 March 2019]

Burkeman O (2010) Why everything you've been told about evolution is wrong. The Guardian. Retrieved from: https://bit.ly/3k9Y6Li. [Accessed 19 March 2010]

CDC - Centers for Disease Control and Prevention (2020) Food and coronavirus disease 2019. CDC. Retrieved from: https://www.cdc.gov/coronavirus/2019-ncov/daily-lifecoping/food-and-COVID-19.html. [Accessed 22 August 2020]

Chand S (2011) Malthusian theory of population: Criticisms and applicability. Your Article Library. Retrieved from: https://bit.ly/3jab8ak. [Accessed 10 November 2011]

Chy W (2017) Algal cultivation blooming as production methods look to unleash its power. Nutraingradients. Retrieved from: https://bit.ly/3dupcdr. [Accessed 30 August 2017]

$\mathrm{CO}_{2}$.Earth (2020) Earth's $\mathrm{CO}_{2}$ home page. Retrieved from: https://www.co2.earth/. [Accessed 30 April 2020]

Cody D, Parry I, Sears L, Shang B (2015) How large are global energy subsidies? International Monetary Fund. Retrieved from: https://bit.ly/3k4DxzN. [Accessed 10 May 2015]

Connelly R (2011) How algal biofertilizers can accelerate sustainable agriculture. Austin, USA: The University of Texas at Austin.

Davis DR, Epp MD, Riordan HD (2004) Changes in USDA food composition data for 43 garden crops, 1950 to 1999. Journal of the American College of Nutrition 23(6): 669-682.

Davis R, Markham J, Kinchin C, Grundl N, Tan ECD (2016) Process design and economics for the production of algal biomass: algal biomass production in open pond systems and processing through dewatering for downstream conversion. US National Renewable Energy Laboratory.

Dupont (2019) Investment insights global equities. Retrieved from: https://dupontcapital. com/wp-content/uploads/2019/02/2019.02-Betting-on-Human-Ingenuity.pdf. [Accessed 10 February 2019]

EC - European Commission (2017) Report from the commission to the European parliament, the council, the European economic and social committee and the committee of the regions renewable energy progress report. European Commission.

EC (2020a) Organic farming statistics. European Commission.

EC (2020b) Biofuel production by farmers. European Commission. 
EIA - US Energy Information Administration (2019) What is energy? US Energy Information Administration.

Encyclopaedia (2020) Energy. Retrieved from: https://www.britannica.com/science/ene rgy. [Accessed 29 May 2020]

EPA - US Environmental Protection Agency (2016) Greenhouse gas inventory guidance direct emissions from mobile combustion sources. Center for Corporate Climate Leaderships. US Environmental Protection Agency.

EPA (2018) Inventory of US greenhouse gas emissions and sinks: 1990-2016. US Environmental Protection Agency.

European Environment Agency (2018) Annual European union greenhouse gas inventory 1990-2016 and inventory report 2018. Submission to the UNFCCC Secretariat. European Environment Agency.

Falkowski P, Scholes RJ, Boyle E, Canadell J, Canfield D, Elser J et al. (2000) The global carbon cycle: a test of our knowledge of earth as a system. Science 290(5490): 291-296.

FAO - Food and Agriculture Organization of the United Nations (2011) The state of the world's land and water resources for food and agriculture (SOLAW) - Managing systems at risk. Food and Agriculture Organization of the United Nations.

FAO (2015) Food wastage footprint \& Climate change. Food and Agriculture Organization of the United Nations.

FAO (2017) The future of food and agriculture - trends and challenges. Food and Agriculture Organization of the United Nations.

FAO (2018a) Restoring the land. Food and Agriculture Organization of the United Nations.

FAO (2018b) Transforming food and agriculture to achieve the SDGs. Food and Agriculture Organization of the United Nations.

FAO (2020) What effect will biofuels have on forest, land and poor people's access to it? Food and Agriculture Organization of the United Nations.

Farm Energy (2019) Rapeseed and canola for biodiesel production. Retrieved from: https://farm-energy.extension.org/rapeseed-and-canola-for-biodiesel-production/. [Accessed 14 October 2020]

Fertilizers Europe (2015) Energy efficiency and greenhouse gas emissions in European mineral fertilizer production and use. Retrieved from: https://issuu.com/efma2/docs/ energy_efficiency_v9. [Accessed 10 March 2015]

Fifield A (2019) Beijing's one-child policy is gone. But many Chinese are still reluctant to have more. The Washington Post.

García JL, de Vicente M, Galán B (2017) Microalgae, old sustainable food and fashion nutraceuticals. Microbial Biotechnology 10(5): 1017-1024.

Gilbert N (2012) One-third of our greenhouse gas emissions come from agriculture. Nature News.

Grant WB, Lahore H, McDonnell SL, Baggerly CA, French CB, Aliano JL et al. (2020) Evidence that vitamin D supplementation could reduce risk of influenza and COVID19 infections and deaths. Nutrients 12(4): 988.

Guterres A (2020) Secretary-general's remarks to the general assembly on his priorities for 2020. United Nations.

Helmenstine AM (2019) Chemical composition of the human body. ThoughtCo.

HHMI - Howard Hughes High Medical Institute (2020) Geological history of oxygen. Howard Hughes High Medical Institute.

IBRD-WB-IEA - International Bank for Reconstruction and Development-World BankInternational Energy Agency (2017) Sustainable energy for all Global tracking framework. Progress toward sustainable energy. International Bank for Reconstruction and Development-World Bank-International Energy Agency. 
IEA - International Energy Agency (2015) Biodiesel GHG emissions, past, present, and future. International Energy Agency.

IEA (2019a) World energy investment 2019. International Energy Agency.

IEA (2019b) Renewables. Market analysis and forecast from 2019 to 2024. International Energy Agency.

IFOAM - International Federation of Organic Agriculture Movements (2020) Principles of organic agriculture. International Federation of Organic Agriculture Movements.

IPFS - InterPlanetary File System (2016) Composition of the human body. InterPlanetary File System.

Jacobson MZ (2019) Evaluation of nuclear power as a proposed solution to Global warming, Air pollution, and energy security. Cambridge, UK: Cambridge University Press.

Johnstone J (1932) Chemical composition of the animal body. Nature 130(Dec): 890.

Keating D (2018) Despite EU palm oil ban, biofuel problems will continue. DW Akademie.

Ketchell M 2019 US military is a bigger polluter than as many as 140 countries shrinking this war machine is a must. The Conversation.

Kopp OC (2020) Fossil fuel. Encyclopaedia Britannica. Retrieved from: https://www.bri tannica.com/science/fossil-fuel. [Accessed 28 March 2020]

Kuo L, Wang X (2019) Can China recover from its disastrous one-child policy? The Guardian.

Lane J (2017) Letter sent to Dutch cabinet by 178 Dutch scientists urges end to food-based biofuels. Biofuels Digest.

Langholtz MH, Stokes BJ, Eaton LM (2016) 2016 Billion-ton report: advancing domestic resources for a thriving bioeconomy. Volume 1: economic availability of feedstocks. US Department of Energy.

Liska AJ, Perrin RK (2010) Securing foreign oil: a case for including military operations in the Climate change. Impact of fuels. Environment Science and Policy for Sustainable Development 52(4): 9-22.

Ma S, He F, Tian D, Zou D, Yan Z, Yang Y et al. (2018) Variations and determinants of carbon content in plants: a global synthesis. Biogeosciences 15(3): 693-702.

Maghbooli Z, Sahraian MA, Ebrahimi M, Pazoki M, Kafan S, Tabriz HM, et al. (2020) Vitamin D sufficiency, a serum 25-hydroxyvitamin D at least $30 \mathrm{ng} / \mathrm{mL}$ reduced risk for adverse clinical outcomes in patients with COVID-19 infection. PLOS ONE 15(9): e0239799.

McCarthy N (2019) The US military emits more $\mathrm{CO}_{2}$ than many industrialized nations. Forbes.

MedicineNet (2020) 20 Vitamins and supplements to boost immune health for COVID-19. Retrieved from: https://bit.ly/3dAon2D. [Accessed 10 May 2020]

Mroczek K, Kalisz S, Pronobis M, Sołtys J (2011) The effect of halloysite additive on operation of boilers firing agricultural biomass. Fuel Processing Technology 92(2): 845-855.

Narayanan N, Nai DT (2020) Vitamin $B_{12}$ may inhibit RNA-dependent-RNA polymerase activity of nsp12 from the SARS-CoV-2 virus. IUBMB Life 72(10): 2112-2120.

Nickel R (2011) Canola's biodiesel advantage. Successful Farming. Retrieved from: https://www.agriculture.com/crops/other-crops/canola/colas-biodiesel-advtage_155ar18799. [Accessed 11 March 2011]

Nunez C (2019) What are fossil fuels? US National Geographic Society.

OECD-FAO - Organisation for Economic Co-operation and Development-Food and Agriculture Organization of the United Nations (2017) Agricultural outlook 20172026. Organisation for Economic Co-operation and Development-Food and Agriculture Organization of the United Nations. 
OECD-FAO (2018) Agricultural outlook 2018-2027. Organisation for Economic Cooperation and Development-Food and Agriculture Organization of the United Nations.

Pathak J, Rajneesh, Maurya PK, Singh SP, Häder DP, Sinha RP (2018) Cyanobacterial farming for environment friendly sustainable agriculture practices: Innovations and perspectives. Frontiers in Environmental Science 6(Feb): 7.

Peterson EWF (2017) The role of population in economic growth. SAGE Open 7(4): 1-15.

Raja R, Shanmugam H, Ganesan V, Carvalho IS (2014) Biomass from microalgae: an overview. Oceanography 2(1): 118-124.

Roach TNF, Salamon P, Nulton J, Andresen B, Felts B, Haas A et al. (2018) Application of finite-time and control thermodynamics to biological processes at multiple scales. Journal of Non-Equilibrium Thermodynamics 43(3): 193-210.

Rogelj J, den Elzen M, Höhne N, Fransen T, Fekete H, Winkler H et al. (2016) Paris Agreement climate proposals need a boost to keep warming well below $2{ }^{\circ} \mathrm{C}$. Nature 534(7609): 631-639.

Ronga D, Biazzi E, Parati K, Carminati D, Carminati E, Tava A (2019) Microalgal biostimulants and biofertilisers in crop productions. Agronomy 9(4): 192-213.

Rulli M, Bellomi D, Cazzoli A, De Carolis G, D'Odorico P (2016) The water-land-food nexus of first-generation biofuels. Scientific Reports 6(Mar): 22521.

Samson P (2018) Evolution of the atmosphere: composition, structure and energy. Michigan, USA: Michigan University.

Sayre R (2010) Microalgae: The potential for carbon capture. BioScience 60 (9): 722-727.

Schlesinger WH, Bernhardt ES (2020) Biogeochemistry: an analysis of global change. Amazon.

Searchinger T (2020) Biofuels and land use. Princeton, USA: Princeton University.

Seth T (2018) Malthusian theory of population: explained with its criticism. Your Article Library. Retrieved from: http://www.economicsdiscussion.net/articles/malthusiantheory-of-population-explained-with-its-criticism/1521. [Accessed 12 May 2011]

Shermer M (2016) Why Malthus is still wrong. Why Malthus makes for bad science policy. Scientific American 314(5): 72.

Singer G (2012) What does carbon do for human bodies? Azcentral.

Skjanes K, Lindblad P, Muller J (2007) BioCO $_{2}$-A multidisciplinary, biological approach using solar energy to capture $\mathrm{CO}_{2}$ while $\mathrm{H}_{2}$ and high value products. Biomolecular Engineering 24(4): 405-413.

Smil V (2016) Energy transitions: global and national perspectives. $2^{\text {nd }}$ Edition. Praeger, ABC-CLIO.

Stocker TS, Qin D, Plattner GK (2013) Technical summary. In Climate Change 2013: The Physical Science Basis Contribution of Working Group I to the Fifth Assessment Report of the Intergovernmental Panel on Climate Change. Cambridge, UK: Cambridge University Press.

Tannenwald N, Acton JM, Vaynman J (2018) Meeting the challenges of the new nuclear age: emerging risks and declining norms in the age of technological innovation and changing nuclear doctrine. American Academy of Arts \& Sciences.

TCS - Taxpayers for Common Sense (2014) 2014 Farm bill crop insurance subsidies for biofuels crops. Retrieved from: https://www.taxpayer.net/energy-natural-resources/ 2014-farm-bill-crop-insurance-subsidies-for-biofuels-crops/2014/. [Accessed 18 June 2015]

Theodoropoulos T (2011) The secret world of energy. Amazon.

UK Royal Academy of Engineering (2017) Sustainability of liquid biofuels. UK Royal Academy of Engineering.

UN - United Nations Organization (2020) Putting the UN framework for socio-economic response to COVID-19 into action: insights. United Nations Organization. 
UNEP - United Nations Environment Programme (2016) The emissions gap report 2016. United Nations Environment Programme.

UNEP (2019) Emissions gap report 2019. Global progress report on climate action. United Nations Environment Programme.

US Department of Energy (2016) National algal biofuels technology review. Office of Energy Efficiency and Renewable Energy and Bioenergy Technologies.

USDA - US Department of Agriculture (2016a) Effects of conservation practice adoption on cultivated cropland acres in Western lake Erie basin, 2003-2006 and 2012. US Department of Agriculture.

USDA (2016b) National organic program. US Department of Agriculture.

WEF - World Economic Forum (2018) Innovation with a purpose: the role of technology innovation in accelerating food systems transformation. World Economic Forum.

WEF (2020a) The global risks report. World Economic Forum.

WEF (2020b) Incentivizing food systems transformation. World Economic Forum.

WEF (2020c) The net-zero challenge: fast-forward to decisive Climate action. World Economic Forum.

WHO - World Health Organization (2020) Emergencies preparedness, response. World Health Organization.

Wik M, Pingali P, Broca S (2008) Background paper for the world development report 2008: global agricultural performance: past trends and future prospects. World Bank.

Worldometers (2020) World population by year. Retrieved from: https://www.worldome ters.info/world-population/world-population-by-year/. [Accessed 20 Junuary 2020]

Xie X, Wang L, Xuang Z (2017) Regional water footprints of potential biofuel production in China. Biotechnology for Biofuels 10(1): 95.

Yara (2018) Fertilizer industry handbook 2017. Retrieved from: https://bit.ly/3m4hLNh. [Accessed January 2017]

Yara (2020) Fertilizer industry handbook 2018. Retrieved from: https://bit.ly/2H9usXS. [Accessed October 2020]

Zabel F, Putzenlechner B, Mauser W (2014) Global agricultural land resources - A high resolution. Suitability evaluation and its perspectives until 2100 under Climate change conditions. PLOS ONE 9(12): e114980. 
